\title{
High-Albedo Materials for Reducing Building Cooling Energy Use.
}

\author{
January 1992
}

\section{Prepared by}

Haider Taha, David Sailor, Hashem Akbari

Energy and Environment Division

Lawrence Berkeley Laboratory

University of California

Berkeley, CA 94720

This work was jointly supported by the California Institute for Energy Efficiency (CIEE) and the Sacramento Municipal Utility District through the U.S. Department of Energy, under contract DE-AC0376SF00098. 


\section{DISCLAIMER}

The research reported here was funded in part by the California Institute for Energy Efficiency (CIEE), a research unit of the University of California. Publication of research results does not imply CIEE endorsement of or agreement with these findings, nor that of any CIEE sponsor. 


\section{Table of Contents}

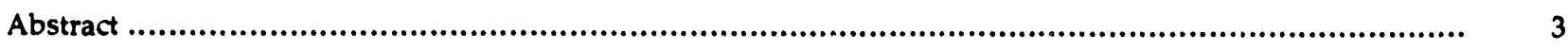

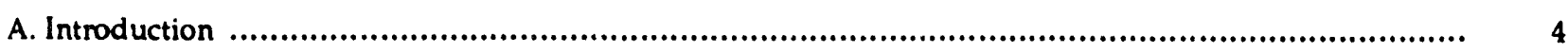

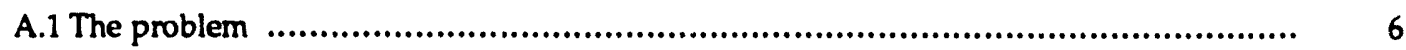

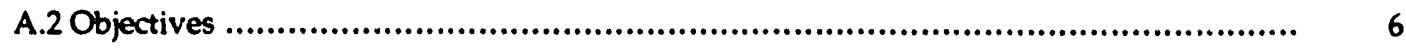

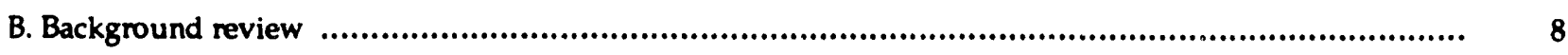

B.1 Impact of albedo on microclimate .......................................................... 8

B.2 Impact of albedo on energy use ......................................................................... 15

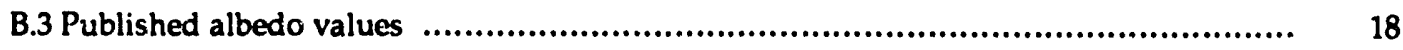

B.4 Albedo and emissivity ............................................................................ 22

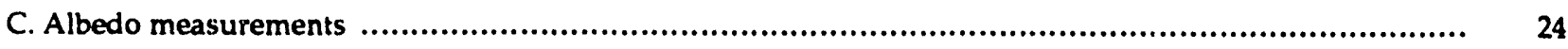

C.1 Experiment design and instrumentation ........................................................ 24

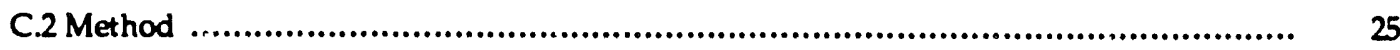

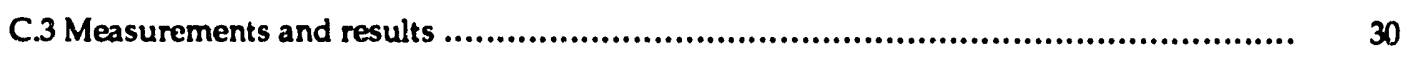

C.3.1 Urban albedo ....................................................................... 30

C.3.2 Roofing materials' albedos and surface temperatures ............................ 31

C.3.2.A Albedo values ............................................................... 32

C.3.2.B Hourly variables .......................................................... 32

C.3.3 Comparison with field data from other researchers ................................ 34

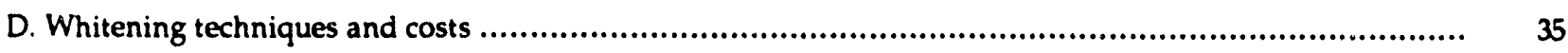

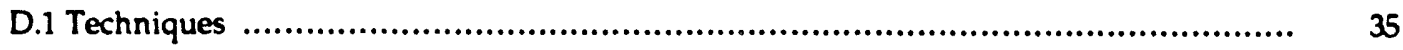

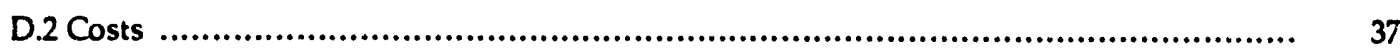

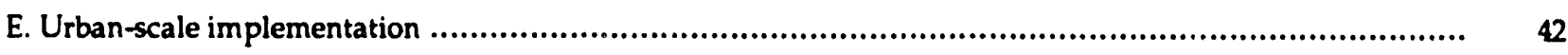

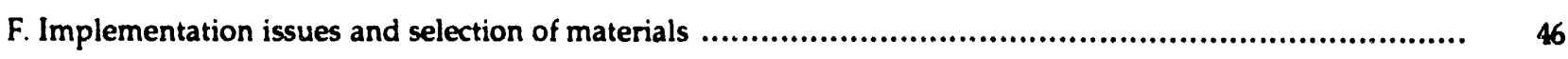

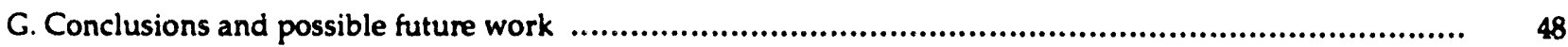

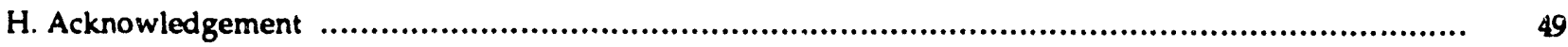

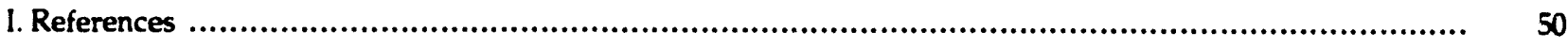

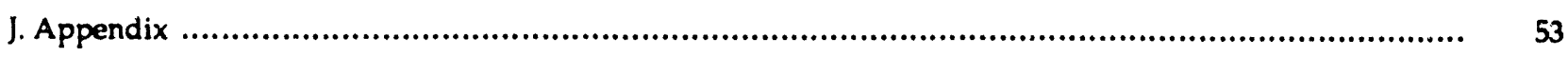

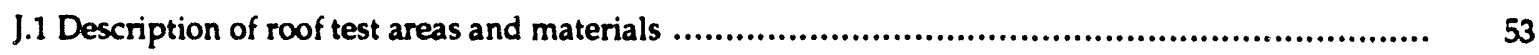

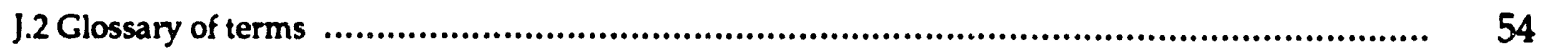




\title{
High-Albedo Materials for \\ Reducing Building Cooling Energy Use
}

\begin{abstract}
One simple and effective way to mitigate urban heat islands, i.e., the higher temperatures in cities compared to those of the surrounds, and their negative impacts on cooling energy consumption is to use high-albedo ${ }^{1}$ materials on major urban surfaces such as rooftops, streets, sidewalks, school yards, and the exposed surfaces of parking lots. High-albedo materials can save cooling energy use by directly reducing the heat gain through a building's envelope (direct effect) and also by lowering the urban air temperature in the neighborhood of the building (indirect effect). Our previous analyses of the direct and indirect effects through computer simulation suggest that major urban-scale changes in albedo can reduce peak cooling loads in many American cities by $30-50 \%$.

This project is an attempt to address high-albedo materials for buildings and to perform measurements of roof coatings. We search for existing methods and materials to efficiently implement lighter colors on major building and urban surfaces. Their cost effectiveness are examined and the possible related technical, maintenance, and environmental problems are identified. We develop a method for reliably measuring albedo in the field by studying the instrumentation aspects of such measurements. The surface temperature impacts of various albedo/materials in the actual outdoor environment are studied by measuring the surface temperatures of a variety of materials tested on an actual roof. We also generate an albedo database for several urban surfaces to serve as a reference for future use.

The results indicate that high-albedo materials can have a large impact on the surface temperature regime. On clear sunny days, when the solar noon surface temperatures of conventional roofing materials, such as built-up roofs with gravel, black EPDMs, ${ }^{2}$ and bitumenous roofs, were about $40^{\circ} \mathrm{C}\left(72^{\circ} \mathrm{F}\right)$ warmer than air, the surface temperature of high-albedo coatings were only about $5^{\circ} \mathrm{C}\left(9^{\circ} \mathrm{F}\right)$ warmer than air. In the morning and in the late afternoon, the highalbedo materials were as cool as the air itself. Our results show that while conventional roofing materials warm up by an average $0.055^{\circ} \mathrm{C} /\left(\mathrm{W} \mathrm{m}^{-2}\right)$, the high-albedo surfaces warm up by an average $0.015^{\circ} \mathrm{C} /\left(\mathrm{W} \mathrm{m}^{-2}\right)$.
\end{abstract}

\footnotetext{
I In the context of this report, albedo is defined as the reflectivity of a surface integrated over the entire hemisphere and the solar wavelength range.

2 For explanation of terms and abbreviations, refer to the glossary at the end of this report.
} 


\section{A. INTRODUCTION}

Whitening of external surfaces of buildings is an effective energy conservation strategy particularly in those locations where soil conditions or water availability restrict the implementation of vegetation as a climate moderator. It is also important where "conventional" roofing is done with asphalt over insulation: asphalt becomes very hot on sunny days, leading to possible structural damage or even failure of the asphalt layer. In this case, the application of white coatings over the asphalt layer reduces its surface temperature and prevents it from melting. This procedure results in lower exterior surface temperatures, reduced cooling loads, and a comfortable indoor environment. This in turn can help reduce the need for power generation, leading to reduced emissions from power plants. Additional energy savings can result from the reduced need for street lighting, because lighter surfaces make the nighttime visual environment equally comfortable with less illumination.

Generally speaking, lower effective urban albedos, caused by either geometrical effects (multiple reflection) or truly darker colors, intensify the heat island. In turn, it is possible that higher urban air temperatures increase city-scale cooling loads and the frequency of smog episodes [Akbari et al. 1989].

To describe albedo, one can use qualitative terms such as "high" and "low", corresponding to "reflective/light colors" and "absorptive/dark colors", respectively, or quantitative terms, i.e. values between 0 and 1. The contribution of lower albedos to heat islands can be significant. On a clear summer day, the average insolation (over daylight hours) in a mid-latitude city is about $500 \mathrm{~W} \mathrm{~m}^{-2}$ (with a maximum of about $950 \mathrm{~W} \mathrm{~m}^{-2}$ ). Although urbanization acts to attenuate solar gains by $5-10 \%$ (by increasing atmospheric absorption, reflection, and scattering), the typical effective urban surface albedo $(-0.15)$ is lower than that in rural areas $(-0.25)$ and, therefore, net heat absorption is generally larger than in rural areas [Taha et al. 1990a].

At the Lawrence Berkeley Laboratory ( $L B L)$, we have been looking at possible ways to decrease the summer daytime temperatures in American cities by increasing the urban albedo. Our preliminary analysis and computer simulations for Sacramento, CA, show that a change in overall urban albedo, from an existing 0.25 to a "whitewashed" 0.40 , will reduce peak cooling demand by as much as $40 \%$ [Taha et al. 1988 ].$^{3}$ In fact, each $1^{\circ} \mathrm{C}\left(1.8^{\circ} \mathrm{F}\right)$ of urban air temperature reduction may result in savings of $2-3 \%$ of the system-wide electric utility load in most major mid-latitude cities [Akbari et al. 1989].

Cities can be easily whitened. Most buildings and flat roofs are painted (or resurfaced) every 10 years; in the next painting cycle, they can be painted white. This procedure should not entail any additional costs. Also, on streets and parking lots, whiter asphalts can be used at low

\footnotetext{
3 We estimate that, nation wide, light-colored surfaces can save 0.25 quad per year with a payback time of less than a month, and decrease $\mathrm{CO}_{2}$ emissions by about 10 million tons of carbon per year.
} 
incremental cost. ${ }^{4}$ Furthermore, for new buildings, albedo can be easily incorporated into building codes, thus integrating high-albedo materials into a city's energy policy.

A significant potential for implementing high-albedo surfaces in urban areas exists. For instance, our preliminary analysis of Sacramento data indicates an "urban fabric" consisting of approximately $22 \%$ rooftops, $17 \%$ streets, $39 \%$ vegetated areas, and $22 \%$ other impervious surfaces (such as parking lots, sidewalks, school yards, and driveways). Sacramento, CA, is a city with many parks and well-vegetated residential neighborhoods; in arid cities, the fraction of vegetated areas is much smaller than in Sacramento and the potential for high-albedo applications may be larger.

While the application of high-albedo materials seems to be relatively easy to do, and while there seems to be plenty of room for implementing this strategy in hot climates, there might be problems that one should look for. Namely, there might be glare problems caused by the highly reflecting surfaces which might lead to hazards and discomfort. Another potential problem concerns people's preferences which might limit the colors/hues that will be applied on their homes and places of business. However, the glare problems can be easily overcome and avoided if careful planning is sought in advance. The preferences problem can be easily settled by letting people choose their colors (which is what they see in the visible spectrum) while the near-infrared (unseen) albedo can be controlled to achieve the desired effects.

Another issue is the dirt pick-up qualities of the surfaces to be treated. If these surfaces pick up dirt easily, their albedos may change over time (some light-colored surfaces may become darker and some dark surfaces may be become lighter). Variations of up to $15 \%$ in albedo have been associated with such changes. In this paper, we briefly discuss each of these issues.

In order to design a full-scale research program for whitening cities, however, we first need to understand the following key parameters:

1. What is the typical urban albedo, and by how much can it be increased (from practical, visual, and climatic points of view)?

2. What percentage of the urban surface is available for albedo modification?

3. How much will albedos of light surfaces change because of weathering?

4. What is the strength of the correlation between albedo modification and surface temperature changes?

4 There are, of course, costs associated with these changes; however, in addition to energy benefits, light-colored roofs and asphalt reflect more UV radiation and will last longer. And because they remain cooler, there is an improvement in pavement performance and reduced rutting. A program of white surfaces could pay for itself many times over simply by extending the life time of the asphalt roofs and streets. 
5. What are the related implementation issues such as cost, durability, maintenance, and public acceptability?

This report is a first start to examine these issues, particularly items 2 through 5 . The "Objectives" section below explains in further detail the tasks addressed in this paper.

\section{A.1 The problem}

Before a full-scale implementation of albedo modifications can be undertaken, a solid demonstration of its effectiveness in saving cooling energy should be conducted. The impacts of albedo modifications on microclimate must be quantified and demonstrated and the correlation between changes in surface albedo, material's physical properties, and modifications in temperature should be understood. So far, estimates have been typically based on simulations of regional climates with urban boundary layer models and the associated energy use patterns using the DOE-2 computer program. We have reached a stage where validation of simulations and observation of the effects of albedo on surface temperature in the outdoor environment are needed.

An overall search for data and personal contacts with researchers and representatives of the paint/coatings industry revealed that not much has been done in terms of monitoring energy savings from white surfaces and the inicroclimate changes associated with albedo modifications in urban areas. The issues of surface albedo, surface temperature, and energy use have been addressed in limited and small experiments by researchers at national laboratories, universities, and in the private sector. But the results are either incomplete or qualitative (some of these studies are described in section B.1 of this report). For example, the Asphalt Institute indicates that no significant research of this kind has been undertaken to study the performance of asphalt with different albedos [Shuler 1991]. A similar response was obtained in a personal communication with the Cedar Shake and Shingle Bureau, 5 although they have performed a study comparing the thermal characteristics of cedar roofs with those of asphalt. The measurements, performed by the University of Texas at Arlington, under the Asphalt Institute's sponsorship, were not performed in an actual outdoor environment, but under controlled indoor conditions in the laboratory.

\section{A.2 Objectives}

The objectives of this project were to explore in further detail the microclimatic and energetic implications of high-albedo materials and to document the technical aspects and microclimate consequences of producing and using light-colored materials on external surfaces of

5 Cedar Shake and Shingle Bureau, Suite $275,515116^{\text {th }}$ Avenue, N.E., Bellevue, WA 98004.5294. Personal communication, March 13, 1991. 
buildings and on major urban surfaces such as streets, side walks, school yards, and parking lots ${ }^{6}$.

We developed a method for reliably measuring albedo in the field and performed numerous measurements of albedo in urban settings and for actual buildings. Also, measured hourly surface temperatures were correlated with incident solar radiation. ${ }^{7}$

Finally, procedures and products to implement use of high-albedo materials in building and urban surfaces were identified.

In summary, the objectives of this project were to:

(1) compile information on methods, procedures, and materials to implement efficiently the use of lighter colors on building and urban surfaces,

(2) develop a method for reliably measuring/documenting albedo in the field and on actual outdoor and controlled surfaces,

(3) measure the time variation in albedo and corresponding surface temperatures in the actual outdoor environment and on controlled surfaces under natural sunlight,

(4) perform preliminary cost-effectiveness analysis in terms of the CCE index (Cost of Conserved Energy), and

(5) investigate the potential for a full-scale research program on the mitigation of cooling loads in hot climates through albedo modifications.

The following sections are organized as follows. Section B describes general background information on albedo, its characteristics, available data, and implications on microclimate and energy use. Section $C$ shows the setup and experiment design of this project and instrumentation, and provides a discussion of the measurement data. Section D presents techniques and costs issues, whereas sections $E$ through J discuss other issues such as implementation, future work, and definitions.

6 Parking lots differ in terms of use. Lots that are heavily used may not have sufficiently large surface areas exposed to the sky (too many cars) and, thus, the effect of surface albedo is small in this case. We estimate that parking lots with car covers smaller than $50 \%$ would be candidates for albedo treatment. In any case, parking driveways can always be treated with high-albedo surfacing.

7 One feature that distinguishes this study from other similar ones is the direct field measurement of albedo with a pyranometer and the surface temperature with a hand-held infrared thermometer. 


\section{B. BACKGROUND REVIEW}

\section{B.1. Impact of albedo on microclimate}

Equation (1) defines albedo on a spherical coordinate system.

$$
\alpha=\frac{\int_{\lambda_{1}}^{\lambda_{1}} \int_{\lambda_{1}}^{2 \pi} K \uparrow \cos \theta d \omega d \lambda}{\int_{\lambda_{1}}^{\lambda_{2}} \int_{0}^{2 \pi} K \downarrow \cos \theta d \omega d \lambda}
$$

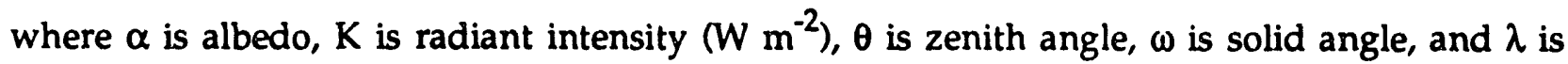
wavelength (refer to the appendix for definitions). The upward and downward pointing arrows indicate reflected and incident radiation, respectively. In order to find an average albedo, a fourth integral over time (e.g., over daylight hours) should be added to equation (1).

By definition, albedo may encompass any wavelength range as appropriate to the context of use. In this paper, we discuss albedo in the wavelength band $0.28-2.8 \mu \mathrm{m}$ since we are interested in studying the response in surface temperature of building materials to solar irradiation. 8

Albedo for shortwave and near-infrared radiation is one of the most important factors in microclimates. ${ }^{9}$ The sensitivity of the surface energy balance, and thus surface and air temperatures, to this variable is high. Simulations by Taha [1990b] and Taha et al. [1988] showed that a change of 0.01 in albedo can produce a change of $0.2-0.25^{\circ} \mathrm{C}\left(0.4-0.5^{\circ} \mathrm{F}\right)$ in air temperature at an average height of $5 \mathrm{~m}$ (16 ft) above the surface.

Urban areas tend to decrease the overall effective albedo through two mechanisms. The first is a result of larger absorption on darker building and urban surfaces whereas the second results from the effects of multiple reflections inside urban canyons producing significantly lower effective albedos. Aida [1982] showed that because of irregular urban structure, absorptance in clear weather was increased by $20 \%$ over the absorptance of a flat surface made of the same material. In other words, the geoinetrical effect of urban structures decreased the effective albedo by $20 \%$ while keeping all other factors constant. As the urban canyon gets deeper (buildings become taller), the albedo decreases more, and the difference between the effective albedo and that of a corresponding flat surface increases.

\footnotetext{
8 The pyranometer used in this study was sensitive to this range $(0.28-2.8 \mu \mathrm{m})$ which accounts for $98 \%$ of the solar irradiance at sea level; ozone absorbs $100 \%$ of the UV radiation under $0.28 \mu \mathrm{m}$, and above $2.8 \mu \mathrm{m}$ there is little radiation from the sun, and the absorption by atmospheric water vapor and other gases results in practically no radiation above $2.8 \mu \mathrm{m}$ reaching sea level from the sun.

9 We are referring to albedo in the wavelength band between 0.1 and $4 \mu \mathrm{m}$.
} 
In the same experiments, Aida (1982) showed that both irregular and flat surfaces exhibit diurnal and seasonal variations in albedo, but that the "urban" albedo (of the irregular surfaces) was always lower by an average of $10-15 \%$ throughout the year. Aida showed that the increase in urban absorptance was greater than $20 \%$ at large zenith angles ${ }^{10}$ (sun is lower), as seen in Figure 1. But at small zenith angles (higher sun), the absorptivity increased by an average of $18 \%$ in urban areas with respect to flat areas of the same material. In Figure 1, the curves represent the normalized increase in absorptivity of "urban" geometries with respect to a flat surface of similar material. The upper curve corresponds to a block pattern, that is, building blocks uniformly distributed whereas the lower curve corresponds to long urban canyons. Aida [1982] originally reported absorptivity values for north-south canyons separately from those of east-west canyons. In Figure 1, we have averaged both N-S and E-W values into one curve. The important point to keep in mind is that in compariscns of urban versus rural albedos, one should realize that even with lighter colors on urban and building surfaces, in some 'cases, the effective albedo of the urban area nay still be lower than that of the relatively flat rural surrounds.

In two-dimensional simulations, the effects of canyon geometry on effective urban albedo were demonstrated by Aida and Gotoh [1982] based on a Monte Carlo model developed by Craig and Lowry [1972]. Results from these two-dimensional simulations support the experimental finding: reported above: geometry plays an important role in determining the effective urbarı albedo, and as irregularity increases, the effective albedo decreases (Figure 2). For the simulations shown, Aida and Gotoh assumed an atmospheric transmissivity of $70 \%$, a $50 \%$ isotropic reflection. a $50 \%$ specular reflection, and that the height of the buildings was equal to the width of the canyon (street). ${ }^{11}$ The results show that the largest differences between urban and open albedos (flat surfaces) for similar materials are found in the range of large solar zenith angles, i.e., at low solar altitudes such as in winter or near sunrise and sunset.

One should keep in mind that albedo also depends on the ratio of isotropic to specular reflection. In the above findings, it was assumed that all surfaces were reflecting at $50 \%$ isotropic nd $50 \%$ specular. The difference between albedo of specular and diffuse surfaces is smaller at smaller zenith angle and larger at large zenith angles [Aida and Gotoh 1982].

Also, the effective albedo depends on the radiant intensity from reflecting surfaces which, in turn, vary as a function of building density. In dense areas, such as city centers with tall buildings and narrow streets, ine effective urban albedo depends mainly on the conditions of the rooftops and the multiple reflections inside canyons, whereas in a low density area, such as a residential neighborhood with widely-spaced buildings, the effective urban albedo depends

\footnotetext{
10 See Appendix for definitions.

11 Radiation whose radiance is independent of direction is called isotropic whereas radiation whose radiance does depend on direction is called specular.
} 
mostly on the conditions of the rooftops, walls, streets, and sidewalks. The "canyon effect" of multiple reflections in this case is small.

Other simulations by Aida and Gotoh (1982) attempted to identify the urban density that would produce the lowest albedo values. They found that for a fixed building height, an urban area with canyon width about twice the width of buildings produced the lowest albedo at all zenith angles, and that as the streets get narrower (larger roof area per unit urban area) the effective albedo increases because of the reduced effect of the internal reflections within the canyons. Figure 3 shows the effective albedo as a function of selected building width-to-street width ratios and solar zenith angle. We can see that when the streets are wider than the buildings, the effective albedo is smaller than when buildings are wider than the streets.

Despite the spatial and temporal variability in albedo mentioned above, low-latitude urban albedos tend to be generally higher than the rural ones whereas mid- and high-latitude urban albedos tend to be lower than those of their rural counterparts. North African cities, such as those in Tunisia and Morocco, are good examples of high-albedo urban areas (0.30 to 0.45) whereas most U.S. and Europeans cities represent urban areas with low albedos $(0.15$ to 0.20$)$. Overall, the typical range of urban albedos is between 0.10 and 0.30 [Chandler 1976]. In comparison, the average albedo of the whole earth-atmosphere system is $0.30 .^{12}$

Table 1 list: values of snow-free urban albedos observed by tower-mounted or airborne sensors. Wher available, the difference between urban and rural albedo is given in the third column. These differences, except for Lagos, Nigeria, indicate that mid-latitude urban albedos are usually 0.02 to 0.07 lower than their corresponding rural values, either because of darker roofing/paving materials or multiple reflection in urban canyons. The example of Lagos is a special case because the city is built on an intricate mesh of creeks and lagoons that decrease the effective urban albedo as one gets closer to the suburbs (the albedo of water is lower than that of the light-colored buildings). While going through this table, the reader should be reminded that albedo varies significantly from one spot to another (only meters apart), and thus, these numbers should be viewed as "representative" of that area in their authors' opinion.

Because a higher urban albedo reduces the absorbed solar radiation within the urban canopy layer, building and urban surfaces remain cooler and, in turn, the intensity of longwave re-radiation is reduced. Ambient air temperatures also stay lower because of reduced convective heat flux, thanks to lower surface temperatures. One-dimensional simulations by Taha et al. [1988] for the City of Sacramento suggested that afternoon air temperatures in July might be lowered by as much as $4^{\circ} \mathrm{C}\left(7^{\circ} \mathrm{F}\right)$ by changing the effective urban albedo of a neighborhood from 0.25 to 0.40 . Also, Taha [1990b] used the URBMET planetary boundary layer (PBL) model of Bornstein [1975] to perform winter and sun!mer microclimate simulations with albedo values

12 This includes the effects of clouds and oroans. For the curious, the solar albedos for Uranus, Neptune, Saturn, Mars, and the Moon are 0.93, v.84, 0.76, 0.16, and 0.07 respectively [Sellers 1965]. 


\begin{tabular}{|c|c|c|c|}
\hline \multicolumn{4}{|c|}{ Table 1. Selected urban albedo values ${ }^{*}$} \\
\hline Urban area & Albedo & $\Delta$ (urban-rural) & Source \\
\hline Madison, WI (urban) & $0.15-0.18$ & & Kung et al. 1964 \\
\hline Madison, WI (suburban) & $0.13-0.17$ & & " \\
\hline St. Louis, MI (urban) & $0.12-0.14$ & -0.03 & Dabberdt and Davis 1978 \\
\hline St. Louis, MI (suburban) & 0.16 (mean) & & $"$ \\
\hline St. Louis, MI (center) & $0.19 \cdot 0.16 t$ & $-0.02 /-0.04$ & Vukovich 1983 \\
\hline Hartford. CT (urban) & $0.09-0.14$ & & Brest 1987 \\
\hline Hartford, Ct (suburban) & $0.11-0.16$ & & $"$ \\
\hline Adelaide, AUS (commercial) & 0.27 (mean) & & Coppin et al. 1978 \\
\hline Adelaide, AUS (suburban) & 0.18 (mean) & & 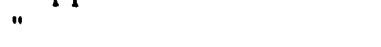 \\
\hline Hamilton, Ontario & $0.12-0.13$ & & Rouse and Bello 1979 \\
\hline Munich, West Germany & 0.16 (mean) & -0.08 & Mayer and Noack 1980 \\
\hline Vancouver, B.C. & $0.13-0.15$ & & Steyn and Okı! 1980 \\
\hline Tokyo & 0.10 (mean) & -0.02 & Aida 1982 \\
\hline Southampton/Portsmouth UK & $0.15-0.18$ & $0.02 /-0.08$ & Barry and Chambers 1966 \\
\hline Ibadan, Nigeria & 0.12 (mean) & $0.03 /-0.09$ & Oguntoyinbo 1970 \\
\hline Lagos, Nigeria & 0.45 & 0.25 & Oguntoyinbo 1986 \\
\hline \multicolumn{4}{|l|}{ Overall values: } \\
\hline North American Cities (urban) & $0.12-0.23$ & & Kung et al. 1964 \\
\hline North American Cities (suburban) & $0.11-0.24$ & & $"$ \\
\hline
\end{tabular}

thimited shortwave sensitivity of sensors

*We are presenting this iable to introduce the problem addressed in this project. The table contains no information on the exact location of measurement, or locations whose albedos have been averaged. In general, published albedo values are poorly documented. Also, the averaging procedure is unclear.

ranging from 0.05 to 0.45 . Selected results are presented in Figure 4 depicting urban air temperatures at $25 \mathrm{~m}(82 \mathrm{ft})$ above the surface. Figure $4 \mathrm{a}$ shows the simulated temperatures for January 15 in Phoenix AZ. The impact of albedo on $4 \mathrm{pm}$ temperatures is larger than on 10 am temperatures because of the longer exposure to solar radiation. A change of albedo from 0.05 to 0.45 resulted in a fall of about $5^{\circ} \mathrm{C}\left(9^{\circ} \mathrm{F}\right)$ at $4 \mathrm{pm}$. The reason nighttime temperature $(10 \mathrm{pm}$ and $4 \mathrm{am}$ ) also fell (although only slightly) with increasing albedo was the decrease in absorbed daytime heat as albedo increased. Overall, the wintertime effect of albedo was small.

In summer, on the other hand (Figure $\mathbf{4 b}$ ), the effect of albedo on air temperatures was more pronounced because of larger insolation. The summertime temperature slopes were generally steeper than those in wintertime. For example, the same change in albedo (from 0.05 to $0.45)$ at $4 \mathrm{pm}$ caused a decrease in air temperature of about $11^{\circ} \mathrm{C}\left(20^{\circ} \mathrm{F}\right)$ in July, compared to 5 ${ }^{\circ} \mathrm{C}\left(9^{\circ} \mathrm{F}\right)$ in January. Other hours showed steeper lines, except of course, the one at 4 am. Because an inversion developed at $10 \mathrm{pm}$, the temperature at $25 \mathrm{~m}$ was higher at that time than at $10 \mathrm{am}$.

The simulations show that the relative effects of albedo are larger in summer than in winter, and suggest that it is relatively 'safe' to whiten urban surfaces in hot climates to reduce cooling energy requirements in summer without a significant penalty of increasing heating 
loads in winter [Taha 1988] ${ }^{13}$. However, these results should be interpreted carefully for the following t'wo reasons.

(1) These results were obtained from one-dimensional simulations, and because of that, the effects of adverted air masses were not accounted for. Depending on their thermodynamic state (where they are being advected from) moving air masses can increase or decrease the impact of surface albedo on air temperature.

(2) The model used for these simulations had a soil-moisture-related problem. As the model runs, soil moisture is depleted, and because of that, the surface and air temperatures increase significantly. The absolute temperatures given by this model overestate the typical surface and air temperatures one would expect at the specified location, time of the year, and for the given soil and air conditions.

A few studies have correlated surface temperatures to albedo as the main variable. For example, Reagan and Acklam [1979] measured the surface temperatures and reflectivities of several roof samples. Their results are summarized in Table 2.

\begin{tabular}{|rrrr||rrrr|}
\hline \multicolumn{5}{|c|}{ Table 2. Reflectivity and surface temperature. Tucson, AZ, June 1976t } \\
\hline \multicolumn{5}{|c|}{ CRAVEL ROOF } & \multicolumn{4}{c|}{ ASPHALT SHINGLE ROOF } \\
\hline Reflectivity & $\mathrm{T}_{\mathrm{s}}\left(\mathrm{C}^{\circ}\right)$ & $\mathrm{K} \downarrow\left(\mathrm{W} \mathrm{m} \mathrm{m}^{-2}\right)$ & Local time & Reflectivity & $\mathrm{T}_{\mathrm{s}}\left(\mathrm{C}^{\circ}\right)$ & $\mathrm{K} \downarrow\left(\mathrm{W} \mathrm{m} \mathrm{m}^{-2}\right)$ & Local time \\
\hline 0.34 & 43 & 947.6 & $10: 50$ & 0.17 & 51 & 891.9 & $14: 20$ \\
0.17 & 46 & 836.1 & $14: 45$ & 0.21 & 47 & 996.3 & $12: 15$ \\
0.31 & 46 & 947.6 & $14: 00$ & 0.13 & 62 & .96 .3 & $12: 30$ \\
0.35 & 47 & 884.8 & $14: 30$ & 0.25 & 51 & 975.6 & $13: 30$ \\
& & & & 0.08 & 56 & 884.8 & $14: 35$ \\
& & & & 0.16 & 48 & 837.6 & $15: 00$ \\
& & & & 0.09 & 54 & 759.5 & $15: 30$ \\
\hline
\end{tabular}

+ Based on data from Reagen and Ackdam [1979]. No corresponding wind speed data were given. $T_{s}$ is surface temperature and $K \downarrow$ is hemispheric solar flux density incident on the surface.

Researchers at the Florida Solar Energy Center [Chandra et al. 1991] performed a limited study of the effects of shingle color on temperatures in scaled-down prototypes of industrialized housing systems. The basecase's roof was covered with dark shingles whereas the test case had several large, white-colored cloths attached to it. The higher reflectivity of these cloths (0.59) resulted in the cooling down of the shingles; regression fits indicated that instead of surface temperatures of 46 and $65^{\circ} \mathrm{C}\left(115\right.$ and $\left.150^{\circ} \mathrm{F}\right)$, the new temperatures (with the cloths) became 35 and $46^{\circ} \mathrm{C}\left(95\right.$ and $\left.115^{\circ} \mathrm{F}\right)$, respectively.

At the University of Texas-Arlington, a study sponsored by the Cedar Shake and Shingle Bureau aimed at studying the differences in air temperatures of two attic spaces: one under a

13 We tend to think that dark surfaces may be an advantage in winter since they gain heat. In reality, however, the benefits of a darker membrane in winter can be overriden by stronger winds, snow cover, more frequent rain, and the short duration of sunshine. 
cedar shingle roof, the other under an asphalt roof. That indoor experiment, using simulated solar heating, showed that the attic space under the red cedar shingles had temperatures about $16^{\circ} \mathrm{C}\left(29^{\circ} \mathrm{F}\right)$ lower than the attic space under the asphalt roof, averaged over ventilated and non-ventilated ccnditions [CSSB 1991].

Backenstow [1987] performed experiments with panels of different colors, coatings, and aging. The panels, assembled by Carlisle SynTec Systems, were sent to Florida for testing under a variety of conditions, and particularly under intense solar radiation, high temperatures, and low wind speeds. Such a combination probably represents the most severe climate conditions that can be encountered in the U.S. The panels, with an R-11 insulation, were horizontally mounted and tested during the month of September 1986. The highest temperature recorded under the black membrane during that period was $81^{\circ} \mathrm{C}\left(178^{\circ} \mathrm{F}\right)$; under the beige membrane, it was $57^{\circ} \mathrm{C}\left(135^{\circ} \mathrm{F}\right)$; and under the white membrane, it was $51^{\circ} \mathrm{C}\left(124^{\circ} \mathrm{F}\right)$. Figure 5 depicts hourly information of the membrane temperatures on clear and overcast days (Sept.11 and Sept. 8, 1986, respectively). We can see in this figure that the effects of reflectivity ar: smaller during overcast periods and larger when there is intense insolation. The high surface temperatures at 13:00 hours of the overcast day are presumably caused by a break in the cloud cover. Notice how the surfa': $e$ temperatures converge to the same values after sunset.

Other researchers have studied albedo-temperature correlations on urban (non-building) surfaces. For example, Berg and Esch [1983] studied the relationship between surface color and surface temperature on test sections of an asphaltic concrete highway in Fairbanks, Alaska and translated that relationship into thawing indices. They also studied the effects of tire wear and soiling on surface albedo. Berg and Quinn [1978] reported that, in Fairbanks' mid-summer, white-painted roads with albedos of 0.55 have about the same temperature as ambient air whereas the unpainted roads with albedos of 0.15 were approximately $11^{\circ} \mathrm{C}\left(20^{\circ} \mathrm{F}\right)$ warmer than the air.

As the issue of albedo and energy use is receiving more attention from industry, some companies have started to experiment with surface color and temperature. Polythane Company for example, measured the surface temperature of 2" polyurethane roofs after coating them with various colors (Figure 6). Their measurements, with small thermocouples emtedded in or under the coating material, were performed in Austin, Texas, in August, under clear sky conditions and ambient temperatures of $32^{\circ} \mathrm{C}\left(90^{\circ} \mathrm{F}\right)$. They measured the coating surface temperature between noontime and $4 \mathrm{pm}$, because they were interested in albedo effects at times of peak temperatures [Cordell 1991]. They used different colors of similar materials and the underlying structure was a metal deck. However, Polythane Company did not actually measure the in-situ albedo corresponding to these colors.

In other measurements of a similar nature, Rohm and Haas Corporation studied the surface temperat ire and energy use pattern associated with a white elastomeric coating over a built-up roof [Boutell and Salinas 1986]. In thac year-long study [September 1, 1985 through 
October 31, 1986], they compared the surface temperature of virtually identical scaled-down test buildings, one roofed with a standard black built-up roofing system whereas the other was sprayed with a Rohm and Haas white elastomeric coating. ${ }^{14}$ Figure 7 shows the temperature depressions on one day, resulting from the application of the white coating. The bold line represents the ambient air temperature and the solid line represents the surface temperature of a typical dark built-up roof. During daylight nours, the built-up roof was significantly warmer than the ambient air. At noon, the roof was $36^{\circ} \mathrm{C}\left(65^{\circ} \mathrm{F}\right)$ warmer than the air; in the early afternoon, it was over $28^{\circ} \mathrm{C}\left(50^{\circ} \mathrm{F}\right)$ warmer. The broken line represents the same roof with a Rohm and Haas white elastomeric coating. The roof's temperature was close to that of the ambient air most of the time, the highest deviation being around 13:00 hours when the roof was about $6^{\circ} \mathrm{C}$ $\left(11^{\circ} \mathrm{F}\right)$ warmer. The application of the coating lowered the roof's surface temperature by $28^{\circ} \mathrm{C}$ $\left(50^{\circ} \mathrm{F}\right)$ in the early afternoon hours.

Rohm and Haas also experimented with a mastic that is easy to apply over an existing roof and has all the advantages of a high-albedo material plus low installation and maintenance costs. Roofs whose shingles were coated with white mastic were $-28^{\circ} \mathrm{C}\left(50^{\circ} \mathrm{F}\right)$ cooler in the early afternoon than roofs with regular dark shingles.

Habel and Florence [1985] demonstrated the cooling effects of a reflective coating applied to a roof's surface at the Williams Engineering Center in San Diego, CA. They studied the impact of applying a layer of Superprep ${ }^{15}$ on indoor and outdoor surface temperatures and derived the roof coating's reflectivity from the surface energy balance, assuming that the radiative flux from the surface was negligible and accourting for the conductive and convective fluxes only. The energy balance was carried out after making some non-site-specific assumptions, such as wind speed; they also did not monitor wind speed and performed their tests on a relatively well-insulated roof. Their results are, therefore, relatively less significant in terms of reduction in building's cooling load. Figure 8 shows the effects of Superprep on roof surface temperature. The roof coated with Superprep was $17^{\circ} \mathrm{C}\left(31^{\circ} \mathrm{F}\right)$ cooler than the uncoated roof at midday. As expected, both roofs had the same temperature during nighttime hours.

After this review of surface temperature and albedo of various materials, certain points need to be kept in mind about the strength of this relationship. Although difficult to quantify, the following affect the strength of the albedo-surface temperature correlation:

- The effects of aging, soiling, and wear and tear on the effective, final albedo of a surface; this will modify the impact of albedo as originally intended by the specification;

14 Both buildings had R-11, 4" batt fiberglass ceiling insulation, uninsulated concrete block walls and foundations, standard single-pane windows, standard doors, and built-up roof systems. These buildings were tested in Mississippi.

15 "Thermo Superprep", an elastomeric coating, is manufactured by Thermo Materials, San Diego, California. 
- The effects of biological growth and contamination of the surface;

- The available annual insolation and its distribution;

- The effects of wind speed on the surface's energy balance (convective effects) and, hence, on the effect of albedo on surface temperature. Simulations by Griggs et al. [1989] showed that for a black roofing membrane, the surface temperature reached $82^{\circ} \mathrm{C}\left(180^{\circ} \mathrm{F}\right)$ at no wind, but only $46^{\circ} \mathrm{C}\left(115^{\circ} \mathrm{F}\right)$ with a wind of $15 \mathrm{~m} \mathrm{~s}^{-1}(50 \mathrm{ft} / \mathrm{s})$;

- The effects of insulation on heat conduction through the surface and hence on surface temperature.

\section{B.2. Impact of albedo on energy use}

An important issue to consider when studying the direct (building scale) energy impacts of albedo is the identification of relevant surfaces, i.e., the walls or roofs that are relatively more important in the determination of heat fluxes through the building envelope. In low latitudes, roofs and other horizontal surfaces are more important from the heat gain point of view than vertical surfaces. In the high latitudes, Equator-facing vertical surfaces are more important. Since this project is for California cities, and California latitudes are between $-32^{\circ}$ and $-42^{\circ}$, both south walls and roofs are important from the albedo application point of view and are equivalent if similar construction and insulation levels are used. Because we are mainly interested in summer cooling loads, roofs are generally more important to this study than south walls ${ }^{16}$ as explained in the following paragraph.

In Figure 9, the solar path for latitude $36^{\circ} \mathrm{N}$ is shown to represent south and central California locations. The shaded area represents the typical times of day and year when cocling may be needed in Central and Southern California. The heavy line is drawn to denste an altitude angle of $45^{\circ}$, above which a roof would be a more important sun receiver than a wall. From this figure, we can see that during most of the cooling hours, the roof is the most important receiver of solar radiation. ${ }^{17}$

Reagan and Acklam [1979] performed simple calculations to estimate the albedo effects on energy use. ${ }^{18}$ They computed the heat gain/loss changes after changing and measuring the

16 South walls are important in winter when the sun is low.

17 East and west walls may also be important in terms of energy use, depending on the mass of the building envelope. In a massive construction, the east wall is an important solar receiver because the heat stored from the morning sun is released to the indoor spaces in the afternoon, coinciding with the time of peak cooling load. In a light structure, the west wall is the most important solar receiver because its instantaneous transmittal of the afternoon sun's heat contributes to the peak cooling load. Considerations such as these should be accounted for when deciding which wall is a candidate for albedo modification strategies.

18 They assumed steady state conditions, and accounted for the effects of solar radiation absorption and surface temperature with a TETD (total equivalent temperature differential) as described in the ASHRAE Book of Fundamentals [Pierce 1972]. Refer to Reagan and Acklam [1979] for an ex- 
external surface reflectivities of homes with constructions typical of the Southwestern U.S. They studied the energy implications of varying reflectivity of selected materials and finishes, and although their measurements were performed in Tucson, $A Z$, the materials they studied were typical of common building practices in the U.S.

For some typical building configurations in Tucson, AZ, they showed that in a low insulation house, lightening the roof color by changing the reflectivity from 0.25 to 0.65 , had the effect of cutting down the heat gain through the roof by half ( $-59 \mathrm{MJ}$ to $-29 \mathrm{MJ})$, whereas in a more insulated version of the same house, these changes in reflectivity produced a similar percent reduction in roof heat gain, although at lower absolute value (from $-25 \mathrm{MJ}$ down to $-13 \mathrm{MJ}$ ). With respect to the total heat gain from the entire outer envelope of the house, these reductions in heat gain through the roof corresponded to reductions of $6.4 \%$ in the low-insulation house and $4.8 \%$ in the more insulated house [Reagan and Acklam 1979]. If walls were also whitened when the reflectivity of roofs was increased, higher savings would have resulted.

In the study of Habel and Florence [1985], the effects of Superprep were demonstrated. They computed the heat flux through the roof based on measured outside-inside temperature differences and they computed the heat fluxes through the walls using steady state analysis. Their results indicated that the application of Superprep could save $40 \%$ of the heat gain through the roof on a clear summer day.

In the study by Chandra et al. [1991], they reported a reduction of $10 \%$ in cooling energy through the use of a white cloth on the dark shingle roofs (the reflectivity of the cloth was 0.59 ). Similarly, the Rohm and Haas study in Mississippi found significant savings in measured cooling power. At noon, the prototype with the Rohm and Haas coating used $64 \mathrm{~kW}$ whereas the prototype with conventional dark built-up roof used $78 \mathrm{~kW}$ (a reduction of $18 \%$ ). At $5 \mathrm{pm}$, the first prototype used $77 \mathrm{~kW}$ whereas the second prototype used $104 \mathrm{~kW}$ (a reduction of $26 \%$ ). In general, they found that an average summer cooling energy savings of $-20 \%$ was possible (recall that only the roof was coated). They also found that the effects of the white coating on wintertime heating energy was negligible.

Backenstow [1987] estimated air-conditioning energy savings resulting from using a white EPDM $^{19}$ instead of a black one. He calculated the savings for a $10,000 \mathrm{ft}^{2}$ roof based on measured values of roof -urface temperatures for different insulation levels, as shown in Table 3. We can see that savings of $56 \%$ in energy costs are obtained.

In addition to field-measurements, researchers have performed computer simulations to study the effects of albedo modifications on energy use. An example is given in Table 4, that shows the impact of lightening the external surfaces of a residential building on the space

planation of the methodology.

19 EPDM: Ethylene Propylene Diene Terpolymer Membrane (rubber-like sheet). See Appendix for definitions. 


\begin{tabular}{|llll|}
\hline \multicolumn{4}{c|}{$\begin{array}{c}\text { Table 3. Savings in air conditioning energy use } \\
\text { from using a white EPDM instead of a black EPDM }\end{array}$} \\
\hline Insulation level & $\begin{array}{l}\text { Black EPDM energy } \\
\text { costs (\$/day) }\end{array}$ & $\begin{array}{l}\text { White EPDM energy } \\
\text { costs (\$/day) }\end{array}$ & $\begin{array}{l}\text { Savings } \\
\text { (\$/day) }\end{array}$ \\
\hline R-1 & 40.8 & 18.0 & 22.8 \\
R-5 & 8.16 & 3.6 & 4.56 \\
R-10 & 4.08 & 1.8 & 2.28 \\
R-15 & 2.72 & 1.2 & 1.52 \\
R-20 & 2.04 & 0.9 & 1.14 \\
R-30 & 1.36 & 0.6 & 0.76 \\
\hline
\end{tabular}

Source: Backenstow [1987]. Percent reduction in energy costs is $56 \%$.

heating and cooling loads (not system) by moving from an albedo of 0.3 tc an albedo of 0.7 .

\begin{tabular}{|c|c|c|c|c|c|}
\hline \multicolumn{6}{|c|}{ Insulated buildings } \\
\hline \multirow[t]{2}{*}{ Location } & \multicolumn{2}{|c|}{ Load (kWh $\left.\mathrm{yr}^{-1}\right)$ for $\alpha=0.3$} & \multicolumn{3}{|c|}{$\Delta \%$ Load $(\alpha=0.3 \rightarrow \alpha=0.7)$} \\
\hline & Heating & Cooling & Heating & Cooling & Net \\
\hline Madison & 12110 & 1844 & +5.2 & -24.8 & +1.2 \\
\hline Seattle & 6639 & 820 & +7.7 & -37.6 & +2.7 \\
\hline Washington DC & 5990 & 3207 & +7.7 & -19.4 & -1.7 \\
\hline Phoenix & 306 & 11283 & +35.6 & -12.1 & -10.8 \\
\hline \multicolumn{6}{|c|}{ Uninsulated buildings } \\
\hline \multirow[t]{2}{*}{ Location } & \multicolumn{2}{|c|}{ Load $\left(\mathrm{kWh} \mathrm{yr}^{-1}\right)$ for $\alpha=0.3$} & \multicolumn{3}{|c|}{$\Delta \%$ Load $(\alpha=0.3 \rightarrow \alpha=0.7)$} \\
\hline & Heating & Cooling & Heating & Cooling & Net \\
\hline Madison & 51324 & 2511 & +7.9 & -63.8 & +4.6 \\
\hline Seattle & 34116 & 1031 & +12.6 & -75.8 & +9.9 \\
\hline Washington DC & 29568 & 4836 & +10.9 & -52.9 & +1.9 \\
\hline Phoenix & 6331 & 21000 & +19.3 & -31.7 & -19.9 \\
\hline
\end{tabular}

The resulting decrease in cooling energy is large, especially in uninsulated buildings. However, the increase in heating load offsets the decrease in cooling energy in the heating-dominated climates of Madison, Seattle, and Washington DC. In the hot climate of Phoenix, on the other hand, the decrease in cooling energy was much larger than the corresponding increase in heating requirements, resulting in a net decrease in total annual energy use.

Taha et al. [1988] simulated the direct (envelope) and indirect (urban) effects of albedo on building energy use. The direct effects were quantified by simulating the impact of albedo on heat flow through a building's envelope, whereas the indirect effects were quantified by simulating the impact of albedo on urban air temperature. Table 5 summarizes the results for a 
house in Sacramento CA, for the period between July 9 and July 12.

\begin{tabular}{|c|c|c|c|c|c|}
\hline \multicolumn{6}{|c|}{$\begin{array}{l}\text { Table 5. Direct and indirect effects of albedo modifications on } \\
\text { cooling energy use in a residential building, Sacramento CA, July 9-12. } \\
\alpha_{b} \text { and } \alpha_{s} \text { are the building's and surroundings' albedos, respectively } \\
\text { and the last row represents the cooling hours during that period. } \\
\text { Source: Taha et al. [1988]. }\end{array}$} \\
\hline & Basecase & direct sa & ngs & direct $+i$ & savings \\
\hline $\begin{array}{l}\text { Building } \rightarrow \\
\text { Surroundings } \rightarrow\end{array}$ & $\begin{array}{l}\alpha_{b}=0.30 \\
\alpha_{s}=0.25\end{array}$ & $\begin{array}{l}\alpha_{b}=0.43 \\
\alpha_{s}=0.25\end{array}$ & $\begin{array}{l}\alpha_{b}=0.90 \\
\alpha_{s}=0.25\end{array}$ & $\begin{array}{l}\alpha_{b}=0.43 \\
\alpha_{s}=0.40\end{array}$ & $\begin{array}{l}a_{b}=0.90 \\
a_{s}=0.40\end{array}$ \\
\hline kWh/day & 25 & $2.7 \%$ & $19 \%$ & $49 \%$ & $62 \%$ \\
\hline Peak kW & 7.07 & $2.5 \%$ & $14 \%$ & $24 \%$ & $35 \%$ \\
\hline Cool. hours/day & 14 & $0.0 \%$ & $7 \%$ & $33 \%$ & $44 \%$ \\
\hline
\end{tabular}

In general, our simulations of the direct effects of albedo indicate that in insulated houses, the reduction in cooling energy amounts to $0.3 \%$ for every 0.01 increase in albedo, whereas for uninsulated buildings, the savings amount to about $0.5 \%$ for each 0.01 increase in building albedo [Taha et al. 1988; Martien et al. 1989]. On the other hand, Taha et al. [1988] indicate that the indirect savings resulting from a 0.01 increase in albedo would be $3 \% .^{20}$

It should be noted here that these findings are applicable to envelope-dominated buildings, such as houses, schools, and small commercial buildings. The impact of albedo on energy use in load-dominated structures, such as large commercial, office high-rises, and industrial buildings is smaller. Other factors include are the area percentage the roof represents, compared to the entire envelope of the building, and the percent heat gain through the roof as compared to the gain through the envelope.

In Table 6, a summary of our simulations is shown for both direct and indirect effects of albedo. These findings have led us to formulate energy savings on a national basis. For example, Akbari et al. [1988] estimate that albedo modifications on residential and commercial buildings can save the U.S. about 0.25 quadrillion Btu (quads) in source energy. A reduction of $4^{\circ} \mathrm{C}$ $\left(7^{\circ} \mathrm{F}\right)$ in urban air temperatures could reduce nation-wide peak cooling demand on warm days by several gigawatts.

\section{B.3 Published albedo values}

Because of the albedo's dependence on spatial and temporal variations in incident radiation, surface color, and geometrical characteristics, albedo can take on a wide range of values. As mentioned in the beginning of this report, one can describe albedo with qualitative terms

20 This number should be interpreted cautiously as the simulations were performed with onedimensional PBL models and some parameters remain uncertain. Also, these percents are valid only within the albedo ranges from -0.25 to -0.45 . 


\begin{tabular}{|l|l|l|l|}
\hline \multicolumn{4}{|c|}{ Table 6. Direct and indirect effects of albedo. } \\
\hline Direct & $\Delta \alpha_{\mathrm{b}}$ & $\begin{array}{l}\text { Change in cooling } \\
\text { energy use (\%) }\end{array}$ & $\begin{array}{l}\text { Change in cooling energy (\%) } \\
\text { per } 0.01 \text { albedo change }\end{array}$ \\
\cline { 2 - 4 } & 0.13 & $-2.7 \dagger$ & -0.21 \\
& 0.60 & $-18.9+$ & -0.32 \\
& -0.18 & $6.7 \dagger$ & 0.37 \\
\cline { 2 - 4 } & 0.40 & $-22.3+t$ & -0.56 \\
& 0.40 & $-11.5 \ddagger$ & -0.29 \\
\hline \hline Indirect & $\Delta \alpha_{\mathrm{s}}$ & Change in cooling & Change in cooling energy (\%) \\
& & energy use (\%) 0.01 albedo change & -3.0 \\
\cline { 2 - 4 } & 0.15 & $-45 \ddagger$ & 3.0 \\
\hline
\end{tabular}

In this table, $\Delta \alpha_{\mathrm{b}}$ and $\Delta \alpha_{\mathrm{s}}$ represent the change in the building's and the surrounding's albedos, respectively. The first represents a direct effect, whereas the second represents an indirect effect of albedo modifications.

+ Simulations by Taha et al. [1988]. One-story house, typical of current construction, $143 \mathrm{~m}^{2}$ floor area, in Sacramento CA. Simulation period is only 3 days (9-12 July). Basecase cooling energy use for these three days is $74 \mathrm{kWh}$.

\# Simulations by Akbari et al. [1988]. One-story house representative of the leaky and poorly insulated stock, 130 $\mathrm{m}^{2}$ floor area in Sacramento CA. Simulation period is one year and the basecase cooling energy use for that year is $3767 \mathrm{kWh}$.

$\ddagger$ Same simulations as in $\#$ above, but with tight and well insulated house, $150 \mathrm{~m}^{2}$ floor area. Basecase cooling energy consumption in this case (for one year) is $2372 \mathrm{kWh}$.

\# Same simulations by Taha et al. [1988], for July 9-12 and a basecase cooling energy consumption of $74 \mathrm{kWh}$. In this case, the URBMET PBL model was used to simulate the indirect effects of albedo on the local microclimate, in addition to using the DOE-2 program to simulate the response in cooling energy use by the building. The indirect effects are an order of magnitude larger than the direct effects. Some of this may be due to the one-dimensional nature of the microclimate simulations we have performed.

such as "high" and "low", corresponding to "reflective/light colors" and "absorptive/dark colors", respectively, or with quantitative terms, i.e. values between 0 and 1. Reagan and Acklam [1979] proposed a color-reflectivity classification as given in Table 7. We also add a "reflective" category to Table 7 to indicate reflectivities of shiny and polished materials. We suggest that a classification system like this one be used consistently, because the same color code used by different manufacturers of building materials sometimes refers to different reflectivities.

In Table 8, additional reflectivities for selected "Reflective" surfaces are given for comparison. These are normal specular solar reflectances for beam radiation for coatings usually employed in solar energy conversion applications. While of no direct relevance to this project, these "Metallic" values are given for the reader to get a sense of the highest values solar reflectivity and albedo can possibly reach. Recall that the albedo of fresh snow is -0.95 [Oke 1987].

Reagan and Acklam [1979] measured the reflectivity of a large variety of building materials. In this section, we give an abridged version of their results (Table 9) to list reflectivities for 


\begin{tabular}{ll|ll|}
\hline \multicolumn{4}{|c|}{ Table 7. Suggested color-reflectivity classification } \\
\multicolumn{2}{|c|}{ for opaque building materialst and selected albedo values $\ddagger$} \\
\hline Reflectivity code & Albedo & Color code & Albedo \\
\hline Reflectivett & 0.90 & Reflective & $0.80-0.90$ \\
Very light & 0.75 & White & $0.60-0.75$ \\
Light & 0.65 & Grey-dark grey & $0.50-0.60$ \\
Medium & 0.45 & Green, Red, Brown & $0.30-0.50$ \\
Dark & 0.25 & Dark brown to blue & $0.20-0.30$ \\
Very dark & 0.10 & Dark blue to black & $0.10-0.20$ \\
\hline
\end{tabular}

+ Source: Reagan and Acklam [1979].

‡ Source: Viazria [1979].

\# We propose this term to indicate surfaces with reflectivities higher than the ones given by Reagan and Acklam. In the right hand side of the table we also give albedo values for commonly used color terms. This is to help the reader formulate a qualitative picture of these albedo values.

\begin{tabular}{ll|ll}
\hline \multicolumn{4}{c|}{ Table 8. Specular solar reflectance for selected surfacest } \\
\hline SURFACE & REFLECTIVITY & SURFACE & REFLECTIVITY \\
\hline Electroplated silver (new) & 0.96 & Back-aluminized 3M acrylic (new) & 0.76 \\
High-purity aluminum (new, clean) & 0.91 & Commercial Alzac process aluminum & 0.85 \\
Sputtered aluminum reflector & 0.89 & Aluminum foil, 99.5\% pure & 0.86 \\
\hline
\end{tabular}

+ Source: Duffie and Beckman [1974].

selected wall, roof, and ground surfaces. One can notice the relatively large range of albedo values; for walls, the given albedos range from 0.15 to 0.72 ; for roofs, the range is between 0.08 and 0.70 .

Different treatments of the same surface may result in different albedos. An example is the shake cedar shingles that have an albedo of 0.32 when unoiled and an albedo of 0.28 when oiled (see Table 9, under "SHINGLE ROOFS"). Another example is the effect of the mortar joint on the overall albedo of a wall. For example, the burnt adobe block wall has an albedo of 0.36 with tooled mortar joint, but an albedo of 0.34 with a raked mortar joint.

One can also notice the effects of color on albedo of the same material. For example, an asphalt shingle of Dark Mahogany color has an albedo of $0.08 \mathrm{bl}$ " with the white color, its albedo becomes 0.33. Similarly, a gravel roof of Dark Blend Pea Gravel has an albedo of 0.12 but when the gravel is white-coated, the albedo increases to 0.65 .

Figure 10, based on data from Threlkeld [1970], shows the solar reflectivity for selected surfaces at different solar incidence angles. These are values for diffuse reflectors averaged over the entire solar spectrum on clear days. The average reflectivity for new concrete is 0.33 whereas that of old concrete is $\mathbf{0 . 2 2}$. That shows the potential effect of aging (after curing) and also that of wear and tear. All surfaces (except for the bitumen-gravel roof) have slightly higher reflectivities at large solar zenith angles (low solar altitudes). Also, concrete (even if it is old) has a higher albedo than the bitumen-gravel combination. 


\begin{tabular}{|lr|}
\hline \multicolumn{2}{|c|}{ Table 9. Albedo of selected surfacest } \\
\hline WALLS MADE OF CONCRETE AND ADOBE BLOCKS & \\
\hline Burnt adobe block, running bond, tooled light grey mortar joint & 0.36 \\
Burnt adobe block, running bond, raked light grey mortar joint & 0.34 \\
Colored slump block, running bond, concave mortar joint, Tan & 0.43 \\
Colored slump block, running bond, concave mortar joint, Plain & 0.44 \\
Colored slump block, running bond, concave mortar joint, Buff & 0.39 \\
Colored slump block, running bond, concave mortar joint, Palo Verde & 0.33 \\
Colored slump block, running bond, raked mortar joint, Adobe Red & 0.21 \\
Colored concrete masonry unit, running bond, concave mortar joint, Coral & 0.34 \\
Colored concrete masonry unit, running bond, concave mortar joint, Adobe Red & 0.32 \\
Colored concrete masonry unit, running bond, concave mortar joint, Buff & 0.31 \\
Colored concrete masonry unit, running bond, concave mortar joint, Plain & 0.39 \\
\hline WALLS MADE OF BRICKS & 0.28 \\
\hline Brown scratch brick, common bond, concave grey mortar joint & 0.36 \\
Brown ruffled brick, basket weave bond, same mortar and joint & 0.38 \\
Light red scratch brick, common bond, concave grey mortar joint & 0.41 \\
Orange ruffled brick, plain grey mortar joint & 0.51 \\
Buff plain brick, stretchers, raked grey mortar joint & \\
\hline PAINTED AND COATED WALLS & 0.74 \\
\hline Painted slump block, running bond, concave joint, Pearl White & 0.71 \\
Painted slump block, running bond, concave joint, White & 0.68 \\
Painted slump block, running bond, concave joint, Spanish White & 0.65 \\
Painted slump block, running bond, concave joint, Eggshell White & 0.72 \\
Painted concrete masonry unit, running bond, concave joint, Bone White & 0.55 \\
Painted concrete masonry unit, running bond, concave joint, Sea shell Beige & 0.69 \\
Painted concrete masonry unit, running bond, concave joint, Pearl White & 0.42 \\
Painted concrete masonry unit, running bond, concave joint, Desert Sand & 0.65 \\
Painted stucco, Bone White & 0.15 \\
Painted wood paneling, Avocado Green & 0.26 \\
Painted wood paneling, Sand Dune & 0.40 \\
Painted wood paneling, Beige & \\
\hline
\end{tabular}

t Source: Reagan and Acklam [1979]. The values given here are partial. Refer to this reference for an exhaustive overview. Also note that the same color-labeling from different manufacturer (names not given here) have different reflectivities.

\section{Albedo and weathering.}

Albedo changes over time as a result of the effects of weathering and wearing. Building surfaces are exposed to various environmental factors such as solar radiation, humidity, high temperatures, freeze, rain, and dust, whereas other urban surfaces, such as streets, parking lots, and school yards, are subject to wear effects from pedestrian and vehicular traffic in addition to the environmental factors mentioned above.

The effects of soiling, weathering, and wear have not been extensively researched, but a few estimates are available. Courville [1989] and Griggs et al. [1989] estimate that the albedo of a built-up roof is -0.1 when new (after installation) and it becomes $0.3-0.4$ after about six months. They also estimate that a reflective roof that starts with an albedo of 0.9 reaches values between 0.6 and 0.7 in two years. Thermo Materials indicate that their thermolastic coating (Solar Shield®) has an initial reflectivity of 0.90 , but after aging, the reflectivity drops to 0.78 . 


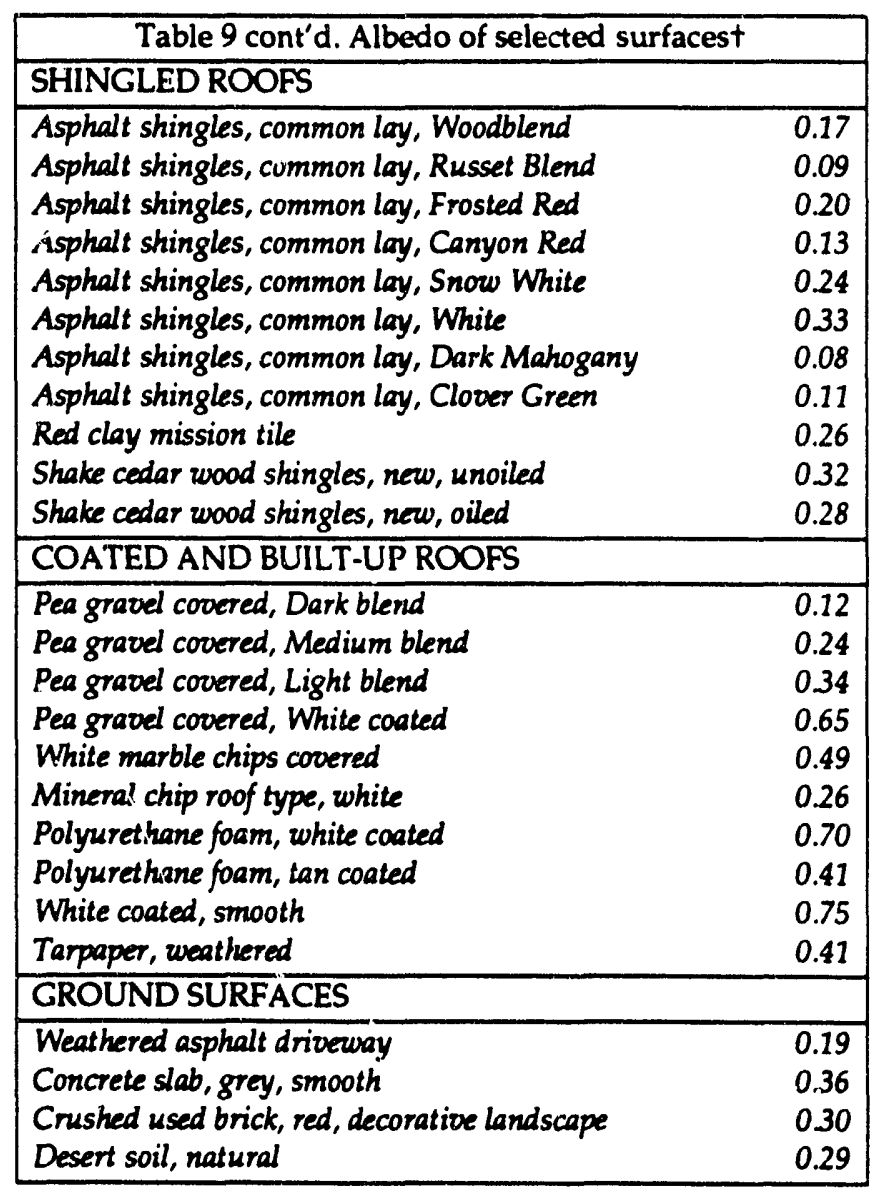

† Source: Reagan and Acklam [1979]. The values given here are partial. Refer to this reference for an exhaustive overview.

These effects must be borne in mind when implementing high-albedo materials as an energy conservation strategy. Sloping the roofs minimizes the effects of dirt accumulation, water ponding, and biological growth on white roofs, and is recommended whenever possible.

For urban surfaces, e.g., streets and parking lots, the change of albedo over time has been monitored in laboratory experiments to a limited extent. Accelerated weathering procedures were used to quantify the impact of weathering on the reflectivity of a selection of surfaces. Table 10 represents results from experiments performed by Kritz and Wechsler [1967] for an accelerated weathering equivalent to 700 hours of solar exposure. Further weathering has insignificant impact on albedo.

\section{B.4 Albedo and emissivity}

Albedo and emissivity of materials vary independently of each other, and knowledge of both quantities is needed for assessing microclimate modifications and energy savings. Low emissivities may counter the desirable effects of higher albedos on building and urban surfaces. 


\begin{tabular}{l|r|r|r|}
\hline \multicolumn{4}{|c|}{ Table 10. Weathering and solar reflectivity of selected paints. } \\
Source: Kritz and Wechsler [1967]. \\
\hline $\begin{array}{l}\text { Paint } \\
\downarrow\end{array}$ & Before weathering & After weathering & Reduction \\
\hline Traffic white (standard) & 0.82 & 0.73 & $-11 \%$ \\
Traffic white (untinted) & 0.82 & 0.74 & $-10 \%$ \\
Custom blend traffic white & 0.75 & $0.77^{* *}$ & $+3 \%$ \\
Traffic white (with pumice) & 0.76 & 0.70 & $-8 \%$ \\
Tank white & 0.75 & $0.76^{* *}$ & $+1 \%$ \\
A100 Latex white & 0.82 & 0.75 & $-9 \%$ \\
Acrylic emulsion white sealer & 0.79 & 0.76 & $-4 \%$ \\
\hline
\end{tabular}

**The authors indicate that the apparent increase in reflectivity is within the uncertainty of the measurement technique.

To save cooling energy in hot climates, the ideal combination would be one of high albedo and high emissivity. Table 11 lists values for albedo and emissivity of selected materials.

\begin{tabular}{|lcc}
\hline \multicolumn{3}{|c|}{ Table 11. Albedo and emissivity for } \\
selected surfaces. Based on data from Wechsler and Glaser [1966]. \\
Refer to this source for chemical composition of paints/coatings. \\
\hline \multicolumn{2}{c}{$\alpha$} & $\varepsilon$ \\
\hline Concrete & 0.30 & 0.94 \\
Red brick & 0.30 & 0.90 \\
Wood (freshly planed) & 0.40 & 0.90 \\
White paper* & 0.75 & 0.95 \\
Tar paper & 0.05 & 0.93 \\
White plaster* & 0.93 & 0.91 \\
Bright galvanized iron & 0.35 & 0.13 \\
Bright aluminum foil & 0.85 & 0.04 \\
\hline White pigment & 0.85 & 0.96 \\
Grey pigment & 0.03 & 0.87 \\
Green pigment & 0.73 & 0.95 \\
White paint on Al & 0.80 & 0.91 \\
Black paint on Al & 0.04 & 0.88 \\
Aluminum paint & 0.80 & 0.40 \\
\hline Water & 0.05 & 0.95 \\
Ice & 0.69 & 0.90 \\
Gravel & 0.72 & 0.28 \\
Dry, plowed ground & 0.10 & 0.80 \\
Sand & 0.24 & 0.76 \\
Vegetated fields & 0.10 & 0.76 \\
Forests & 0.10 & 0.85 \\
\hline
\end{tabular}

*Note that $\varepsilon$ is a characteristic of the surface for long wave radiation whereas albedo covers the entire solar spectrum. *"These are examples for good $c$ and $\varepsilon$ combinations.

One should keep in mind that emissivity may change from a certain initial value because of the effects of weathering, soiling, and wear. However, the change seems to be small. In 
experiments with laboratory paint chips, Kritz and Wechsler [1967] found that a Traffic White (standard) paint had an emissivity of 0.81 before weathering and 0.78 after accelerated weathering. The corresponding numbers for a Custom Blend Traffic White were 0.80 and 0.82 , respectively. Changes of this order of magnitude (as caused by weathering) are not significant. However, it is important to know the emissivity of materials in addition to their albedos so that their performance may be understood and quantified.

In this project, all surfaces that were monitored had similar emissivities $(-0.95)$ except for a corrugated metal roof with $\varepsilon=-0.30$ (these will be discussed in section C.3). Measurements of emissivity and its impact on surface temperature and energy use may be a subject for future research. In this project, we focus on albedo variations while emissivity is constant

\section{ALBEDO MEASUREMENTS}

In this section, we discuss our measurements of albedo in the actual outdoor environment. The purpose of these measurements was to develop a method for dorumenting albedo values and to correlate changes in surface temperature to albedo modifications at several test areas.

\section{C.1 Experiment Design and Instrumentation}

This project focused on measuring albedo, surface temperature, and air temperature in the actual outdoor environment. These variables were measured on an hourly basis between sunrise and sunset, with particular emphasis on early afternoon hours: the times of peak cooling energy consumption. Additionally, surface temperature was also measured once at night.

Albedo measurement: We used an Eppley PSP (Precision Spectral Pyranometer), a high precision radiometer that is sensitive to radiant energy in the $0.28-2.8 \mu \mathrm{m}$ band. This pyranometer yields an output of $9.98 \mu \mathrm{V}$ per $\mathrm{W} \mathrm{m}^{-2}$, has a linearity of $\pm 0.5 \%$ between 0 and $1400 \mathrm{~W} \mathrm{~m}^{-2}$, and a response time of 1 second. These specific characteristics were obtained based on calibration by the EPPLEY laboratory (in Newport, R.I.) on February 15, 1991.

The double-dome design of the Eppley pyranometer minimizes the effects of internal convection resulting from tilting the pyranometer at different angles. For this reason, the PSP was especially suitable for this study, since albedo measurements required the apparatus to alternatively face up and down.

The analog output from the pyranometer was converted to digital output with a readout meter (EPLAB Model 455 Instantaneous Solar Radiation Meter) that has an accuracy of better than $\pm 0.5 \%$ and a resolution of $1 \mathrm{~W} \mathrm{~m}$. The meter was scaled to the sensitivity of our PSP by the EPPLEY laboratory. 
One concern that arose when using the pyranometer facing down was the effect of the pyranometer's shadow. The closer the pyranometer gets to the surface, the larger is the effect of the shadow on the reflected radiation sensed by the radiometer, particularly at small zenith angles. This is because the view factor between the shaded spot and the pyranometer increases significantly when the latter is closer to the surface and thus the albedo values underestimate the true albedo of the surface. On the other hand, as the pyranometer is moved further from the surface, it becomes subject to environmental radiation; radiation that is reflected from surroundings other than the surface in question, particularly if the surface is small.

There seems to be an optimal distance between the pyranometer and a surface at which the effects of both the shadow and environmental radiation are minimal. The definition of this distance and the related pyranometer stand design are discussed in the "Method" section below.

Surface temperature: To measure the surface temperature of the test areas in the outdoor 'nvironment, we used a non-contact infra-red thermometer, the Raynger Type PM4 hand-held radiation thermometer. The PM4 has a variable emissivity setting (0.1 to 1.0$)$, ambient temperature compensation, and an output of $1 \mathrm{mV}$ (millivolt) per ${ }^{\circ} \mathrm{C}$. It has an accuracy of $\pm 1 \%$ of reading \pm 1 digit and a repeatability error of $\pm 0.5 \%$ of reading \pm 1 digit. Its spectral response is in the band 8 to $14 \mu \mathrm{m}$ and its response time is $250 \mathrm{~ms}$ (millisecond). To measure the surface temperature, we scanned the test areas around the spots where the pyranometer was located, and averaged the readings over several seconds (see further description in section C.3).

Air temperature: We used a portable K-type thermocouple thermometer type Telatemp model 90 High Accuracy Thermometer with an air temperature probe, type K-90400. The thermometer has an accuracy of $\pm 0.25 \%$ of reading $\pm 1{ }^{\circ} \mathrm{C}$ and a resolution of $0.1{ }^{\circ} \mathrm{C}$.

Wind speed: We obtained wind speed data from a meteorological station on a building at the Lawrence Berkeley Laboratory, about $500 \mathrm{~m}$ (1640 ft) away from the location of the surface and air temperature measurements. This station was not calibrated against those of the National Weather Service, and was used in this project to give a general indication of the wind speed's variation pattern.

\section{C.2 Method}

Two tasks were conducted in this study. The first concerned generating an albedo data bast for various surfaces/land uses, whereas the second task involved measuring the albedo and surface temperature of several test areas on a roof surface. Both of these tasks were performed in the actual outdoor environment. In the second case, a correlation between surface temperature, surface albedo, and incoming solar radiation was developed. Additionally, air temperature was measured and the emissivity of the surface was estimated. 
To monitor the direct effects of albedo, we chose a large, flat roof, since, as mentioned earlier, roof surfaces are the most appropriate for this project. In addition, roofs can be whitened without much of the glare problem that walls may involve.

One advantage of monitoring several test areas on the same roof is that surface/material characteristics, roof construction, and roof insulation are the same for all monitored samples. Another factor we observed was that the underside of the roof be similar underneath all test areas. This was to ensure that the outside roof surface temperature was not being affected by thermal characteristics of different underlying spaces. The roof selected for this monitoring covered a single, undivided, two-story space. Also, before actually modifying roof surfaces, surface temperatures were scanned with the IR thermometer to make sure that different substrates were not affecting the test sectors, which could bias the temperature readings and albedo correlations. In preliminary tests during noon and early afternoon hours, we found that underlying trusses/beams can make the roof locations above them $6^{\circ} \mathrm{C}\left(10^{\circ} \mathrm{F}\right)$ warmer than the roof deck over the free spans between the support elements.

A large unobstructed roof on an LBL building was selected for this experiment. The builtup roof was flat and uniform. We unrolled two EPDMs next to each other with a distance of 1.2 $\mathrm{m}(4 \mathrm{ft})$ between them. We also painted two strips of coatings at a distance of $0.7 \mathrm{~m}(2.3 \mathrm{ft}) \mathrm{from}$ the white EPDM. The Solar Shield@ strip was $2.13 \times 0.53 \mathrm{~m}$, whereas the Enerchron (2) strip was $2.13 \times 0.48 \mathrm{~m}$. The strips were separated by a space of $1.12 \mathrm{~m}$. See Figure 11 for location of samples. The coatings were applied with a brush onto the gravel to compare the performance of the coatings with the basecase gravel roof and with each other. The Solar Shield@ strip had an average thickness of $6 \mathrm{~mm}$ and the Enerchron strip had an average thickness of $3.3 \mathrm{~mm} .{ }^{21}$ The Solar Shield@ strip was completely white, whereas the Enerchron@ strip had black spots (underlying gravel partially showing) because the amount of paint was small. As we shall see later, this difference in coating does affect the albedo and surface temperatures of the strips.

In addition to the four samples described so far, four others were also tested. These included 1) the basecase roof (greyish gravel), 2) a colored roof (similar gravel, but brownish), 3) a roof bitumen spot, 4) and a corrugated metal deck (with both top and bottom sides exposed to ambient air). 22 All the samples are discussed further in the Appendix (section J).

21 These thicknesses were larger than typical because we had to cover gravel that had a much larger surface area per unit roof area than would be the case with a flat surface. Also, the gaps between the stones had to be filled with paint. The recommended thickness for Enerchronis is -0.5 $\mathrm{mm}$ and for Solar Shieldo is $0.3 \mathrm{~mm}$.

2 The following table lists the test areas and their dimensions (m).

\begin{tabular}{ll|ll|ll|}
\hline Enerchron on gravel & $0.48 \times 2.13$ & Solar Shield on gravel & $0.53 \times 2.13$ & Corrugated metal & $>3.0 \times 3.0$ \\
SynTec White EPDM & $3.0 \times 3.0$ & SynTec Black EPDM & $3.0 \times 3.0$ & Overall roof dimensions & $120.0 \times 40.0$ \\
Enerchron on EPDM & $1.63 \times 1.63$ & Bitumen & $1.0 \times 2.0$ & & \\
Basecase gravel & $>3.0 \times 3.0$ & Colored gravel & $>3.0 \times 3.0$ & & \\
\hline
\end{tabular}


Albedo and surface temperature were measured at the center of the EPDM samples, the basecase sample, the colored roof, and the corrugated metal roof. In the Enerchron $\circledast$, Solar Shield $@$, and bitumen strips, the albedo was measured at the center of the strip, whereas surface temperature was measured along the length axis of each test area. In all cases, the area-averaged surface temperature was used. For the cases where the test area filled less than $95 \%$ of the pyranometer's view factor, i.e., Enerchron $®$ and Solar Shield@ strips, albedo was obtained from pyranometer measurements over the center of each strip and was adjusted for view factor differences.

After two weeks of data collection, an additional amount of Enerchron® was applied onto the black EPDM. The purpose was to compare the albedo of a flat Enerchron® sample to that of the same coating applied to the rough gravel, and to measure the associated surface temperatures under these new conditions. The new Enerchron $®$ sample area was $1.62 \times 1.62 \mathrm{~m}(5.3 \times 5.3 \mathrm{ft})$ and is shown in Figure 11 by a dotted square inside the black EPDM square.

Incoming solar radiation was measured at a point north of the white EPDM, and air temperature was measured at a height of $40 \mathrm{~cm}(1.5 \mathrm{ft})$ above the roof surface. In our temperature readings, the IR thermometer's emissivity was set to 0.95 since this number represents the surfaces monitored in this work, with the exception of the corrugated metal roof, that has an emissivity of -0.30 . Corrections were made to the surface temperature readings in that case.

Another issue was to determine the pyranometer's height above the surface whose albedo was being measured. According to our calculations, as well as others' [Reifsnyder 1967], a ratio of $1 / 10$ between the pyranometer's height and diameter of test area is required for a view factor of $95 \%$ or better from the sample to the inverted pyranometer. Based on this rule of thumb, we looked for an unobstructed/unshaded roof area so that each test sector had a diameter greater than the given minimum. When the test area of a sample was smaller than the given minimum, we used view factor algebra to correct the pyranometer's reading and obtain the albedo for that surface.

Additionally, we identified certain height thresholds for the pyranometer to minimize its own shadow's impact on the amount of reflected radiation. We describe below some of the procedures employed to correct for the effect of a pyranometer's shadow on reflected solar radiation from the surface.

A. We adjusted the measured reflected radiation $(\mathrm{K} \uparrow)$ using measured direct and diffuse radiation intensities. We measured these intensities by reading the pyranometer's output once with shading the dome and once without shading it. In this method, we assumed that the spectral characteristics of the diffuse radiation are independent of time (solar angle) and that the shaded spot receives the same amount of diffuse radiation as the sunlit spots. Obviously, both of these assumptions contain certain errors, but we believe they are insignificant. This procedure can be explained with equations (2) through (4): 


$$
\begin{aligned}
& K \uparrow=K_{m} \uparrow+(K \downarrow-q \downarrow) F_{s \rightarrow p} \frac{A_{s}}{A_{p}} \alpha \\
& \alpha=\frac{K_{m} \uparrow+(K \downarrow-q \downarrow) F_{s \rightarrow p} \frac{A_{s}}{A_{p}} \alpha}{K \downarrow} \\
& \alpha=\frac{\left(\frac{K_{m} \uparrow}{K \downarrow}\right)}{1-\left(\frac{1}{K \downarrow}(K \downarrow-q \downarrow) F_{s \rightarrow p} \frac{A_{s}}{A_{p}}\right)}
\end{aligned}
$$

where $\mathrm{K} \uparrow$ is the corrected reflected radiation (to be calculated), $\mathrm{K}_{\mathrm{m}} \uparrow$ is the reflected (uncorrected) radiation as measured by the inverted pyranometer, $K \downarrow$ is the measured total (diffuse+direct) downward radiation, $q \downarrow$ is the measured downward diffuse radiation, $F_{s \rightarrow p}$ is the view factor from the shaded spot to the pyranometer, $A_{s}$ is the area of the shadow, $A_{p}$ is the area of the sensing element of the pyranometer, and $\alpha$ is the albedo to be computed.

Equation (4) yields the instantaneous value of a surface's albedo after correction for the effects of the pyranometer's shadow. To find an averaged albedo value, we need equation (5):

$$
\alpha_{a}=\frac{\int K \uparrow(t) d t}{\int K \downarrow(t) d t}
$$

B. We experimentally determined the variation in the shadow's effect on measured reflected radiation as the pyranometer's height was varied. We designed a stand from which the pyranometer hung upside down (Figure 12a). The effect of the stand was minimized by hanging the pyranometer with a wire from the end of a 6 foot tube coming off the stand. The reflected radiation from the test surface was measured at several heights and different solar angles to determine the threshold height above which the measured reflected radiation did not change significantly. Each set of measurements was taken in a relatively short period of time (roughly 1 minute) and under absolutely clear sky conditions so that the incoming solar radiation was essentially constant during each measurement interval. This procedure was repeated at several times of the day to analyze the impact of solar angle on measured albedo. We performed this test on two roofs.

The first was the roof of the Harmon Gym building on the campus of the University of California at Berkeley. It was a steel structure roof with plywood deck and white paint over felt. This roof was completely unobstructed and was open to the entire sky's hemisphere. The surface was quite smooth and produced fairly consistent data. Concurrent measurements of incoming short-wave radiation indicated that the albedo of that roof was 0.70 . 
The second test surface was a built-up roof of Building 90 at Lawrence Berkeley Laboratory. The portion of the roof used for this test had a gravel topping and was partially obstructed by a few trees and structures on the roof itself. Results are presented in Figure $\mathbf{1 3}$ which shows a general trend that the reflected radiation (thus measured albedo) approaches a constant value as the instrument height is increased. The results indicate that at heights over $\mathbf{4 0}$ $\mathrm{cm}(1.5 \mathrm{ft})$ the reflected radiation is essentially constant for a given time and surface. Based on similar tests, we determined that the minimum height for albedo measurements (with an inverted pyranometer) should be between 40 and $50 \mathrm{~cm}(-1.5 \mathrm{ft})$ above the surface if the shadow effect is to be minimal. Using this information, we designed another (permanent) stand that puts the inverted pyranometer at a height of $43 \mathrm{~cm}(1.4 \mathrm{ft})$ above the surface (Figure 12b).

\section{Advantages and disadvantages of albedo measurement methods}

This section is a brief review of the possible methods we envisage for measuring the albedo of urban and building surfaces, and the advantages and disadvantages associated with each. Method 1 was not used in this study.

1. Measuring the reflectivities of samples with a reflectometer. In the reflectometer measurements, one can obtain reflectivities at certain wavelengths, which can then be integrated to obtain an albedo value. This is done by weighting the reflectivities by intensity at each wavelength and producing a representative albedo value. This task is appropriate for measuring the weathering and soiling effects on albedo. It is also useful in generating albedo values for selected materials in the relatively more controlled laboratory environment. The advantages of this method are: (1) the controlled environment of the laboratory makes it easy to 'soil' the samples and study that effect on albedo; (2) the freedom of selecting the measurement wavelength; (3) it requires only a small sample, an area less than 2 inches in diameter; and (4) all different materials can be subjected to exactly the same range of environmental conditions, so intercomparison of reflectivities and albedo can be made more reliable and accurate. The main disadvantage of this method is that it yields no temperature-alhedo correlations and that albedo values are not readily available.

2. Measurements in the actual outdoor environment (this study). This method involves measuring albedo and surface temperature in an actual environment, and measuring the associated microclimate parameters. Then the hourly albedo, solar radiation, and surface temperatures can be correlated. Air temperature is also measured and correlated to the other variables.

The disadvantage of this method is that it yields an albedo value that cannot be assigned to a particular surface unless it completely fills the pyranometer's field of view (although this is very useful climatologically speaking). It is also harder to study the effects of soiling as the environment cannot be easily controlled. But the advantages, on the other hand, are: (1) actual hourly values of albedo can be obtained directly; (2) surface temperature correlations to albedo modifications are realistic; and (3) no special or elaborate setup is needed. This task yields 
albedo values that are conventionally accepted (i.e., they can be shared with climate and atmospheric researchers) and that can be readily used as input for climatological and PBL simulations. In this study, we used this method to generate albedo values for a variety of surfaces.

3. Measuring the albedo of controlled surfaces under natural sunlight (this study). This method involves the measurement of albedo and temperatures of small samples in an actual outdoor environment. As discussed earlier in this section, a flat test sector wide enough and close enough to the pyranometer (to increase the view factor) is a common configuration for this method. This setup has also been used by other researchers (e.g., Reagan and Acklam [1979] in their reflectance studies). In Reagan and Acklam's measurements, the sensor was $15 \mathrm{~cm}(0.5 \mathrm{ft})$ above the center of a circular sample $1.8 \mathrm{~m}(6 \mathrm{ft})$ in diameter.

The disadvantages of this method are: (1) it requires a relatively larger sample area $(-12$ $\mathrm{m}^{2}$ for each test sector); and (2) the samples are relatively more difficult to 'soil' than the reflectometer samples. The advantages, on the other hand, include: (1) the ability to directly measure albedo with a pyranometer (no need for wavelength weighting and integration); (2) the sample is large enough to permit the effects of roughness and surface texture to be better accounted for in the albedo measurements; and (3) surface temperature measurements can be performed. In this project, this method was used to study the albedo and temperature patterns of the test samples we obtained from coatings and paint manufacturers.

\section{C.3 MEASUREMENTS and RESULTS}

\section{C.3.1 Urban albedo (spatial and temporal variations)}

Two types of albedo variations were documented: (1) spatial variations among various surfaces of similar and dissimilar nature; and (2) temporal variations of albedo at specific points, over a certain time period (about 2-3 hours on each side of solar noon). In the first case, we moved from one area to another within the eastern part of the San Francisco Bay Area to measure the albedo of various streets, parking lots, yards, grass surfaces, etc. In the second case, we selected two roof sites to measure the albedo variations at specific points on each roof to identify any possible time-dependence in albedo.

In each case, we documented the exact location of the measurement spots so we can return to exactly the same point, perhaps years later, to measure the albedo and be able to quantify the effects of weathering and wearing.

Tables 12 through 14 are examples from our field measurements for the spatial variations in albedo. At each point, three measurements of incoming and reflected solar radiation were performed at 2 minutes intervals. The three albedos were averaged and these averages are presented in the tables. ${ }^{23}$ With each albedo number, information on weather conditions, surface

23 These tables represent the start of a library of albedo values that will be regularly expanded. 
characteristics, type of materials, color, and age is provided.

Figure 14 shows some of these data points for four categories of surfaces. Figure 15 shows data from the second case (measuring time-varying albedo at specific points) for one of the two roofs we chose. This figure shows that the gravel roof had an albedo of 0.09 and that it was independent of solar angle.

\begin{tabular}{|lll|}
\hline \multicolumn{4}{|c|}{ Table 12. Albedos of parking lots (Clear and calm day, 5-23-91). } \\
\hline Description & Time (DST) & Albedo \\
\hline Black asphalt, -3 years old, Powell Street Plaza, Emeryville & $10: 35$ & 0.08 \\
Black asphalt, -3 years old, Powell Street Plaza, Emeryville & $10: 45$ & 0.07 \\
Black asphalt, -2 years old, Market Place, Emeryville & $11: 25$ & 0.05 \\
Black asphalt, - 2 years old, Market Place, Emeryville & $11: 35$ & 0.06 \\
Gravel-topped, moderate light, over 5 years old, Market Place & $11: 50$ & 0.14 \\
Lighter asphalt with speckles, -4 years+, CH2M Hill parking lot & $12: 00$ & 0.13 \\
Asphalt, light-colored, 6 years+, Berkeley Marina & $12: 46$ (spot A) & 0.15 \\
Asphalt, light-colored, 6 years+, Berkeley Marina & $12: 51$ (spot B) & 0.14 \\
Asphalt, dark-colored, 1 year, El-Cerrito Plaza & $13: 05$ & 0.06 \\
Asphalt, light-colored w/speckles, El-Cerrito Plaza & $13: 15$ & 0.12 \\
Asphalt, old, black, cracked, El-Cerrito Plaza & $13: 20$ & 0.06 \\
Asphalt, old, light w/speckles, El-Cerrito Plaza & $13: 25$ & 0.13 \\
Asphalt, light-colored, old (5 years+), Richmond & $15: 00$ & 0.12 \\
Asphalt, light-colored, old (5 years+), w/oil \& grease & $15: 10$ & 0.09 \\
Asphalt, light-colored, (5 years), large pebbles, reddish tint & $15: 35$ & 0.13 \\
\hline
\end{tabular}

\begin{tabular}{lll|}
\hline \multicolumn{3}{|c|}{ Table 13. Albedo of grass areas (UCB Campus, Clear/calm day, 6-5-91). } \\
\hline Description & Time (DST) & Albedo \\
\hline 3" long, moist, deep green & $11: 00$ & 0.22 \\
3" long, moist, yellowish & $11: 10$ & 0.22 \\
2" long, dry, moderate green, patchy & $11: 17$ & 0.20 \\
1" long, wet, moderate green, patchy, w/debris & $11: 27$ & 0.19 \\
2" long, dry, moderate-deep green w/ pink clovers & $11: 45$ & 0.21 \\
3" long, dry, moderate green & $11: 59$ & 0.17 \\
2.5" long, dry, moderate green, wide blade & $12: 07$ & 0.18 \\
2" long, dry, yellowish, old & $10: 40$ & $0.20 \ddagger$ \\
2" long, dry, yellowish, patchy & $10: 45$ & $0.19 \ddagger$ \\
1" long, dry, patchy w/exposed soil & $10: 55$ & $0.17 \ddagger$ \\
3" long, dry, deep green, wide blade & $11: 00$ & $0.20 \ddagger$ \\
\hline
\end{tabular}

‡ These measurements were taken on 5-23-91 at Powell Street Plaza parking lot dividers. Clear and calm day.

\begin{tabular}{llll|}
\hline \multicolumn{3}{|c|}{ Table 14. Albedo of streets (Clear and calm conditions). } \\
\hline Description & Time (DST) & Albedo \\
\hline Light seal with white speckles, residential, El-Cerrito & $13: 35$ & 0.15 \\
Light seal with speckles, residential, El-Cerrito & $13: 45$ & 0.13 \\
Light asphalt with bigger gravel, shopping ctr., Richmond & $14: 10$ & 0.11 \\
\hline
\end{tabular}

\section{C.3.2 Roofing materials' albedos and surface temperatures}

In this section, we describe the measurements of albedo, surface temperature, and air temperature for 8 surfaces on an actual roof at the LBL site. The test areas and materials are 
described in the Appendix. The experimental set-up for this set of measurements was described in the Method section (see above).

\section{C.3.2.A Albedo values (for the test areas)}

After allowing a week of curing time for the elastomeric coatings, we measured the albedo of each of the 8 samples with an Eppley PSP using a stand we specifically designed for this purpose. The measurements indicated that the Black EPDM had an albedo of 0.08 , the white EPDM of 0.72 , the basecase gravel of 0.11 , and the colored gravel of 0.13 . Although the basecase and the colored gravels seemed to be different in color and visual qualities, their albedos were the same (negligible difference). The corrugated roof had an albedo of 0.17 .

The albedos of the Solar Shield \& and Enerchron® strips were 0.73 and 0.61 respectively. These albedos were lower than expected because of the gravel's texture. Though the paints were supposed to have high reflectivities, when painted on a rough surface, their albedos fell because of the geometrical effects (multiple reflections). Also, Enerchron $\otimes$ had a lower albedo than Solar Shield $\circledast$ partly because the former's strip was not as well painted and still showed the underlying dark gravel. However, Solar Shield's measured albedo of 0.73 compared well with the claimed reflectivity of 0.78 . Supporting this reasoning were our albedo values for the flat Enerchron ${ }^{\circ}$ test sample that was painted over the flat black EPDM. The albedo of the flat Enerchron ${ }^{\circ}$ was 0.81 (up from 0.61 ), lower than the manufacturer's claimed reflectivity of 0.995 .

\section{C.3.2.B Hourly variables}

Hourly variables were recorded on the 15th, 17th, 18th, and 22nd of July 1991. At each hourly observation, the following was recorded: synoptic conditions, test surface conditions, cloud cover, cloud type, wind speed, downward total horizontal solar radiation, air temperature, and the surface temperatures of the black EPDM, the white EPDM, the basecase gravel, the Solar Shield $\circledast$ strip, the Enerchron $\otimes$ strip, the bitumen strip, the colored gravel, and the corrugated metal roof. This sequence defined a 'loop' of measurements. Both solar radiation and air temperature were recorded once before the observation loop, and once after the loop so that significant fluctuations in these variables could be detected.

\section{Temperature}

Figures 16 through 19 summarize part of the temperature data for these four days. Each figure shows the surface temperature of all test areas as well as air temperature (bold line). The figures show a consistent pattern of temperature succession starting at the bottom with air temperature and ending at the top with the temperature of the bitumen strip. The reason the air temperature fluctuated so much was that it was taken at a height of $40 \mathrm{~cm}(1.5 \mathrm{ft})$ above the basecase gravel roof. And because the probe was so close to the roof surface, the air temperature measured there was under the influence of warm air convection from the roof at a time of 
low wind speed. But when gusts occurred, or when wind speed picked up, the probe became more influenced by the cooler air advected from the surroundings onto the roof.

The white EPDM was about $45^{\circ} \mathrm{C}\left(81^{\circ} \mathrm{F}\right)$ cooler than the black EPDM in the early afternoon on the clear and warm days (Figs 16 and 17). We can also see that while Enerchron $₫$ and Solar Shield $\otimes$ were about $5^{\circ} \mathrm{C}\left(9^{\circ} \mathrm{F}\right)$ warmer than air, the bitumen strip was about $50{ }^{\circ} \mathrm{C}\left(90^{\circ} \mathrm{F}\right)$ warmer than air in the early afternoon. The Enerchron ${ }^{8}$ strip was warmer than the Solar Shield $\circledast$ strip because of the thickness and uniformity of the coating (refer to previous section). The reason the lines of the black EPDM and the basecase temperatures cross other lines after $16: 00$ is that they were shaded by the trees while the other surfaces were still sunlit.

On 7-18-91 (Figure 18), the morning started with thick radiation fog (Tule fog) at roof level. Until 10:00 am, the temperatures of all the surfaces were close to each other, varying by no more than $4^{\circ} \mathrm{C}\left(7^{\circ} \mathrm{F}\right)$ from the air temperature. The pyranometer at that time $(10: 00 \mathrm{am})$ was recording $80 \mathrm{~W} \mathrm{~m}^{-2}$, which was low compared to the average $700 \mathrm{~W} \mathrm{~m}^{-2}$ recorded on the two preceding days at the same solar time. When the sun shone, the temperature difference among the test areas increased until the range reached about $40^{\circ} \mathrm{C}\left(72^{\circ} \mathrm{F}\right)$ around $14: 00$ which was similar to the afternoon temperature range shown in Figures $\mathbf{1 6}$ and 17. In these three figures, note that the surface temperature of the white EPDM and the Solar Shield® strip was lower than that of ambient air early in the morning, and in fact, these surfaces were covered with dew at these times. Finally, Figure 19 shows similar information during daylight hours, but extends into the night. We can see that after 20:00 hours, all surfaces had the same temperature and were cooler than air. Until 22:00 hours on that day, skies were clear and wind speed was low. Radiative cooling was thus large.

Figures 20 through 23 represent another way to look at the same data. In these figures, the surface temperature is plotted against solar radiation. The figures include all hours of the experiment, except those with rapidly varying cloud cover (in which case it was difficult to assign a certain value for solar radiation since it varied by more than $300 \mathrm{~W} \mathrm{~m}^{-2}$ within seconds). The scatter was fitted with simple linear regression lines to show the trend in temperature as solar radiation varies. What these fits tell us, for example, is that for the same increase in incident solar radiation, the increase in surface temperature of the black EPDM is 4 times larger than that of the white EPDM (Figure 20). Similarly, the Solar Shield $₫$ strip warmed 3 times less than the basecase gravel roof (Figure 21) whereas the Enerchron ${ }^{\circledR}$ strip warmed twice less than the basecase (Figure 22). ${ }^{24}$ In comparison with the basecase gravel roof, the bitumen strip warmed 1.5 times more, whereas both the colored roof and the corrugated metal roof warmed by about the same amount (Figure 23).

24 Recall that the Enerchron@ strip was not as well painted as the Solar Shield@ strip, and thence the difference in temperature response to solar heating. 
We also tested the Enerchron $\otimes^{8}$ sample on the flat EPDM. As we mentioned earlier, its albedo was higher than that of the rough Enerchron test area and that affected its surface temperature accordingly. Snapshot measurements indicated that the Enerchron's surface temperature was similar to and lower than that of the white EPDM that was the coolest surface in the previous tests (Figures 16 through 19). The flat Enerchron $\otimes$ was only $1-2^{\circ} \mathrm{C}\left(-3^{\circ} \mathrm{F}\right)$ warmer than air in the morning and afternoon hours. It also was about $4^{\circ} \mathrm{C}\left(7^{\circ} \mathrm{F}\right)$ cooler than the rough Solar Shield $\otimes$ strip. Table 15 summarizes some of these results.

\begin{tabular}{|c|c|c|c|c|}
\hline \multicolumn{5}{|c|}{ Table 15. Flat Enerchron 1 temperatures } \\
\hline Date $\rightarrow$ & \multicolumn{2}{|c|}{$7-25-91$} & \multicolumn{2}{|c|}{$7-26-91$} \\
\hline DST $\rightarrow$ & $16: 01$ & $16: 13$ & $11: 15$ & $11: 34$ \\
\hline Flat Enerchrono (T) & 25.2 & 24.4 & 26.2 & 26.6 \\
\hline White EPDM $\left(T_{s}\right)^{s}$ & 24.1 & 24.4 & 25.7 & 26.8 \\
\hline Black EPDM $(T\}$ & 59.9 & 59.2 & 58.7 & 61.7 \\
\hline Air temperature $\left(T_{2}\right)$ & 24.2 & 21.7 & 23.0 & 22.0 \\
\hline
\end{tabular}

Finally, Figures 24 and 25 represent data from a separate test done on the roof of site 90 at the Lawrence Berkeley Laboratory. In Figure 24, we can see that during a sunny summer day, the surface temperature of a gravel roof with 0.09 albedo was $30^{\circ} \mathrm{C}\left(54^{\circ} \mathrm{F}\right)$ higher than that of the air, early in the afternoon. In Figure 25, the data show that the roof was warming at about $0.03^{\circ} \mathrm{C} /\left(\mathrm{W} \mathrm{m}^{-2}\right)$.

In terms of urban warming and cooling rates versus heat island intensities, the slopes shown in Figures 20-23 explain why a dark city will create a heat island while a whiter city will not heat up as much. However, the translation from surface temperature heat islands to air temperature heat islands is not straightforward. Developing a correlation between the two requires knowledge of relevant micrometeorological conditions.

\section{C.3.3 Comparisons with field data from other researchers}

Albedo and surface temperature information of the type we have measured and documented are scarce. For this reason, we have only little data from other researchers to compare with ours. For example, our albedo values for gravel roofs ranged between 0.09 and 0.14 , comparing well with the 0.12 value reported by Reagan and Acklam [1979]. The values we obtained for the gravel coated with Enerchron $\circledast$ and Solar Shield@ coatings (albedos of 0.61 and 0.73, respectively) compared well with the 0.65 average value reported by Reagan and Acklam [1979] for a pea gravel roof coated white. For the flat white surface (Enerchron® applied to the EPDM) the albedo of 0.81 compared well to the reported 0.82 and 0.80 albedos for a flat white paint [Reagan and Acklam 1979, Kritz and Wechsler 1967]. Similarly, the grass and parking lot albedos (average -0.2 and -0.10 ) compared well with those obtained by Oke [1987].

In terms of surface temperature data, our measurements indicate results that are similar to those obtained by other researchers. For example, the temperature differences we obtained 
between the black and white EPDMs were similar to those obtained by Backenstow [1987] in both clear and overcast conditions. Temperature depressions of $\sim 40^{\circ} \mathrm{C}\left(72^{\circ} \mathrm{F}\right)$ around solar noon on a clear summer day were typical. Our comparisons of surface temperatures for eight different samples indicated the same kind of temperature depressions given by Cordell [1991]. Our findings are also supported by the data from Rohm and Haas Company and Habel and Florence [1985].

\section{WHITENING TECHNIQUES and COSTS}

This section examines the available technologies for producing light-colored surfacing on streets, yards, sidewalks, parking lots, roofs, and walls. It includes a brief review of the present procedures with notes on their applicability and performance, as well as preliminary estimates of related material and application costs.

\section{D.1. Techniques}

Generally speaking, there are two scales at which the lightening of cities and urban areas can be carried out. The first is the building scale, including the external surfaces of buildings, whereas the second comprises the myriad of urban surfaces such as streets, parking lots, yards, and sidewalks. In either case, the techniques involve either coating existing surfaces or modifying the makeup of new surfaces so that they incorporate light-colored ingredients.

\section{Building surfaces}

As stated earlier, the emphasis in this paper is on roof surfaces. The available techniques for roof whitening include:

1 Adding light-colored aggregate to the roofing material. A common example is modified bitumen where the black bitumen (layer or tiles) is covered with a granular layer of a light color. In addition to the effects on roof surface temperature and energy use, this procedure is beneficial for protecting the bitumen from the deleterious effects of UV radiation; also reflecting solar radiation keeps roof cooler, increasing the lifespan of the roof.

2 Light-colored rocks on flat or gently-sloped roofs. This has the advantages of \#1 above and also does not require special materials-only white rocks, provided that the roof is able to withstand the additional load.

3 Colored and painted roofs. This procedure may be especially suitable for exposed metal roofs and those finished with wood sheets. This procedure is easy to perform and does not require special materials.

4 Coating with elastomeric coatings and single plies. This procedure has the advantage that it may not require extensive roof preparation: most elastomeric coatings can be directly applied to existing roofs after appropriate cleaning. Mechanically attached or adhered 
EPDM with light-colored coating (such as Acrylic) can also be used. Coatings do not add significant loads on the roof whereas EPDMs generally do.

5 Using light-colored concrete tiles on sloping roofs. This practice, although relatively new to the U.S., has been popular for quite a long time in Europe, Japan, and Australia [Concrete Construction 1983]. Although the tiles would require additional expenses in underlayments to insure watertightness, the roof has an expected life of well over 50 years compared to an average life of about 20 years for conventional roofs. The main disadvantage of tiles is their larger loading (about $950 \mathrm{lbs} / 100 \mathrm{ft}^{2}$ ).

\section{Urban surfaces}

"Urban surfaces" refer to streets, sidewalks, parking lots, school yards, and other similar surfaces. The commonly available techniques for lightening such urban surfaces include:

1 Using light-colored aggregates in the upper layer of the asphalt in new pavements. Although initially dark, the albedo of the paving will increase after some weathering and road wear, when the aggregates will be exposed. On the other hand, there are some synthetic binders of light colors that can be used to hold the aggregates instead of the dark asphalt, but their initial costs preclude their use for major construction or large surfaces [Shuler 1991]. Since the aggregates form about $95 \%$ (by weight) of the mixture, using light aggregates seems to be a good strategy provided that the binders' issues are addressed.

2 Using a light-colored slurry or chip seal when resurfacing. These procedures have the same problems associated with (1) above. Slurry seal may be more vulnerable to wear and tear effects and would thus require more frequent maintenance.

3 Using concrete rather than asphalt, with a light-colored aggregate and binder. When opting for this technique, it should also be considered that concrete is harder to dig (for servicing and maintenance) than asphalt.

4 Whitetopping. This is performed to resurface an existing asphaltic area or to create new surfaces. The process involves producing light-colored concrete pavements. Several such pavements have been tested at different locations in the U.S. [KRMCA 1988, MIRMCA 1985]. In these cases, concrete pavements, 7 to $10 \mathrm{~cm}$ ( 3 to 4 inches) thick, were used as an overlay treatment to distressed asphalt. The procedure is named "Whitetopping" to contrast it with the usual "Blacktop" term.

5 Using artificial lighteners in preparing the mixtures of asphaltic concrete and slurry seals.

6 Using paints of light colors that are designed specifically to resist weathering, wear and tear, and other environmental effects. Paint categories suitable for this purpose include: (1) highway marking paints, (2) liquid storage tank paints, (3) aerospace coatings, and (4) industrial coatings. Kritz and Wechsler [1967] discussed the performance and relative benefits of each type. 
Generally speaking, the decision whether to use asphalt or concrete depends on several factors such as the desired setting time, strength of the subbase, loads, and expected finishing. Asphalt's setting time is much shorter than concrete's curing time, and can thus be more appropriate in situations where immediate use of a paved surface is needed. Strength versus material quantity is another issue. For example, 12" of asphalt have the equivalent load-bearing capacity of 9" of concrete [PCA 1986]. The initial costs of asphalt and concrete are similar for equivalent designs, according to the Federal Highway Administration (FHA) in its Price Trends for Federal-Aid Highway Construction report. In many cases, the cost of concrete can be lower than that of asphalt.

The average service life ${ }^{25}$ of concrete pavements is about 25 years, whereas the average for asphalt is about 15 years according to the FHA. Finally, the maintenance costs for concrete are lower than the corresponding costs for asphalt, even in cases where the initial costs for the concrete pavements are higher than their asphalt counterparts. This discussion seems to favor concrete over asphalt, but we should recall that the choice depends also on the purpose of the pavement, the local weather characteristics, and the environment.

\section{D.2. Costs}

At present, we have a general idea of the material and labor costs associated with increasing the albedo of building and urban surfaces. In this section, estimates are given based on published data and personal communications. Note that these estimates do not include the cost of preparing a surface for application (such as road bed and substrate preparation and roof construction and layering); they include only the costs of the material and the labor needed to apply it. Thus, our estimates should be used to get a sense of the order of magnitude of these costs and not the exact price.

For paved surfaces, large costs are associated with whitetopping and replacing the dark asphalt surfaces with ones that have light aggregates. The use of light aggregates in resurfacing the top layer seems to be one cost-effective option; unless light-colored aggregates are not locally available, there should be no significant additional cost over that of dark materials. For example, white limestone should cost approximately the same as dark grey basalt [Shuler 1991]. Table 16 gives further information on paved surfaces (note in this table how some initially dark materials, such as asphalt and regular slurry seal, get higher albedos over time as lightercolored deposits accumulate and parts of the lighter aggregates get exposed).

For roofing, elastomeric coatings have been used in several instances and their costs have been quantified. According to Habel and Florence [1985], for example, the cost of Superprep $₫$

25 Service life is the average time between the initial paving and the first resurfacing. 
is $\$ 2.15 / \mathrm{m}^{2}\left(\$ 0.2 / \mathrm{ft}^{2}\right)$ and the application cost is $\$ 0.53 / \mathrm{m}^{2}\left(\$ 0.05 / \mathrm{ft}^{2}\right)$ as of 1985 . Michael Cordell of the National Coatings Corporation [personal communication, March 1991], states that the contractor cost for their Acryshield@ elastomeric coating is $\$ 2 / \mathrm{m}^{2}\left(\$ 0.19 / \mathrm{ft}^{2}\right)$ for materials only if used at a rate of $1 \mathrm{gal} / 4.5 \mathrm{~m}^{2}\left(1 \mathrm{gal} / 48 \mathrm{ft}^{2}\right)$. The corresponding labor costs range from $\$ 2.7$ to $\$ 5.4$ per $\mathrm{m}^{2}$ ( $\$ 0.25$ to $\$ 0.5$ per $\mathrm{ft}^{2}$ ). Firestone Building Products Company recommends three roof types for energy use reduction. These are (a) the Ultraply $78+$ thermoplastic alloy membrane, (b) EPDM with acrylitop coating, and (c) SBS Granular modified bitumen. Exact costs were not available at the time of this writing, but they seem to be within the range stated above. Thermo Materials recommends Solar Shield $₫$, a thermolastic coating with a claimed initial reflectivity of 0.90 and an aged reflectivity of 0.78 . The expected life is over 15 years (warranty) depending on individual roof conditions and structure.

Carlisle SynTec recommends a white Hypalon-base membrane or a white EPDM [Gillenwater 1991]. The expected life for their EPDMs can be inferred from the minimum specifications they must meet. Carlisle SynTec guarantees the black EPDM for 20 years and the white EPDM for 10 years. Of course, the actual life is probably longer but these membranes have to meet a certain minimum ASTM standard. The membrane costs are $\$ 3.87 / \mathrm{m}^{2}\left(\$ 0.36 \mathrm{ft}^{2}\right)$ for the black EPDM and $\$ 5.8 / \mathrm{m}^{2}\left(\$ 0.54 / \mathrm{ft}^{2}\right)$ for the white EPDM. The approximate installed costs are as follows. For the black EPDM, the installed costs are $\$ 20.4 / \mathrm{m}^{2}\left(\$ 1.9 / \mathrm{ft}^{2}\right)$ and $\$ 26.9 / \mathrm{m}^{2}\left(\$ 2.5 / \mathrm{ft}^{2}\right)$ for mechanically fastened and fully adhered systems, respectively. For the white EPDM, these costs are respectively $\$ 25.8$ and $\$ 32.3$ per $\mathrm{m}^{2}\left(\$ 2.4 / \mathrm{ft}^{2}\right.$ and $\left.\$ 3 / \mathrm{ft}^{2}\right)$. Of course, these costs include only the membrane system. Enerchron $®$ costs $\$ 9.7 / \mathrm{m}^{2}\left(-90 \mathrm{k} / \mathrm{ft}^{2}\right)$ and the total cost (labor plus material) reaches $\$ 15.6 / \mathrm{m}^{2}\left(-\$ 1.45 / \mathrm{ft}^{2}\right)$. Enerchron's recommended coverage is $\sim 50 \mathrm{ft}^{2} / \mathrm{gal}$ for roof surfaces and $\sim 100 \mathrm{ft}^{2} /$ gal for walls. Table 17 gives additional cost information.

Table 18 gives information on costs of conserved energy for albedo measures, using a hypothetical Sacramento house as an example. Note that the estimates, particularly those related to the effects of weathering, are variable and still uncertain. Also, in the case where light-colored aggregates are not locally available, costs may increase due to the need for transportation. And, there can be a $100 \%$ increase in cost for replacing standard cement with white cement.

To construct this table, it was assumed that a $150-\mathrm{m}^{2}$ house, located in Sacramento, would use $-3000 \mathrm{kWh}$ per year in cooling energy. It was also assumed, based on our computer simulations, that the annual cooling energy use of that house would decrease by $0.4 \%$ for each 0.01 increase in the albedo of the building and by $3 \%$ for each 0.01 increase in the albedo of the surrounds [Taha et al. 1988, Martien et al. 1989]. In computing the Cost of Conserved Energy (CCE) for indirect effects, it was assumed that the albedo modifications were implemented in only $50 \%$ of the available surface area of paved streets and roofs. In this example, vertical surfaces were assumed to have no contribution to modifications in urban albedo. The table indicates the entries that involve direct, indirect, or both effects. 
In Table 18, the savings from direct and indirect effects of albedo were quantified by Martien et al. [1989] as follows:

$$
\begin{gathered}
S_{d}=\Delta \alpha_{h}\left(\frac{\Delta E_{h} \%}{100}\right) Q, \quad \text { where } \quad \Delta \alpha_{h}=\frac{a_{r} \Delta \alpha_{1}+a_{w} \Delta \alpha_{w}}{a_{r}+a_{w}} \\
S_{i}=\Delta \alpha_{s}\left(\frac{\Delta E_{s} \%}{100}\right) Q, \quad \text { where } \Delta \alpha_{s}=\frac{a_{r} \Delta \alpha_{r}+a_{c} \Delta \alpha_{c}+a_{a} \Delta \alpha_{a}+\ldots . .+a_{n} \Delta \alpha_{n}}{a_{r}+a_{c}+a_{a}+\ldots . .+a_{n}}
\end{gathered}
$$

In equation (6), $S_{d}$ is the annual energy savings from direct effects, $\Delta \alpha_{h}$ is the change in albedo, computed for the entire house, $\Delta E_{h} \%$ is the percent savings in cooling energy use per 0.01 change in the house albedo (in this example, it is equal to $0.4 \%$ ), $Q$ is the annual cooling energy use for the house, $a$ is area, $\alpha$ is albedo, and the subscripts $r$ and $w$ stand for roof and wall, respectively. Similarly, in equation (7) $S_{i}$ is the annual energy savings from indirect effects, $\Delta \alpha_{s}$ is the change in the albedo of the surroundings, $\Delta \mathrm{E}_{\mathrm{s}} \%$ is the percent savings in cooling energy use per 0.01 change in the albedo of the surroundings (in this example, it is equal to $3 \%$ ), $Q$ is the annual cooling energy use for the house, $a$ is area, $\alpha$ is albedo, and the subscripts $r$, $c$ and a stand for roof, concrete, and asphalt pavements. As indicated in equation (7), the number of surfaces can be expanded to include $n$ surfaces of various albedos, depending on the surface makeup at the location of interest.

The total savings can be found by adding up the $S_{d}$ and $S_{i}$ terms. When the costs of implementing the direct and indirect albedo modifications are known, the CCE can be computed. 


\begin{tabular}{|c|c|c|c|c|c|}
\hline \multicolumn{6}{|c|}{ Table $16+$. Cost estimates for paved surfaces ${ }^{a}$} \\
\hline Paving Material & Average $\operatorname{cost}^{b}\left(\$ / \mathrm{m}^{2}\right)$ & $\begin{array}{l}\text { Estimated new } \\
\text { albedoc }^{c}\end{array}$ & $\begin{array}{l}\text { Estimated weathered } \\
\text { albedod }^{d}\end{array}$ & Expected life $\left(\gamma_{r}\right)$ & $\begin{array}{l}\text { Annualized cost } t^{f} \\
\left(\$ / \mathrm{m}^{2}\right)\end{array}$ \\
\hline & \multicolumn{5}{|c|}{ RESURFACINC PAVED SURFACES (uppermost layer only) } \\
\hline $\begin{array}{l}\text { Regular asphalt }(-2.5 \\
\mathrm{cm})\end{array}$ & $\$ 2.3$ & $0.05-0.10$ & $0.15-0.20$ & $3-5$ & $\$ 0.68$ \\
\hline $\begin{array}{l}\text { Asphalt with light } \\
\text { aggregates }(-2.5 \mathrm{~cm})\end{array}$ & $\$ 2.6$ & $0.05-0.10$ & $0.30-0.40$ & $3-5$ & $\$ 0.77$ \\
\hline $\begin{array}{l}\text { Regular chip seal } \\
(-1.3 \mathrm{~cm})\end{array}$ & $\$ 1.2$ & $0.15-0.20$ & $0.15-0.20$ & $3-5$ & $\$ 0.35$ \\
\hline $\begin{array}{l}\text { White chip seal }(-1.3 \\
\mathrm{cm})\end{array}$ & $\$ 1.5$ & $0.40-0.50$ & $0.30-0.40$ & 3-5 & $\$ 0.44$ \\
\hline \multirow[t]{2}{*}{$\begin{array}{l}\text { Regular slurry seal } \\
(-1.0 \mathrm{~cm})\end{array}$} & $\$ 1.2$ & $0.05-0.10$ & $0.15-0.20$ & $3-5$ & $\$ 0.35$ \\
\hline & \multicolumn{5}{|c|}{ REPAVING SURFACES (entire depth) } \\
\hline $\begin{array}{l}\text { Regular asphalt } \\
(-18.0 \mathrm{~cm})\end{array}$ & $\$ 16.4$ & $0.05-0.10$ & $0.15-0.20$ & $20-25$ & $\$ 1.47$ \\
\hline $\begin{array}{l}\text { Asphalt with light } \\
\text { aggregates }(-18.0 \mathrm{~cm})\end{array}$ & $\$ 16.7$ & $0.05-0.10$ & $0.30-0.40$ & $20-25$ & $\$ 1.50$ \\
\hline $\begin{array}{l}\text { Regular concrete } \\
\text { whitetopping }(\sim 13.0 \\
\mathrm{cm})\end{array}$ & $\$ 16.4$ & $0.35-0.40$ & $0.25-0.30$ & $20-25$ & $\$ 1.47$ \\
\hline $\begin{array}{l}\text { Whitetopping with } \\
\text { white concrete }(-13.0 \\
\mathrm{cm})\end{array}$ & $\$ 18.9$ & $0.70-0.80$ & $0.40-0.60$ & $20-25$ & $\$ 1.70$ \\
\hline
\end{tabular}

+ Based on data from Martien et al. [1989].

a). Assumptions: Estimates for resurfacing an existing asphalt urban street in good structural condition. The estimates inclide the costs of materials and labor only, and do not include the cost associated with road bed preparation.

b). Sources: Means [1989], Reese [1989], ISSA [1989], PCA [1989].

c). Sources: Threlkeld [1970], Oke [1987], Criggs et al. [1989], Reagan and Acklam [1979].

d). Sources: Estimates based on Threlkeld [1970] Oke [1987], Griggs et al. [1989], Reagan and Acklam [1979]. We emphasize that the weathering estimates are highly variable and uncertain.

e). Source: PCA [1989], American City and County [1986], Riverside Cement [1989].

f. The real interest rate is assumed to be $7 \%$. 


\begin{tabular}{|c|c|c|c|c|c|}
\hline \multicolumn{6}{|c|}{ Table 17t. Cost estimates for roofs $\mathrm{a}^{\mathrm{a}}$} \\
\hline $\begin{array}{l}\text { Roof Material } \\
\downarrow\end{array}$ & $\begin{array}{l}\text { Average installed } \\
\operatorname{cost} t^{b}\left(\$ / \mathrm{m}^{2}\right)\end{array}$ & $\begin{array}{l}\text { Estimated new } \\
\text { albedoc }^{c}\end{array}$ & $\begin{array}{l}\text { Estimated weathered } \\
\text { albedo }^{d}\end{array}$ & Expected life $(Y r)$ & $\begin{array}{l}\text { Annualized cost } \mathrm{f}^{\mathrm{s}} \\
\left(\$ / \mathrm{m}^{2}\right)\end{array}$ \\
\hline & \multicolumn{5}{|c|}{ STEEP ROOFS } \\
\hline $\begin{array}{l}\text { Regular, dark asphalt } \\
\text { shingles }\end{array}$ & $\$ 8.7$ & $0.05-0.10$ & $0.15-0.20$ & 20 & $\$ 0.82$ \\
\hline $\begin{array}{l}\text { Asphalt shingles with } \\
\text { light aggregates }\end{array}$ & $\$ 8.7$ & $0.35-0.40$ & $0.30-0.35$ & 20 & $\$ 0.82$ \\
\hline $\begin{array}{l}\text { Roll asphalt (smooth) } \\
\text { with reflective paint }\end{array}$ & $\$ 10.0$ & $0.80-0.90$ & $0.60-0.70$ & 20 & $\$ 0.94$ \\
\hline $\begin{array}{l}\text { Untreated cedar } \\
\text { shakes }\end{array}$ & $\$ 18.3$ & 0.30 & $0.20-0.25$ & $15-18$ & $\$ 1.90$ \\
\hline Concrete tile & $\$ 18.3$ & $0.35-0.40$ & $0.25-0.30$ & 50 & $\$ 1.34$ \\
\hline White concrete tile & $\$ 23.7$ & $0.70-0.80$ & $0.60-0.70$ & 50 & $\$ 1.72$ \\
\hline \multirow[t]{2}{*}{ Painting only } & $\$ 3.0$ & - & - & $3-5$ & $\$ 0.89$ \\
\hline & \multicolumn{5}{|c|}{ FLAT AND GENTLY SLOPED ROOFS } \\
\hline Dark built-up asphalt & $\$ 18.3$ & $0.05-0.10$ & $0.15-0.20$ & 20 & $\$ 1.47$ \\
\hline Light built-up asphalt & $\$ 18.3$ & $0.30-0.40$ & $0.25-0.30$ & 20 & $\$ 1.47$ \\
\hline $\begin{array}{l}\text { Built-up asphalt with } \\
\text { white-coated gravel }\end{array}$ & $\$ 18.3$ & $0.50-0.60$ & $0.40-0.50$ & 20 & $\$ 1.47$ \\
\hline $\begin{array}{l}\text { Built-up asphalt with } \\
\text { reflective paint }\end{array}$ & $\$ 18.3$ & $0.70-0.80$ & $0.60-0.70$ & 20 & $\$ 1.47$ \\
\hline $\begin{array}{l}\text { Single-ply white } \\
\text { polymer roofing }\end{array}$ & $\$ 18.3$ & $0.70-0.80$ & $0.60-0.70$ & 20 & $\$ 1.47$ \\
\hline Painting only & $\$ 2.5$ & - & - & $3-5$ & $\$ 0.74$ \\
\hline
\end{tabular}

+ Based on data from Martien et al. [1989].

a). Assumptions: Estimates include materials and labor costs only. They do not include the costs of removing an existing roof. We define steep roofs to be those with greater than a 4 inch rise per foot of run.

b). Sources: Concrete Construction [1983], Kiley and Mosell [1989], Means [1989]. For white concrete: Estimate based on increased materials costs as indicated by a manufacturer of white cement.

c). Sources: Threlkeld [1970], Oke [1987], Griggs et al. [1989], Reagan and Acklam [1979].

d). Sources: Estimates based on Threlkeld [1970] Oke [1987], Griggs et al. [1989], Reagan and Acklam [1979]. We emphasize that the weathering estimates are highly variable and uncertain.

e). Source: Concrete Construrtion [1983] and discussions with roofing contractors and manufacturers.

f). The real interest rate is assumed to be $7 \%$. 


\begin{tabular}{|c|c|c|c|c|c|}
\hline \multicolumn{6}{|c|}{ Table 18t. Cost of conserved energy (CCE) for direct and indirect measures } \\
\hline Measure & $\Delta \alpha_{i}(\%)$ & $\Delta \alpha_{b}(\%)$ & $\Delta \alpha_{\mathrm{s}}(\%)$ & $\mathrm{CCE}(\boldsymbol{c} / \mathrm{kWh})$ & \\
\hline Repaint walls white & 0.30 & 0.15 & - & -0 & direct \\
\hline $\begin{array}{l}\text { Replace dark asphalt shingles } \\
\text { with light on steep roof }\end{array}$ & 0.15 & 0.075 & 0.017 & -0 & dir.+indir. \\
\hline $\begin{array}{l}\text { Replace dark asphalt shingles } \\
\text { with roll roof and reflective } \\
\text { coating on steep roof }\end{array}$ & 0.50 & 0.25 & 0.055 & 2.3 & dir.+indir. \\
\hline Paint steep roof & 0.50 & 0.25 & 0.055 & 17 & dir.tindir. \\
\hline $\begin{array}{l}\text { Replace dark built-up flat } \\
\text { roof with light gravel }\end{array}$ & 0.30 & 0.15 & 0.033 & $\overline{-0}$ & dir.+indir. \\
\hline $\begin{array}{l}\text { Replace dark built-up flat } \\
\text { roof with reflective coating }\end{array}$ & 0.50 & 0.25 & 0.055 & -0 & dir.tindir. \\
\hline $\begin{array}{l}\text { Replace dark built-up flat } \\
\text { roof with single ply with } \\
\text { white polymer }\end{array}$ & 0.50 & 0.25 & 0.055 & -0 & dir.+indir. \\
\hline Paint flat roof & 0.50 & 0.25 & 0.055 & 14 & dir.+indir. \\
\hline $\begin{array}{l}\text { Resurfacing dark asphalt } \\
\text { pavement with light aggregates }\end{array}$ & 0.20 & - & $\overline{0.028}$ & $\overline{3.4}$ & indirect \\
\hline Resurfacing with whitetopping & 0.10 & - & 0.014 & -0 & indirect \\
\hline $\begin{array}{l}\text { Repaving dark asphalt with } \\
\text { light aggregates }\end{array}$ & 0.20 & - & 0.028 & 1.1 & indirect \\
\hline $\begin{array}{l}\text { Repaving with white cement } \\
\text { whitetopping }\end{array}$ & 0.40 & - & 0.056 & 4.4 & indirect \\
\hline Repaving concrete with white cement & 0.30 & - & 0.017 & 6.0 & indirect \\
\hline
\end{tabular}

+ Based on data from Martien et al. [1989]. $\Delta \alpha_{i}$ is the percent change in the albedo of a surface component (i), $\Delta \alpha_{b}$ is the percent change in the albedo of a building, where we assume equal roof and wall areas, $\Delta \alpha_{s}$ is the percent change in the albedo of the surroundings, and CCE = (annualized cost per building) / (Annual savings per building)

\section{E. URBAN-SCALE IMPLEMENTATION (Scoping)}

Having established an estimate of the potential changes in surface temperatures from high-albedo materials and the relative costs of implementing the use of such materials, the next questions to answer are (a) how much surface area is actually available for the implementation of this strategy and (b) in the case of this project, what roofing types are commonly used in today's roofing market. In a sense, we can discuss this issue under climate scoping and energy scoping.

Climate scoping involves identification of surfaces that most affect the climate variables in the area of interest. Although this scoping should vary from one location to another, we can make some general statements with respect to urban areas. For example, roads, building tops, parking lots/side-walks, and school yards are all important surfaces from the climate and energy perspectives. 
We would like to know the percentage of total urban surfaces represented by roofs in California's urban areas. We discuss the city of Sacramento as an example.

We can see in Table 19 that about $23 \%$ of the residential areas is occupied by roof surfaces and in commercial zones, about $43 \%$ is covered with roofs. These numbers indicate that roofs represent a minimum ${ }^{26}$ of about $22 \%$ of the total surface area in urban Sacramento, whose albedo can be modified. Based on these numbers, Martien et al. [1989] estimated the potential for modifying albedo (Table 20). They show that it is possible to modify the urban albedo of Sacramento by an effective amount equivalent to $0.15 .{ }^{27}$ Of that, the contribution from roof surfaces is equivalent to changing the city's albedo by 0.06 . However, this number can become larger if less than $50 \%$ of the surfaces are actually light-colored (which is probably the case).

\begin{tabular}{|l|l|c|c|}
\hline \multicolumn{4}{|c|}{ Table 19. Estimates of the urban fabric. } \\
\hline AREA & $\begin{array}{l}\text { RESIDENTIAL (46\% of } \\
\text { TOTAL) }\end{array}$ & $\begin{array}{l}\text { COMMERCIAL/ IN- } \\
\text { DUSTRIAL (25\% of } \\
\text { TOTAL) }\end{array}$ & TOTAL* \\
$\%$ & $\%$ & $\%$ \\
\hline \hline Rooftop & 23 & 43 & 22 \\
\hline Impervious Street & 22 & 15 & 17 \\
\hline Impervious Othert & 22 & 42 & 22 \\
\hline Green & 33 & -0 & 39 \\
\hline Total & 100 & 100 & 100 \\
\hline
\end{tabular}

* Includes schools, parks, open space, and freeways as well as residential and commercial/industrial areas.

† Includes parking lots, driveways, sidewalks, etc.

Source: Myrup and Morgan (1974).

Now we answer the second question. In order to identify the types of roofs that an energy conservation policy should target, it is important to bear in mind the market's breakdown by roof types and determine what type of roof is commonly used and/or is easier to modify. In the Western States ${ }^{28}$, a total of about $\$ 3$ billion is generated in the roofing market (compare to $\$ 16.7$ billion nation-wide) [Dodsen 1991]. Of that, $\$ 1.81$ billion is in the commercial sector and $\$ 1.12$ in the residential sector. Of the Western States roofing constructions (worth $\$ 3$ billion), $51 \%$ is in the state of California. Of that, about $\$ 0.92$ billion (60\%) and $\$ 0.6$ billion ( $40 \%$ ) is in commercial and residential roofing products, respectively. Table 21 gives further breakdown for the state of

\footnotetext{
26 Keep in mind that other surfaces may be more difficult to modify in terms of albedo, e.g., streets, parking lots, etc. that represent about $39 \%$ of the total horizontal urban surface area.

$D$ They conservatively assumed that about $50 \%$ of the roofs and other impervious materials are already light-colored.

28 Western States include: Alaska, Arizona, California, Colorado, Hawaii, Idaho, Montana, Nevada, New Mexico, Oregon, Utah, Washington, and Wyoming.
} 


\begin{tabular}{|ll|ccc|}
\hline \multicolumn{5}{|c|}{ Table 20. Potential for modifying urban albedot } \\
\hline SURFACE & & AREA (\% of total) & $\Delta$ ALBEDO & TOTAL $\triangle$ ALBEDO \\
\hline Streets & & 17 & 0.30 & 0.051 \\
\hline Roof & (dark) & 12 & 0.50 & 0.06 \\
& (light) & 10 & 0 & 0 \\
\hline Impervious Other & (dark) & 12 & 0.30 & 0.036 \\
& (light) & 10 & 0 & 0 \\
\hline TOTAL & & $*$ & $*$ & $\sim 0.15$ \\
\hline
\end{tabular}

tSource: Martien et al. [1989].

California, by roofing types. It can be seen in this table that any albedo modification strategy for roofs should be aimed at the built-up and modified bitumen types of commercial roofs and the asphalt shingle and built-up types of residential roofs, as these actually represent about $55 \%$ of the roofing types in both commercial and residential buildings. Built-up gravel roofs can be easily raked and coated with an elastomeric coating or covered with an EPDM. Shingle roofs can be made whiter by painting the shingles or replacing them with whiter ones. Finally, the modified bitumen is easy to lighten: just choose the one with high-albedo topping.

\begin{tabular}{|c|c|c|c|c|c|}
\hline \multicolumn{3}{|c|}{ Commercial } & \multicolumn{3}{|c|}{ Residential } \\
\hline Type & $\$$ billion & $\%$ & Type & \$ billion & $\%$ \\
\hline Built-up roofing & 0.44 & 47.5 & Fiberglass asph. shingle & 0.2 & 36.6 \\
\hline EPDM & 0.07 & 7.2 & Organic asph. shingle & 0.025 & 4.5 \\
\hline Hypalon & 0.02 & 2.2 & Wood shingles/shakes & 0.045 & 8.0 \\
\hline PVC & 0.03 & 3.3 & Clay tiles & 0.015 & 2.7 \\
\hline Other single-plies & 0.01 & 1.1 & Cement tiles & 0.035 & 6.3 \\
\hline Polyurethane foam & 0.02 & 2.2 & Slate & 0.01 & 1.8 \\
\hline Liquid-applied & 0.01 & 1.1 & Metal & 0.08 & 7.1 \\
\hline Metal & 0.055 & 6.1 & Built-up roofing & 0.11 & 18.8 \\
\hline Modified bitumen & 0.13 & 14.9 & Modified bitumen & 0.04 & 7.1 \\
\hline Tile & 0.035 & 3.9 & Single ply & 0.015 & 2.7 \\
\hline Asphalt shingles & 0.07 & 7.7 & Other & 0.025 & 4.4 \\
\hline Other & 0.025 & 2.8 & . & - & - \\
\hline Total $=$ & 0.915 & 100.0 & Total $=$ & 0.6 & 100.0 \\
\hline
\end{tabular}

tSource: Modified, based on data from NRCA.

Note: The 1990 roofing market makeup by types was very much similar to the 1991 market depicted in this table. The nationwide commercial 1990 market total was $\$ 11.58$ billion, $28.7 \%$ of that was in new construction and $71.3 \%$ in re-roofing. Of re-roofing, $59.5 \%$ was tear-off replacement and $40.5 \%$ was recovering. In California, the commercial roofing market reached $\$ 0.36$ billion (37.5\%) in new construction and $\$ 0.6$ billion (62.5\%) in re-roofing. The nationwide 1990 residential market, on the other hand, had a total of $\$ 5.09$ billion, of which $17.4 \%$ was new construction and $82.6 \%$ was re-roofing. Of re-roofing, 68.1 was tear-off replacement and $31.9 \%$ was recovering. In California, the 1990 residential market consisted of $\$ 0.15$ billion (26.6\%) in new construction and $\$ 0.40$ billion (73.4\%) in re-roofing.

In Table 22, the nationwide elastomeric/plastomeric roof membrane market is given in terms of 
total roof area, as of 1985 . We can see that there is a large potential for replacing the dark EPDMs with white ones. The potential available surface area is $-83 \%$ of the elastomeric/plastomeric market.

\begin{tabular}{|ll|}
\hline \multicolumn{2}{|l|}{ Table 22t. National elastomeric/plastomeric roofing sales (1985) } \\
\hline Membrane & Total area (millions of $\mathrm{m}^{2}$ ) \\
\hline Grey-black EPDM, non-ballasted & 14.9 \\
Black EPDM, non-ballasted & 0.93 \\
Grey-black EPDM, ballasted & 43.3 \\
White EPDM & 0.93 \\
White CSPE & 7.0 \\
White CPE & 4.2 \\
\hline Total & 71.26 (million $\mathrm{m}^{2}$ ) \\
\hline
\end{tabular}

tSource: Backenstow [1987]. No estimations available for the Western States or the state of California.

In this project, we concentrated on elastomeric and plastomeric coatings as one effective way to increase the albedo of a variety of roof structures and substrates. These coatings can be applied to almost any kind of roof/finish and National Coatings Corporation provides guidelines for the application of elastomeric roof coatings over several types of roofing materials and toppings. Table 23 gives an estimate of the areal composition of various functions in California.

\begin{tabular}{|lrrrr|}
\hline \multicolumn{5}{c}{ Table 23. Square footage of major functions in California (1985) } \\
\hline & Square footaget & \% of California Totalt & No. of stories $\neq$ & Estimated \% roof area \\
\hline Stores & 842208 & 4.9 & 3 & 3.4 \\
Warehouse & 597817 & 3.5 & 1 & 7.1 \\
Offices & 945986 & 5.5 & 10 & 1.1 \\
Auto & 291086 & 1.7 & 1 & 3.5 \\
Manufacturing & 933232 & 5.4 & 1 & 11.2 \\
Educational & 498902 & 2.9 & 2 & 3.0 \\
Health & 181134 & 1.1 & 2 & 1.1 \\
Public & 66432 & 0.4 & 3 & 0.3 \\
Religious & 190842 & 1.1 & 1 & 2.3 \\
Amusement & 205474 & 1.2 & 1 & 2.5 \\
Miscellaneous & 78669 & 0.5 & 1 & 0.9 \\
Single family & 9028570 & 52.6 & 2 & 54.0 \\
Multi family & 3072950 & 17.9 & 4 & 9.2 \\
Hotel & 122429 & 0.7 & 5 & 0.3 \\
Dormitories & 92660 & 0.5 & 4 & 0.3 \\
\hline
\end{tabular}

tSource: F.W.Dodge, Building Stock Data, Proprietary Information.

$\ddagger$ These are the authors' estimates and assumptions.

It is obvious that the largest surface areas are residential types of buildings. These are therefore the best candidates for albedo applications for urban climate modifications (both direct and indirect effects). Also, these buildings are appropriate for albedo modifications since they are one- or two-storied buildings, where the heat flux through the roof makes up a large proportion 
of the total heat gain into the building. In other kinds of buildings, such as 5-storied or taller, roof albedo effects on energy use (and savings) may be minimal and may not justify these modifications.

\section{F. IMPLEMENTATION ISSUES and SELECTION OF MATERIALS}

This section briefly introduces the issues to consider when selecting and implementing high albedo materials or coatings for the purpose of conserving cooling energy. In general, the selection criteria involve considering the following aspects:

- The albedo and emissivity of the material in question. For the purposes outlined in this paper, one would select a material with a high albedo and a high emissivity.

- Wear resistance and suitability to the underlying surface (gently sloped roofs, steep sloped, walls, etc).

- Dirt-pickup qualities and change of albedo over time. Generally speaking, dark surfaces tend to become lighter, whereas light-colored surfaces tend to become darker, as the material ages, weathers, or picks up dirt.

- Cost and setting time (if important in a particular situation).

- Expected life and maintenance issues/costs.

- Ease of application.

There are also environmental factors to consider regarding albedo's impact on surface temperature and building energy use.

- The intensity and availability of solar radiation. The first is a function of season (solar constant fluctuations, solar angle) and time of day whereas the second is a function of the atmosphere's effects (cloud cover, turbidity, water vapor, airborne particulates) on solar radiation at the surface. The larger the insolation the greater the contrast between the temperatures of materials with different albedos. Thus, potential savings in energy use depend on climate and solar availability.

- Insulation of roofs and walls. Because higher insulation leads to reduced heat flow through the surface, insulation may result in higher surface temperatures. Therefore, higher measured surface temperatures do not necessarily mean larger heat fluxes through the envelope or greater cooling loads, because higher surface temperatures may be due to a roof or wall being wellinsulated. However, simulations by Griggs et al. [1989] showed that after an initial amount of insulation has been added to the roof (from no insulation to R-7), any additional insulation will produce little changes in surface temperature. The initial change being about $5^{\circ} \mathrm{C}\left(9^{\circ} \mathrm{F}\right)$ for a roof 
with a reflectivity of 0.1 , and about $2^{\circ} \mathrm{C}\left(4^{\circ} \mathrm{F}\right)$ for a roof with 0.7 reflectivity. When a roof or wall is well-insulated, the effects of albedo may be larger on surface temperature, but smaller on energy use.

- Surface texture. For the same material/color, a rough texture decreases the albedo compared to that of a smooth texture, because a rough texture increases the possibility that a reflected beam strikes the same surface again and is absorbed. Generally speaking, a rough surface will have a higher temperature than a smooth one.

- Glare. Generally speaking, the issue of visual environmental quality associated with colors and albedo can be discussed within the contexts of daytime and nighttime visions. During daytime, the major concern is of glare resulting from high-albedo materials on building surfaces, streets, lots, and sidewalks. At night, on the other hand, the main concern is that of visibility of surface markings and traffic signs. In either case, there is common concern during wet conditions when surface markings become difficult to notice.

Studies have shown that daytime glare can produce visual discomfort. The problem has been documented, but the fact that visual glare is not covered by nuisance laws makes remedy very difficult. However, using high-albedo materials on roofs only and moderately-high albedo on vertical surfaces should minimize this problem. Also, an advantage of high-albedo street, parking, and sidewalk surfacing is the reduced need for lighting at night, thus saving energy. However, one should be careful about the contrast between the surface color and the marking color, a contrast that decreases as the surfacing is lightened further.

Correlating light-reflecting properties of road surfaces to geometry and viewing position/angle has been carried out by several researchers, such as Jackett and Fisher [1974]. In their study of 6 samples of asphaltic concrete road surfaces in the Sydney, Australia region, they indicated that the nighttime reflectivity of road surfaces depends more on texture than on color. The samples had about 2 years of traffic wear. Despite the general indication that nighttime street lighting can be minimized with higher-albedo pavement surfacing, Jackett and Fisher [1974] indicated that geometry ${ }^{29}$ and texture were more important than color in determining nighttime reflection properties. This is a subject for further study.

- Aesthetics. Since people have various preferences, difficulty might arise when trying to convince homeowners and businesses to use one color or another (i.e.,visible albedo) on their homes and buildings. If a situation such as this arises, one solution would be to allow people to choose the colors/hues they prefer (that is what they see in the visible spectrum) which will affect only the visible albedo. The UV and near-infrared albedos (invisible to the human eye), on the other hand, can be selected by the building scientist so that the final desirable effect is

29 Viewer's position relative to the light source and a point on the surface. 
reached. A solution like this will also prevent "blandness" resulting in a neighborhood having houses of similar (light) colors, which may be quite a boring repetition. It is possible to use different colors while keeping the overall effective albedo under control within a specified range. The final product is one that satisfies both people's preferences and the scientist's need to reduce cooling energy use in buildings. More research is needed on this issue.

\section{G . CONCLUSIONS and POSSIBLE FUTURE WORK}

In this project, we acquired the necessary instrumentation and developed our own method for measuring albedo in the field. We presently have the capability of measuring the albedo of actual or controlled surfaces under natural sunlight. With this setup, we performed extensive measurements of urban surfaces' albedos, such as those of streets, sidewalks, parking lots, and green areas. We plan to build on this preliminary albedo library and develop a comprehensive data base. We documented the exact location of our measurement points so we can revisit them in the future (2-3 years later) to measure albedo again and quantify the impacts of soiling, weathering, and wear on the albedo of surfaces. Finally, we measured the albedo of several "conventional" and "high-albedo" roofing materials, as well as their half-hourly surface temperatures for several days in July 1991. This exploratory project thus provided us with the opportunity to develop the tools and methods needed in future studies related to building and urban albedos.

In this paper, we presented results of our measurement methodology: the instrumentation setup, a preliminary albedo library for urban surfaces, albedo documentation for high-albedo materials, surface temperature, air temperature, and solar radiation measurements on a halfhourly basis for 8 test areas on a flat roof at the LBL site. In addition, we documented the material and application costs associated with high-albedo paints and membranes. More work needs to be done to develop a more complete econometric analysis.

We have begun to quantify the potential of high-albedo materials for reducing the surface temperature heat island. We will extrapolate from these surface temperature reductions to air temperature heat island reductions as our methodology for developing a correlation (between surface and air temperatures) is improved and validated with further field data, particularly from airborne sensing equipment.

As for high-albedo materials, this study is by no means complete. We would like to hear from manufacturers of such materials and compile more information on costs, maintenance, durability, and energy savings issues and potentials. The response from private and public institutions and individuals has been quite positive. We have received many calls from homeowners and other interested parties asking for guidelines and technical assistance to help them use or monitor the implications of high-albedo coatings on indoor microclimate and cooling energy use. 
In future projects, or a possible full-scale CIEE research program on high-albedo materials, we recommend the following tasks:

1) Analyze the effects of wind speed as an additional variable in the correlation between temperature, solar radiation, and albedo. Incorporating wind speed and other micrometeorological variables into the equation will allow us to infer air temperature heat islands from surface temperature fields.

2) Measure the effects of soiling on surface albedo in the laboratory and in the actual outdoor environment over time.

3) Measure the albedo in urban settings and the corresponding urban boundary layer temperatures, wind velocities, and solar radiation.

4) Repeat the same type of measurements in a warm climate zone. The measurements in this project were taken in the San Francisco Bay Area. Our main purpose was to identify future directions and develop a better understanding of the potential and possible difficulties associated with our methodology. Other candidate cities for future measurements include Los Angeles, Fresno, and Sacramento.

5) Monitor an air-conditioned building, and record utility billing data before and after applying light colors on roofs and walls.

6) Study the indirect effects of albedo on urban-scale temperatures and energy use patterns.

7) Investigate the potential for creating a new building albedo code. If proved effective, such a code could be incorporated in California's Title-24 building standards. We would measure the albedo of building materials, label them, and advise the public about using them. Accordingly, albedo could serve as an index for specifying the use of materials/colors on building and urban surfaces. This will require more extensive field measurements, improved climate simulation models, zoning, and extensive simulation of energy implications of albedo modifications. The proposed code will include recommendations on materials and albedo, climate zoning and mapping showing the range of albedo values that could be used in each climate zone, and an albedo threshold value for each climate zone and building type to be used by builders as well as in incentive programs and rebates. We envisage creating a materials and paint labeling laboratory whose function is to assign albedo values to urban and building materials.

\section{H. ACKNOWLEDGEMENTS}

This work was jointly supported by the California Institute for Energy Efficiency (CIEE) and the Sacramento Municipal Utility District through the U.S. Department of Energy, under contract DE-AC0376SF00098. 


\section{REFERENCES}

Aida, M. 1982. "Urban Albedo as a Function of the Urban Structure - A Model Experiment". Boundary Layer Meteorology, 23 (1982), pp. 405-413.

Aida, M. and Gotoh, K. 1982. "Urban Albedo as a Function of the Urban Structure - A TwoDimensional Numerical Simulation". Boundary Layer Meteorology, 23 (1982), pp. 415-424.

Akbari, H., Rosenfeld, A., Taha, H. 1989. "Recent Development in Heat Island Research: Technical and Policy". Proceedings of the Workshop on Heat Islands, February 23-24, 1989, Berkeley, California. pp. 14-30.

Akbari, H., Huang, J., Martien, P., Rainer, L., Rosenfeld, A., and Taha, H. 1988. "The Impact of Summer Heat Islands on Cooling Energy Consumption and Global $\mathrm{CO}_{2}$ Concentration", Proceedings of the ACEEE 1988 Summer Study on Energy Efficiency in Buildings, Vol. 5, 11-23, Asilomar CA, August 1988.

American City and County, July 1986. "Asphalt vs. Concrete", pp. 31-38.

Architect's Journal [AJ 1984]. "Glass Building Dazzles Neighbors", May-June 1984, Vol. 179, No. 26, p. 36.

Asphalt Institute 1978. "Slurry Sealing", Report CL-22, Construction Leaflet No. 22 (January 1978), The Asphalt Institute, College Park, Maryland.

Backenstow, D.E. 1987. "Comparison of White Versus Black Surfaces for Energy Conservation", Proceedings of the 8th Conference on Roofing Technology; "Applied Technology for Improving Roof Performance", April 16-17, 1987, Gaithersburg, Maryland, pp. 27-31. National Bureau of Standards and the National Roofing Contractors Association.

Berg, R. and Esch D. 1983. "Effect of Color and Texture on the Surface Temperature of Asphalt Concrete Pavements", Proceedings of the Permafrost Fourth International Conference, National Academy Press, Washington, D.C., pp. 57-61.

Berg, R. and Quinn, W. 1978. "Use of a Light-Colored Surface to Reduce Seasonal Thaw Penetration Beneath Embankments on Permafrost", Proceedings of the Second International Symposium on Cold Regions Engineering, University of Alaska, pp. 86-99.

Bornstein, R.D. 1975. "The Two-Dimensional URBMET Planetary Boundary Layer Model", Journal of Applied Meteorology, 14, pp. 1459-1477 (1975).

Boutell, C.J. and Salinas, Y. 1986. "Building for the Future-Phase I", Volumes I and II, the University of Southern Mississippi, Department of Construction and Architectural Engineering Technology. An energy saving materials project jointly sponsored by Mississippi Power Company, Rohm and Haas Company, and the University of Southern Mississippi.

Brest, C. 1989. "Seasonal Albedo of An Urban/Rural Landscape from Satellite Observations", in: Controlling Summer Heat Islands, Proceedings of the Workshop on Saving Energy and 
Reducing Atmospheric Pollution by Controlling Summer Heat Islands", Berkeley, California, February 23-24, 1989, pp. 238-255.

Cedar Shake and Shingle Bureau [CSSB] 1991. "A Solar Heat Shield with Red Cedar Shingle Roofing", Brochure by CSSB, $515116^{\text {th }}$ Avenue, N.E., suite 275, Bellevue, WA 98004-5294.

Chandra, S., Gumbs, J., Moalla, S., Roland, J., Melody, I., Tooley, J., and Maxwell, L. 1991. "Cooling Season Tests of Industrialized Housing Systems", Contract Report FSEC-CR-383-91, Florida Solar Energy Center, Cape Canaveral, Florida.

Concrete Construction, October 1983. "Concrete Tiles Put Color on Residential Roofs", pp. 750754.

Cordell, M. National Coatings Corporation, 912 Pancho Road, Camarillo, CA 93012. Personal Communication, March 1991.

Courville, G.E., Oak Ridge National Laboratory, Oak Ridge, Tennessee 37831. Personal communication by Phil Martien of LBL, November 1989.

Craig, C.D. and Lowry, W.P. 1972. "Reflections on the Urban Albedo", Reprints of the Conference on the Urban Environment and Second Conference on Biometeorology, Oct. 31-Nov. 2, 1972, Philadelphia, PA, American Meteorological Society, pp. 159-164.

Dodson, M. Personal communication, April 1991, and "The Growing Western Roofing Market", Dodson Publications, Inc., 27202 Via Burgos, Mission Viejo, CA 92691.

Duffie, J.A. and Beckman, W.A. [1974]. Solar Energy Thermal Processes, Wiley and Sons, New York.

Gillenwater, R. 1991. Director R\&D. Personal communication [May 1991]. Carlisle SynTec Systems, P.O.Box 7000, Carlisle, PA 17013.

Griggs, E.I., Sharp, T.R., and MacDonald, J.M. 1989. "Guide for Estimating Differences in Building Heating and Cooling Energy Due to Changes in Solar Reflectance of a Low-Sloped Roof', Oak Ridge National Laboratory Report ORNL-6527.

Habel, M. and Florence, R. 1985. "Design Methodology for the Analysis of a Solar Reflective Roof Coating and its Effect on the Cooling Load in Actual Environments", Department of Mechanical Engineering, San Diego State University, Draft Report, 1985.

International Slurry Seal Association (ISSA), 1101 Connecticut Avenue, N.W., Washington, D.C., 20036. Personal communication by P. Martien of LBL, November 1989.

Jackett, M.J. and Fisher, A.J. 1974. "The Light Reflecting Properties of Asphaltic Concrete Road Surfaces", Australian Road Research Board (ARRB) Proceedings, Volume 7, Part 5 (1974), pp. 287-306.

Kentucky Ready Mixed Concrete Association (KRMCA) 1988. "Whitetopping Demonstration Puts Asphalt Under Cover", Concrete Construction (August 1988), pp. 785. 
Kiley, M.D. and Mosell, W. (eds) 1989. National Construction Estimator, 37th Edition, Craftsman Book Company, Carlsbad, California.

Kritz, M.A. and Wechsler, A.E. 1967. "Surface Characteristics Effect on Thermal Regime: Phase II", Technical Report 189, U.S. Army Cold Regions Research and Engineering Laboratory, Hanover, New Hampshire.

Liou, K. 1980. An Introduction to Atmospheric Physics, Academic Press, New York, pp. 39.

Martien, P., Akbari, H., and Rosenfeld, A. 1989. "Light-Colored Surfaces to Reduce Summertime Urban Temperatures: Benefits, Costs, and Implementation Issues", Presented at the 9th Miami International Congress on Energy and Environment, 11-13 December 1989, Miami Beach, Florida.

Mazria, E. 1979. The Passive Solar Energy Book, Rodale Press, Emmaus, Pennsylvania.

R.S. Means Company Inc., 1989. Building Construction Cost Data, 2nd Western Annual Edition.

Metropolitan Indianapolis Ready Mixed Concrete Association (MIRMCA) 1985. "Whitetopping an Asphalt Parking Area", Concrete Construction (May 1985), pp. 425-428.

Oke, T.R. 1987. Boundary Layer Climates, Second Edition, Methuen, London.

Pierce, J.D. 1972, in the ASHRAE Handbook of Fundamentals , ASHRAE, New York, pp.375445.

Portland Cement Association (PCA) 1986. "Streets and Highways: Asphalt vs. Concrete", American City \& County (July 1986), pp. 31-38.

Portland Cement Association (PCA), 5420 Old Orchard Road, Skokie, Illinois, 60077. Personal communication by P. Martien of LBL.

Reagan, J.A. and Acklam, D.M. 1979. "Solar Reflectivity of Common Building Materials and its Influence on the Roof Heat Gain of Typical Southwestern U.S.A. Residences", Energy and Buildings, 2 (1979), pp. 237-248. R.S. Means Company Inc., 1989. Building Construction Cost Data, 2nd Annual Western Edition.

Reese, R. California Department of Transportation, Office of Transportation Laboratory, 5900 Folsom Blvd., Sacramento, CA 95819. Personal communication with P. Martien, October 1989.

Reifsnyder, W.E. 1967. "Radiation Geometry in the Measurement and Interpretation of Radiation Balance", Agricultural Meteorology, 4(1967), pp. 255-265.

Riverside Cement Company, Diamond Bar, California. Personal Communication by P. Martien, October 1989.

Sellers, W.D. 1965. Physical Climatology , University of Chicago Press, Chicago, 272 p.

Shuler, S. Director of Research, Asphalt Institute, Executive Offices and Research Center, Research Park Drive, Lexington, Kentucky 40512-4052. Personal communication, April 
1991.

Taha, H., Akbari, H., Sailor, D., and Ritschard R. 1990a. "Causes and Effects of Heat Islands: the Sensitivity of Urban Microclimates to Surface Parameters and Anthropogenic Heat". Submitted to Energy and Buildings, also Lawrence Berkeley Laboratory Report No. 29864, Berkeley, California.

Taha, H. 1990b. "An Urban Microclimate Model for Site-Specific Building Energy Simulation: Boundary Layers, Urban Canyon, and Building Conditions", Doctoral Dissertation, University of California, Berkeley, California.

Taha, H., Akbari, H., and Rosenfeld, A. 1988. "Residential Cooling Loads and the Urban Heat Island: the Effects of Albedo", Building and Environment, 23, No. 4, pp. 271-283.

Threlkeld, J.L. 1970. Thermal Environmental Engineering, Second Edition, Prentice-Hall, Englewood Hills, New Jersey.

Wechsler, A.E. and Glaser, P.E. 1966. "Surface Characteristics Effect on Thermal Regime: Phase I", Special Report (88), U.S. Army, Cold Regions Research and Engineering Laboratory, Hanover, New Hampshire.

\section{J. APPENDIX}

\section{J.1 DESCRIPTION OF ROOF TEST AREAS AND MATERIALS}

Solar Shield®. This is a thermolastic (acrylic elastomer) reflective coating manufactured by Thermo Materials, San Diego, California. It is a white liquid with a specific gravity of 1.03 and a boiling point of $100^{\circ} \mathrm{C}\left(212^{\circ} \mathrm{F}\right)$. It is dilutable in water (which can be used as a thinner) and is nonflammable. Designed for one- or two-coat applications, it is easy to apply with a brush or a roller, and can also be sprayed. It has good UV resistance and remains flexible to temperatures down to $-29^{\circ} \mathrm{C}\left(-20^{\circ} \mathrm{F}\right)$. Thermo Materials claims that Solar Shield's initial reflectivity is 0.90 and its weathered reflectivity is 0.78 and that it is resistant to stains and mildew. It is recommended, and guaranteed, if used at a rate of 2-4 gallons per square (one square $=100 \mathrm{ft}^{2}$ ). When applied at a rate of 1 gallon per square, the final dry thickness of the film would be about 250 microns. Solar Shield $\circledast$ cures in a matter of hours ( 2 hours if a coat of 560 microns is applied at a temperature of $24^{\circ} \mathrm{C}$ and $50 \%$ relative humidity).

EPDMs. Carlisle SynTec Systems provided us with two EPDMs fur testing. One was black, the other white each with dimensions of $3 \times 3 \mathrm{~m}(-10 \times 10 \mathrm{ft})$. EPDMs can be applied in two ways: a) by mechanically attaching the EPDMs to the roof deck and b) by adhesion (glue). EPDMs usually are about $1 \mathrm{~mm}$ thick but can resist tensile strengths up to $1300 \mathrm{MPa}$. They are watertight and $\mathrm{O}_{3}$-resistant. They are also heat-, weather-, and UV-resistant. No claimed reflectivities or albedo were assigned to the EPDMs we received. 
Enerchron@. This polymer coating liquid was supplied by Helios Energy Products, Inc. It is an acrylic based fluid that retains flexibility even at low temperatures. It has good resistance to ponded water, performs well in all climates, and has a good resistance to UV radiation. Additionally, it has low dirt pick up property and thus retains its reflectivity for a long time. The coating can be applied to a variety of roof structures and substrates. Its curing time is about 7 days (before exposure to ponding water conditions) and the dry time is about half an hour. The standard color for Enerchron $₫$ is white, but it also comes in tinted or pastel-colored versions. It has a specific gravity of 1.32 , and is made up of $63 \%$ solids by weight. It weighs $11 \mathrm{lbs}$ per gallon and incorporates DuPont's KEVLAR® fibers that are strong and fire resistant. The specified reflectivity (based on ASTM-D-1729) is $99.5 \%$ initial and $98 \%$ after 1000 hours of weathering. However, our field measurements indicate otherwise. 30

Basecase. The roof of the building at Site 77 of LBL was a built-up roof over a corrugated metal deck. The gravel (uppermost layer) was greyish black with an average size of $2 \mathrm{~cm}\left(3 / 4^{\prime \prime}\right)$ in length and $1.5 \mathrm{~cm}(0.6 ")$ in diameter.

Bitumen. There was a tar strip about $3 \times 1 \mathrm{~m}(-10 \times 3.5 \mathrm{ft})$ on the roof, that was uncoated with the gravel. The strip was about $1 \mathrm{~cm}\left(1 / 2^{\prime \prime}\right)$ thick and uniform.

Colored gravel. There was an extension of the main roof with a differently-colored gravel. The color (judged by eye) seemed lighter and more brownish. The average size of the stones was 2 $\mathrm{cm}\left(3 / 4^{\prime \prime}\right)$ in length and $1.2 \mathrm{~cm}\left(-1 / 2^{\prime \prime}\right)$ across. These stones were flat compared to the ones of the basecase roof.

Corrugated roof. This a different extension of the roof and the underside was also exposed to the ambient air (canopy). This point should be kept in mind when looking at the surface temperature plots of this roof. We cannot compare it directly to the other samples. To the eye, the roof seemed of greyish color.

\section{J.2 GLOSSARY OF TERMS}

Aggregate: a hard, inert mineral material such as gravel, sand, crushed rock, or slag used in the topping. Coarse Aggregate is usually defined as the aggregate retained in a No. 8 sieve, whereas Fine Aggregate is the aggregate passing through a No. 8 sieve (a No. 8 sieve has a mesh spacing of about 0.10 inch).

\footnotetext{
30 ASTM-D-1729 (89) is a qualitative procedure based on visual examination of color. It is not clear how Enerchron was assigned reflectivity values based on this procedure. The difference in methodologies may explain tilese different results. Helios' president, Rick Klimovich, prefers to adopt our numbers instead of those previously published.
} 
Asphalt: A dark brown to black cementitious material in which the predominating constituents are bitumens which occur in nature or are obtained from petroleum processing.

Asphalt Cement: Asphalt that requires heat to make it fluid.

Asphalt surface treatment: is the covering of the asphalt layer with a layer of aggregate or crushed stones to protect it from traffic wear. This layer is called in different ways, such as: chip seal, seal coat, armor coat, or by other names. After spraying the hot, liquid asphalt on top of the subbase pavement, the chip seal layer is applied and pressed into the asphalt by means of rollers. The aggregates can be sand, gravel, crushed stone, crushed slag, and others.

CPE: Chlorinated Polyethylene (single ply membrane). CSPE: Chrolosulfonated Polyethylene (single ply nembrane).

Emulsified Asphalt: An emulsion of asphalt cement and water which contains a small amount of an emulsifying agent. Depending on the emulsifying agent, emulsified asphalts can be either anionic (negative) or cationic (positive).

EPDM (or EPT): Ethylene-Propylene-Diene terpolymer (rubber sheet or membrane) which is an elastomer based on ethylene and propylene terpolymers with small amounts of a nonconjugated diene and which can be vulcanized. The membranes are about $1 \mathrm{~mm}$ thick but can resist large tensile strengths and are water resistant (ASTM D 471). They usually have a $2 \%$ linear dimensional change (ASTM D 1204) and are weather resistant according to ASTM G 26 or G 53.

Equivalent names: bituminous concrete, asphaltic concrete, blacktop, asphalt, and hot mix asphalt. They all indicate liquid asphalt cement plus aggregates.

Raked mortar joint: a mortar joint from which the mortar has been removed (scraped) by about $20 \mathrm{~mm}$. In comparison, the Tooled mortar joint is the one where the mortar is in about the same level as the masonry unit.

Shake: Usually a thick, hand-cut shingle.

Slurry seal: A mixture of fine aggregate, mineral filler (where necessary), emulsified asphalt, and water applied to a pavement as a surface treatment [Asphalt Institute 1978]. This is sometimes called "emulsified asphalt slurry seal".

Solid angle is defined as: 


$$
\omega=\frac{A}{r^{2}}
$$

where $\mathrm{A}$ is a partial spherical area of interest, and $\mathrm{r}$ is the sphere's radius. Solid angle is measured in steradians (sr).

Zenith angle is the angle between the normal to a surface and the incident beam. Altitude angle, on the other hand, is the angle between the incident beam and the tangent to a surface at the point of incidence. 
Figure 1.

Relative increase in absorptance due to effects of geometry

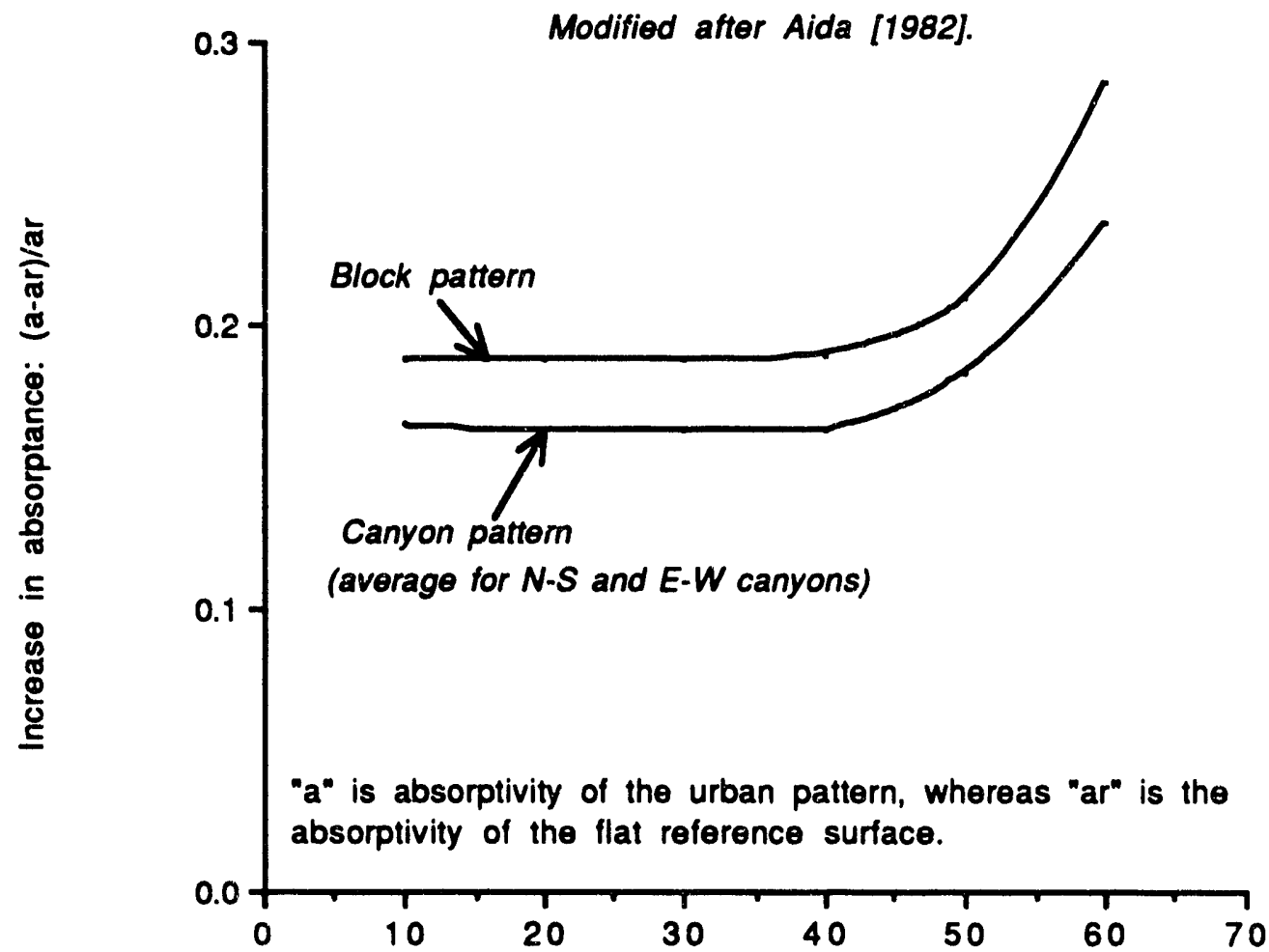

Zenith angle $\left({ }^{\circ}\right)$

Figure 2.

Effective albedo and urban geometry

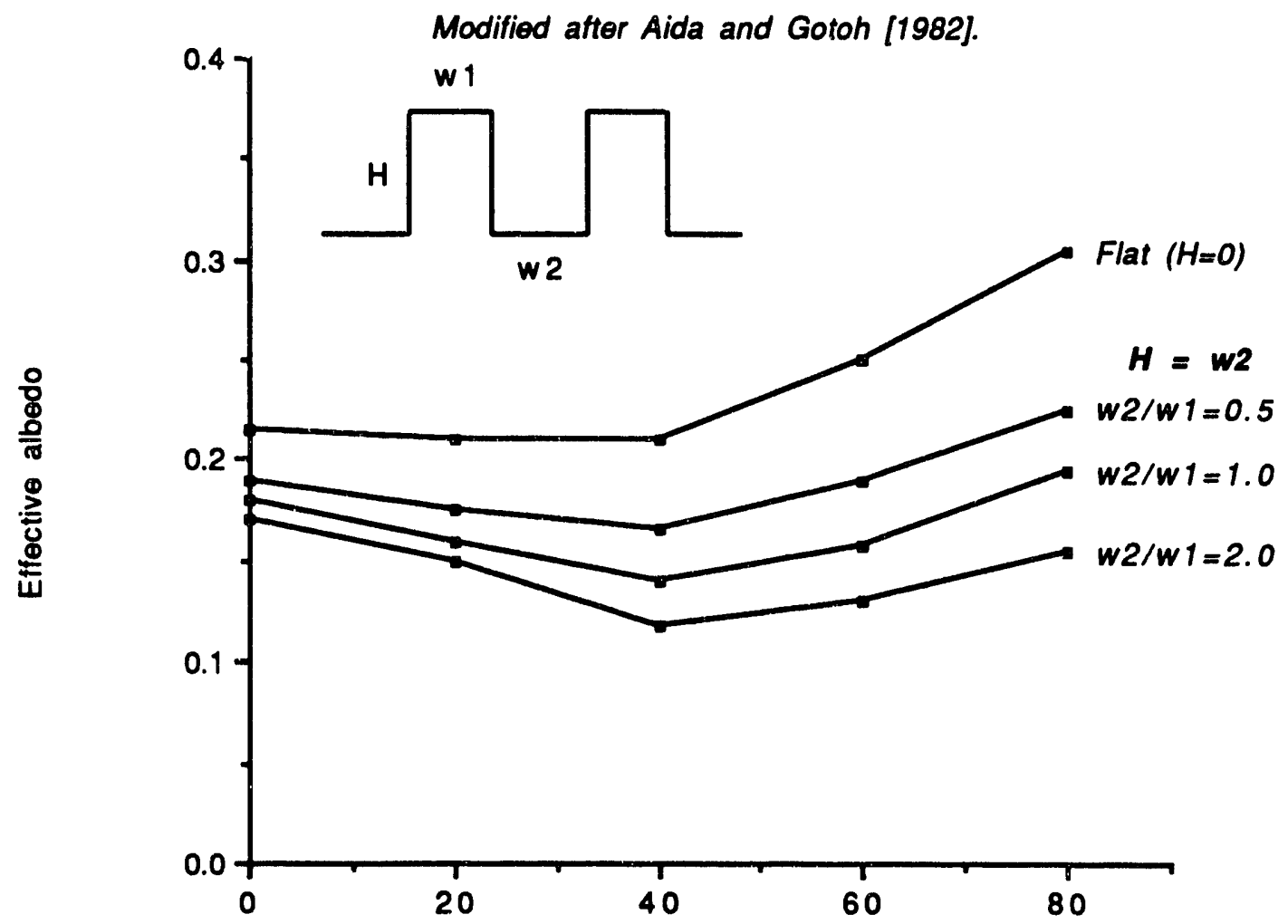

Zenith angle $\left({ }^{\circ}\right)$ 
Figure 3.

Albedo as a function of building width-to-street width ratio (w1/w2) and zenith angle

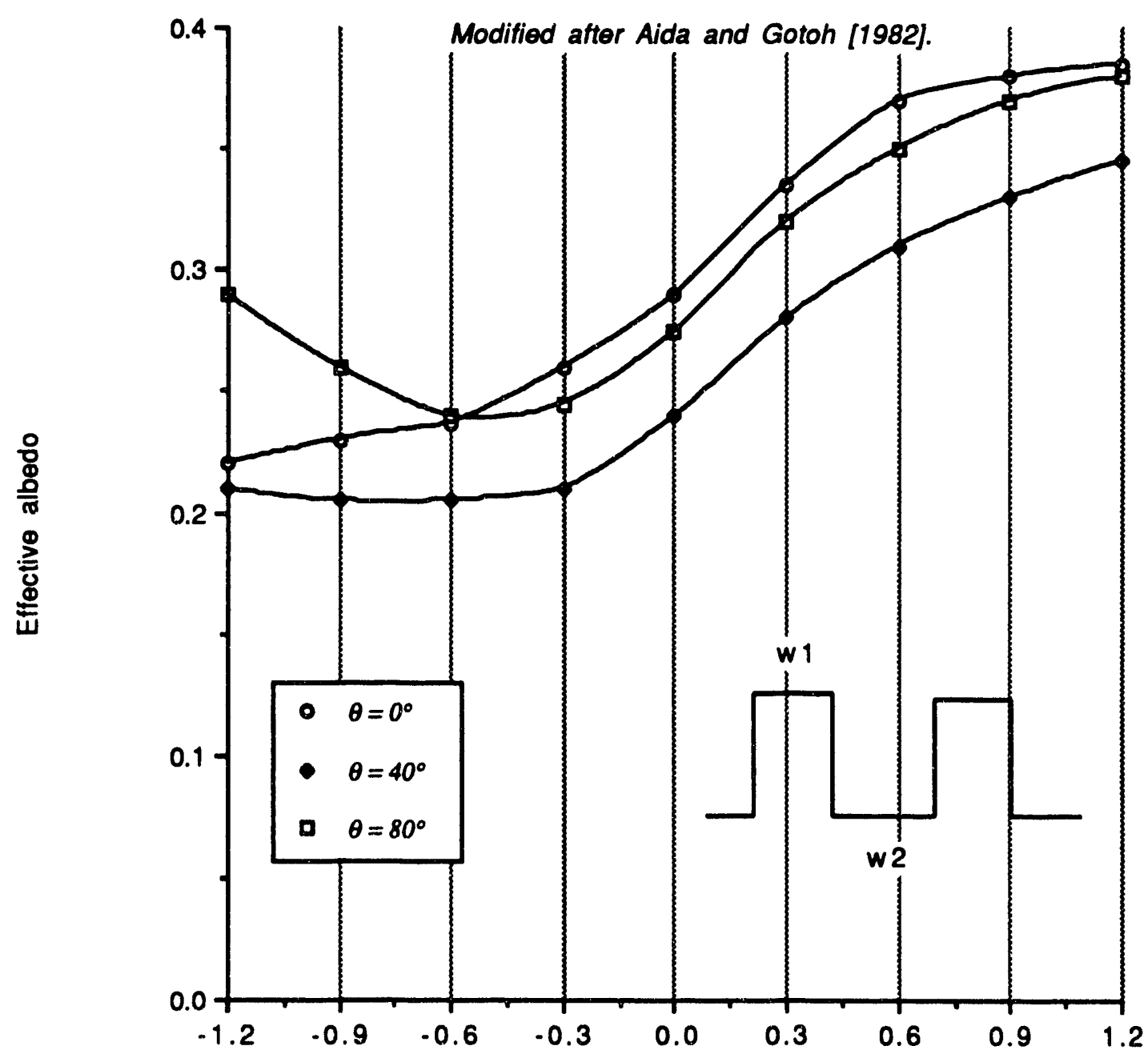

$\log (w 1 / w 2)$ 
Figure 4.
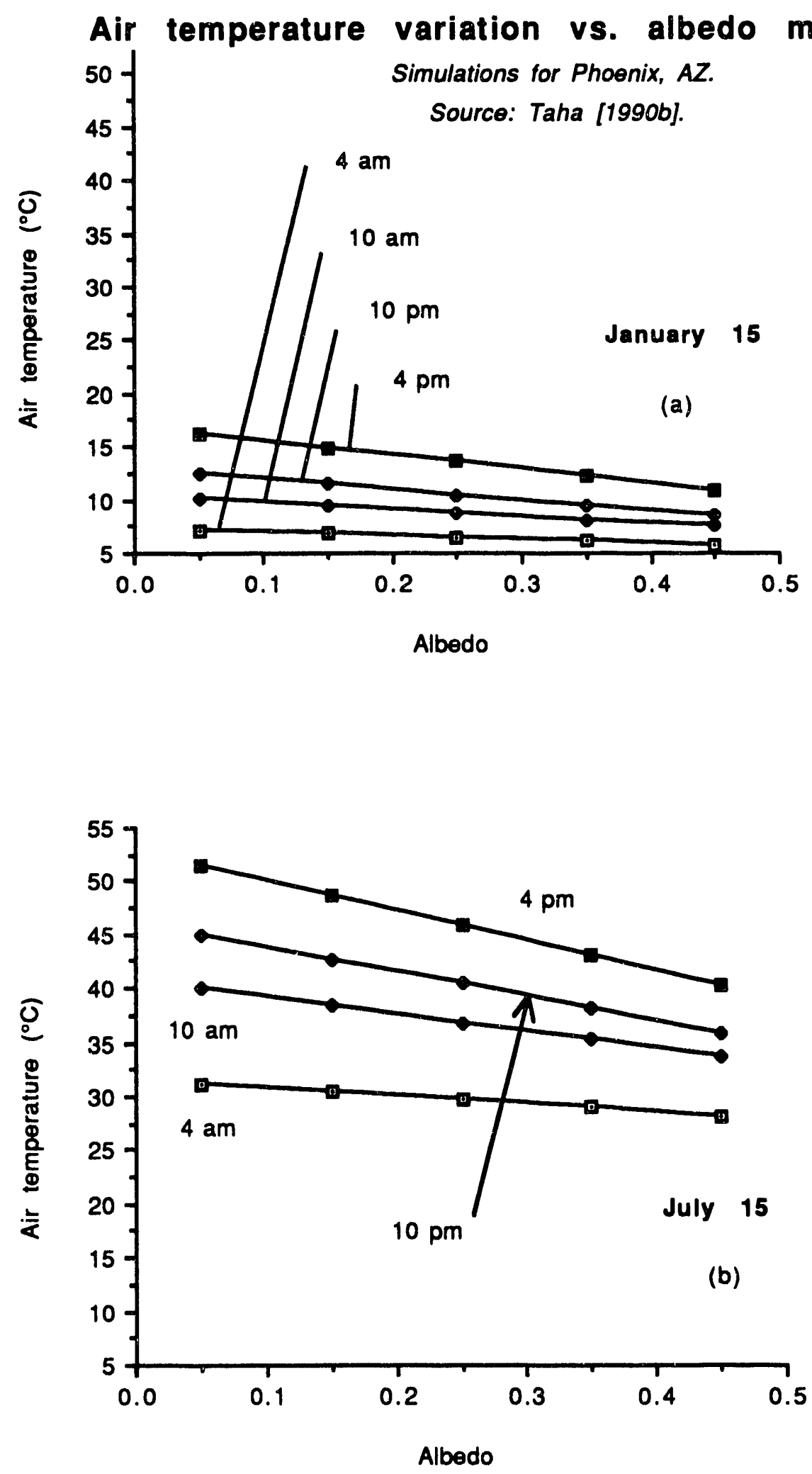
Figure 5.
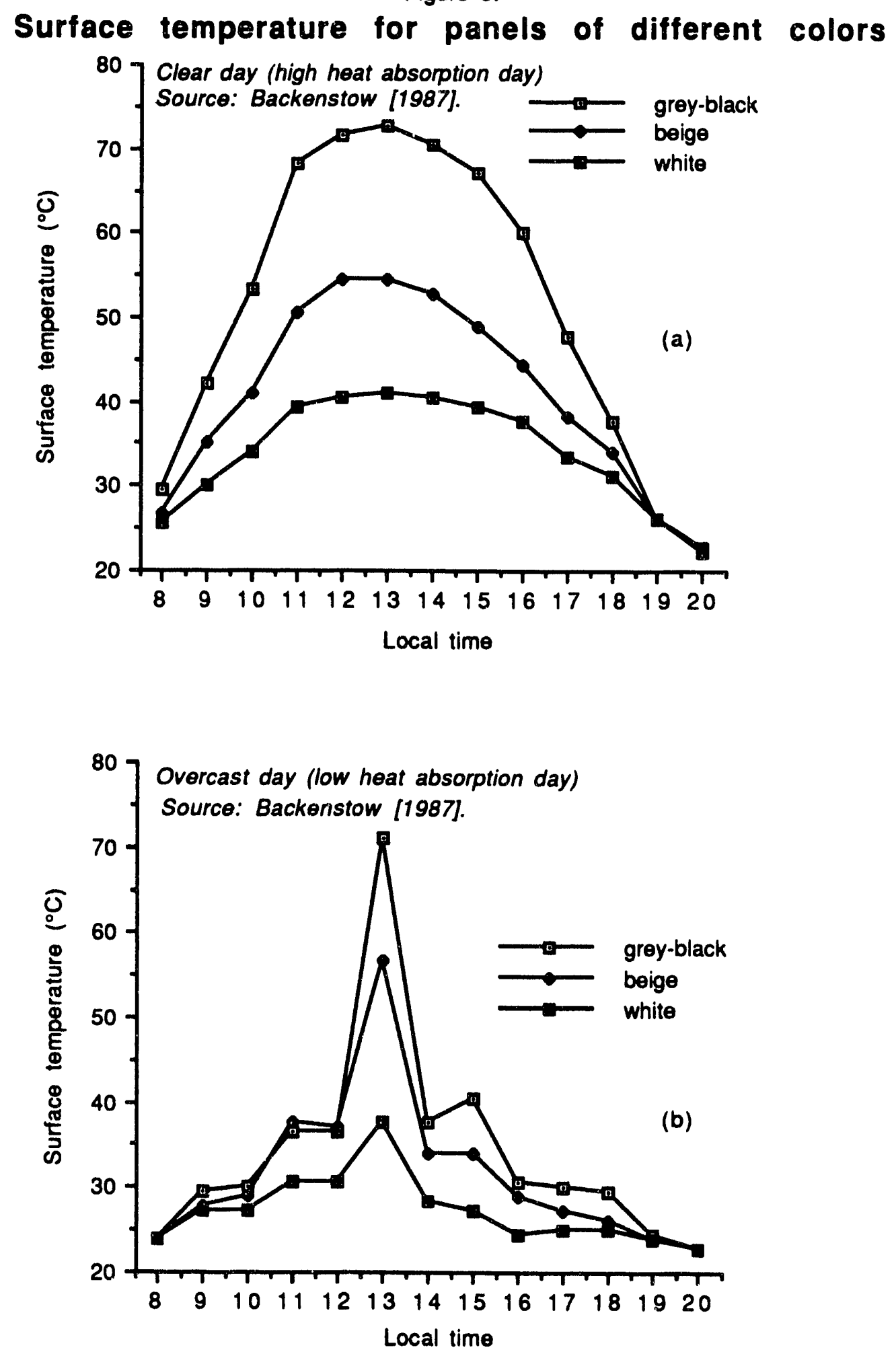
Figure 6.

Surface temperature for various coatings

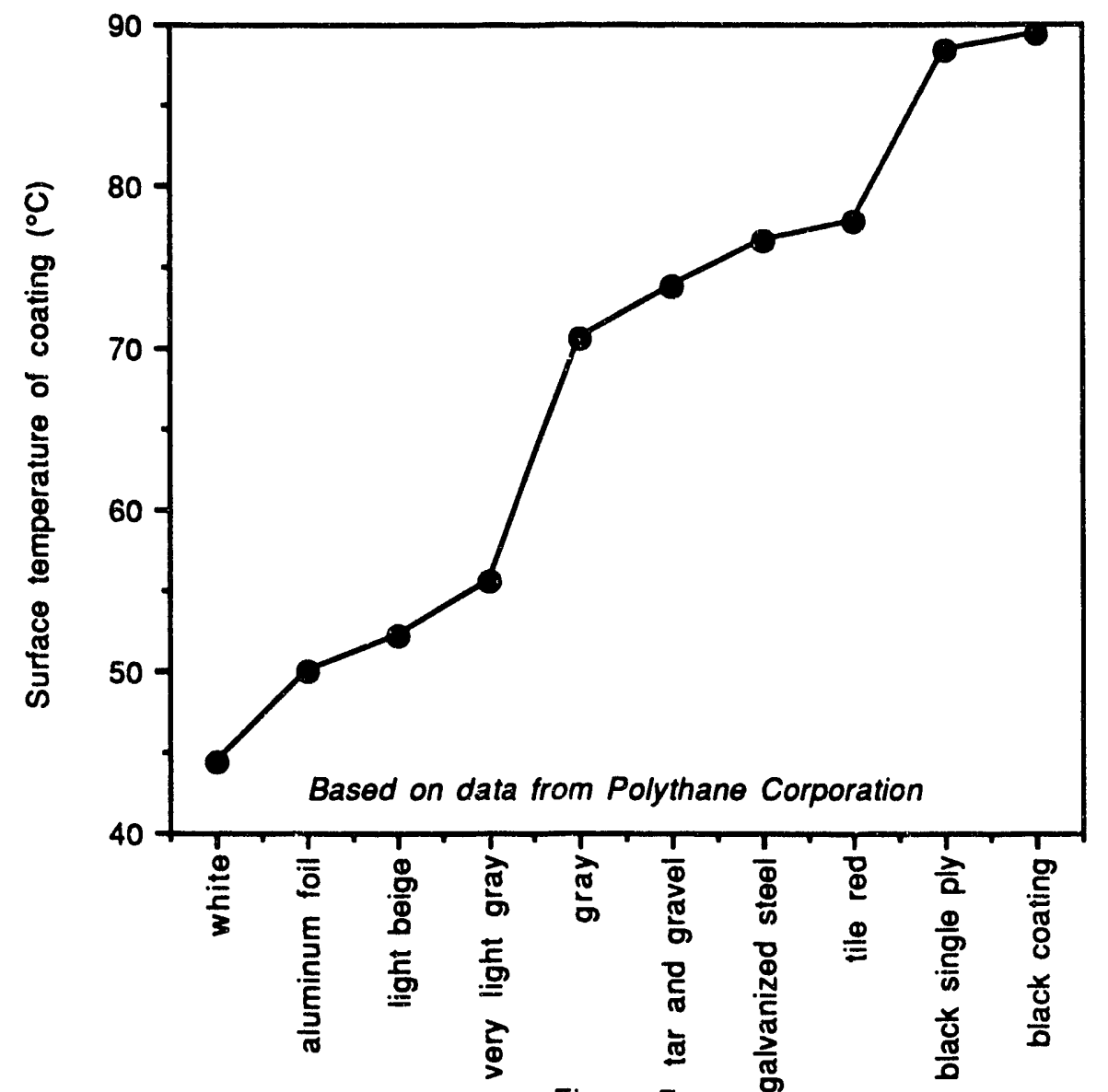

Figure 7.

Surface temperatures for a dark and light-coated roofs

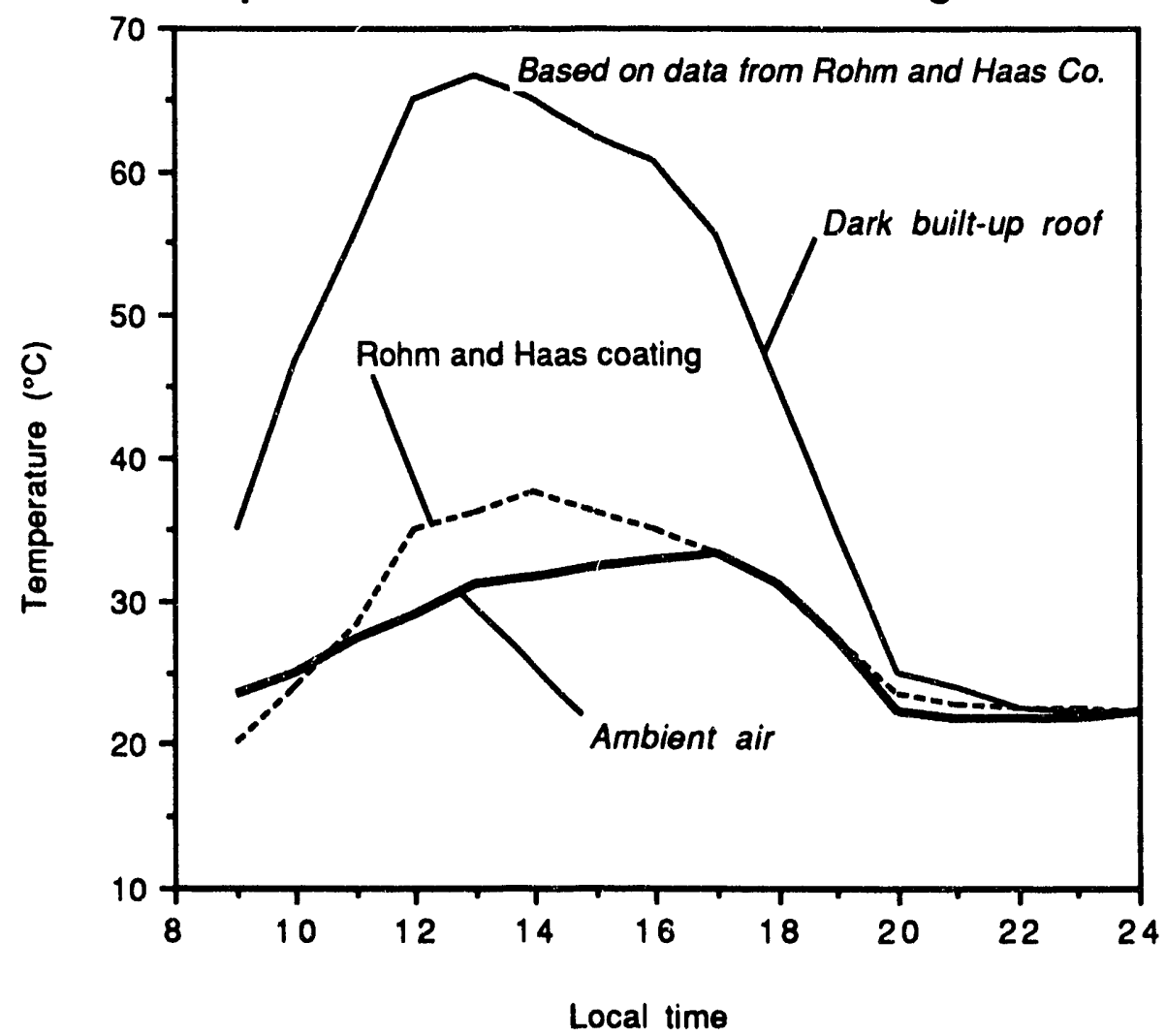


Figure 8.

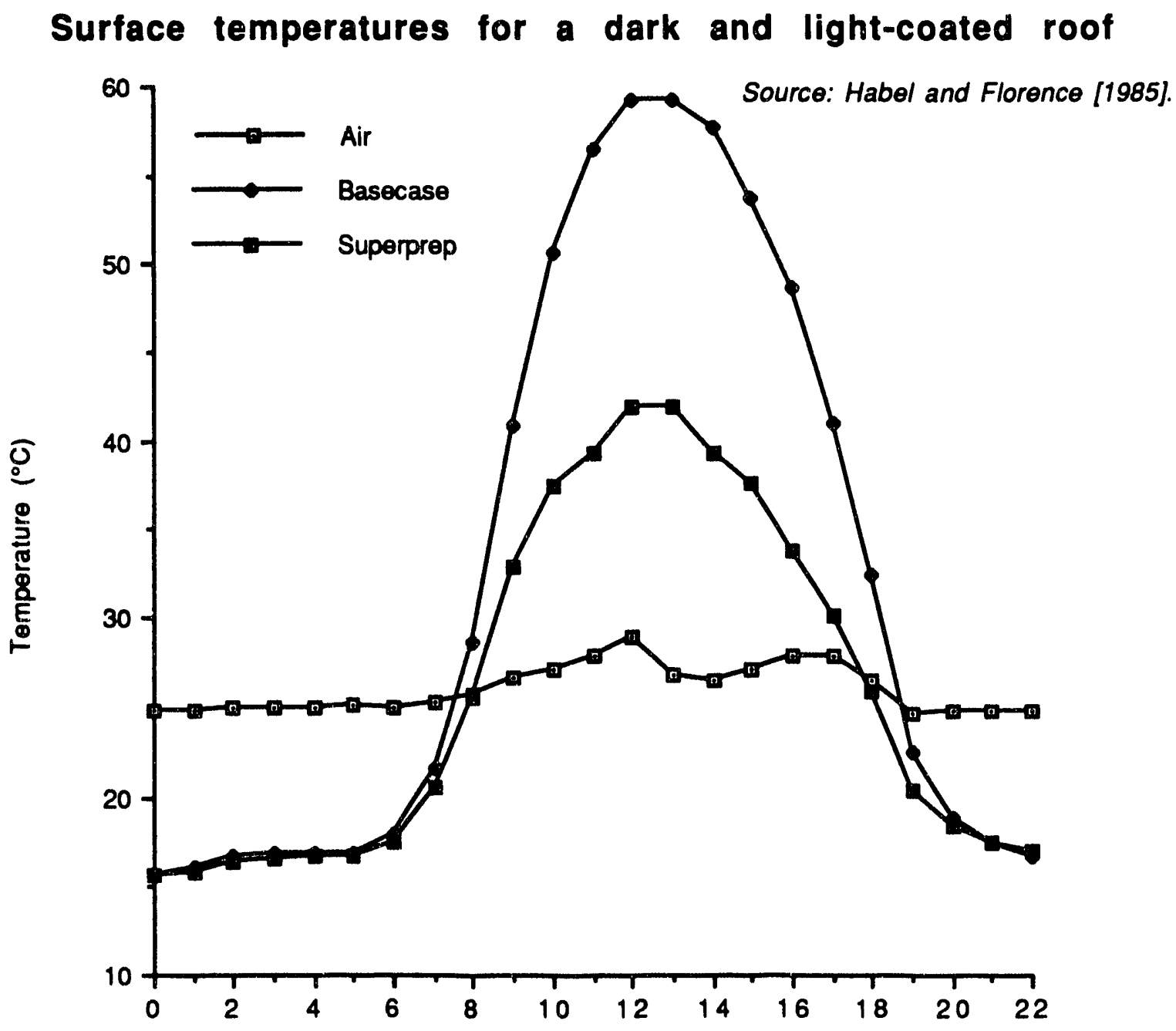

Local time 
Figure 9.

Times of cooling needs.

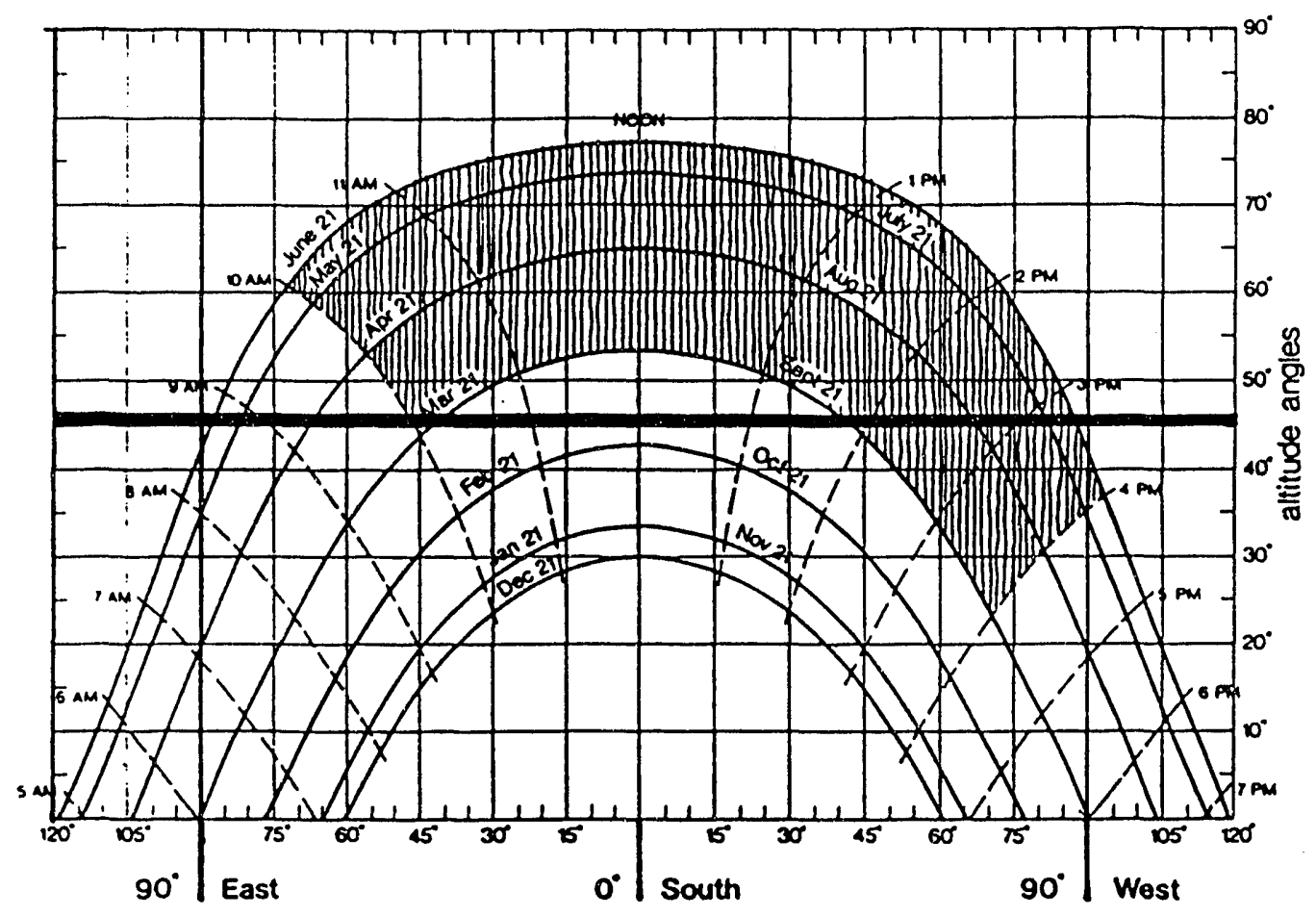

Latitude $36^{\circ}$

Figure 10.

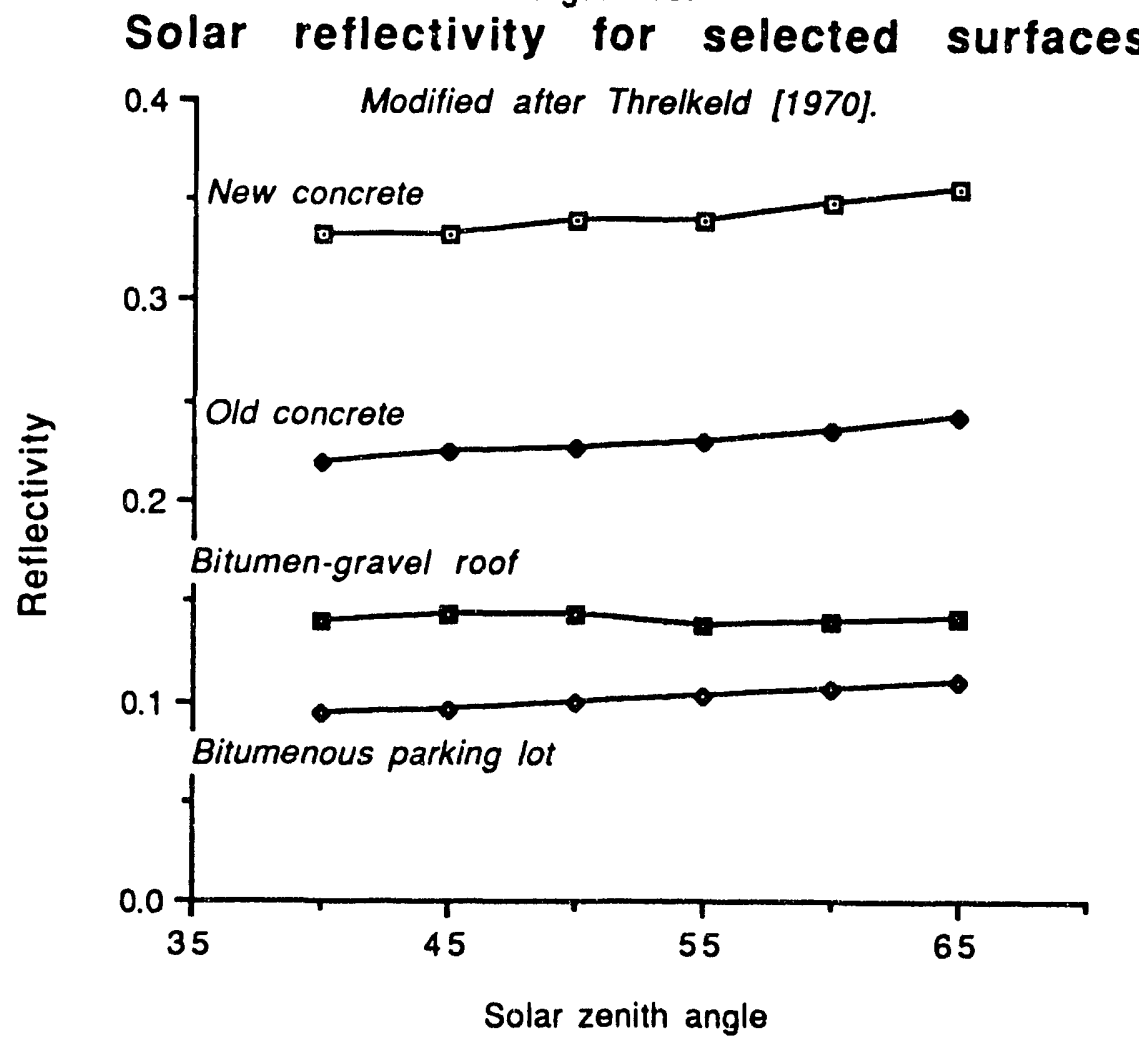



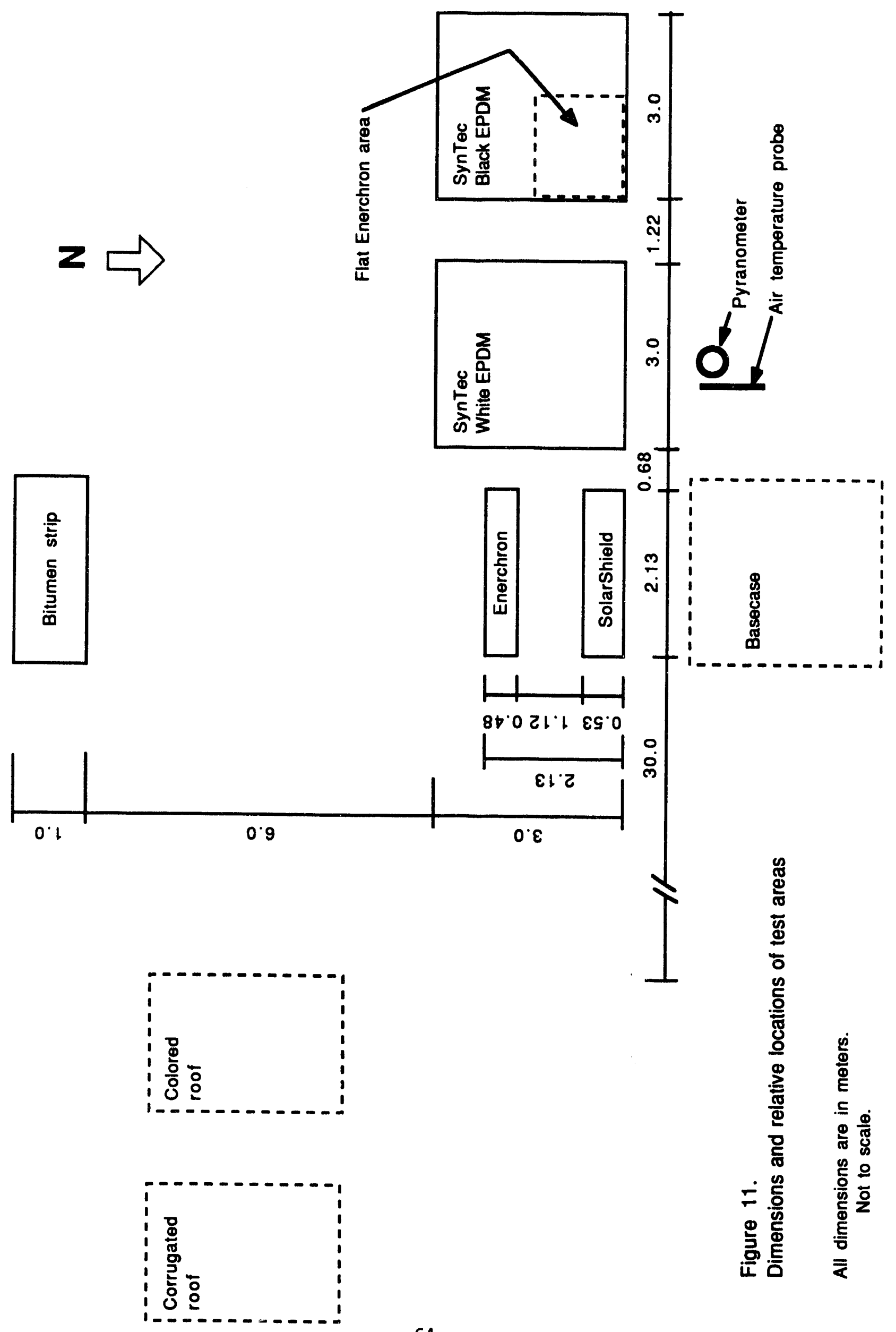


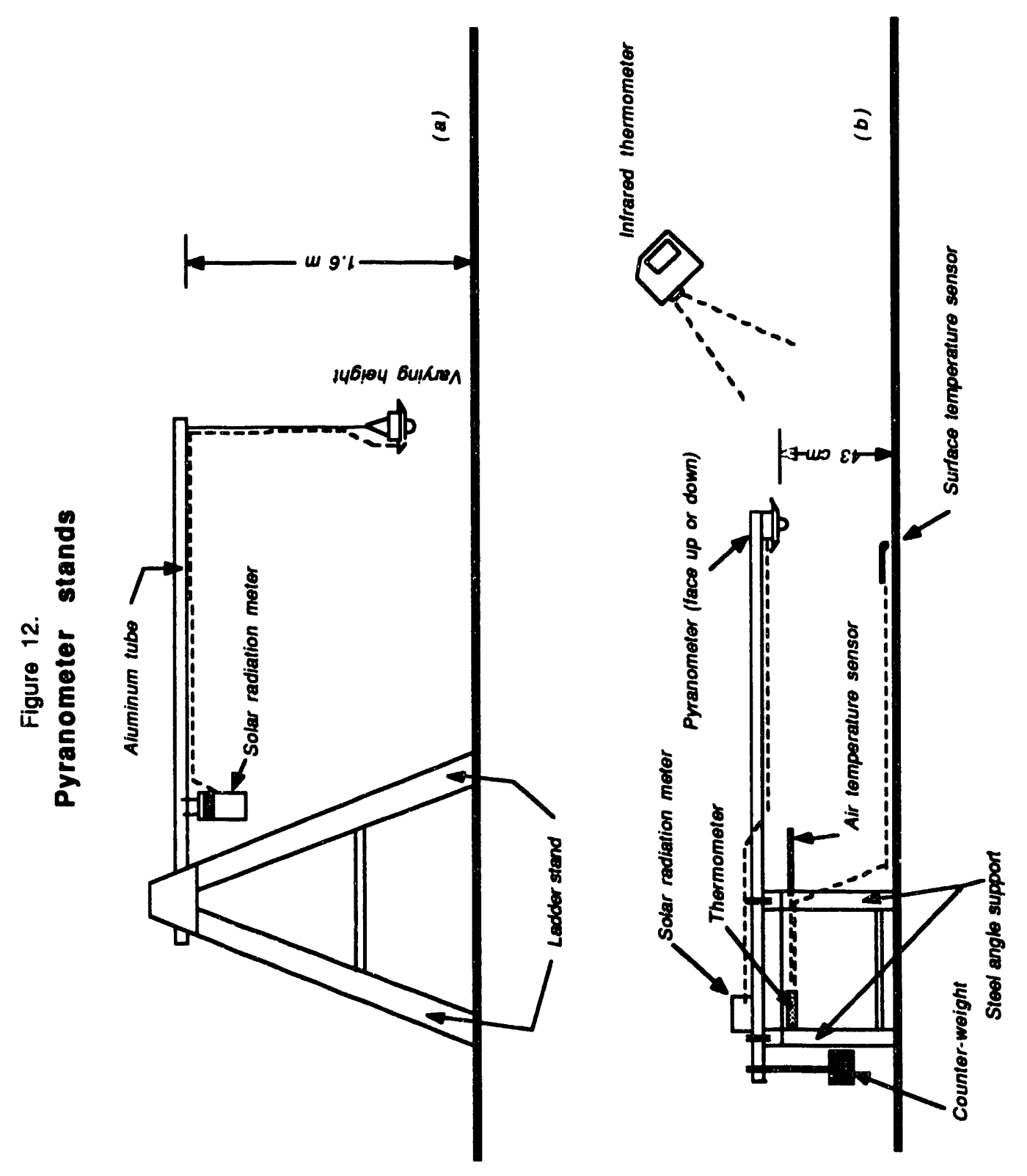


Figure 13.

Reflected solar radiation versus pyranometer height.

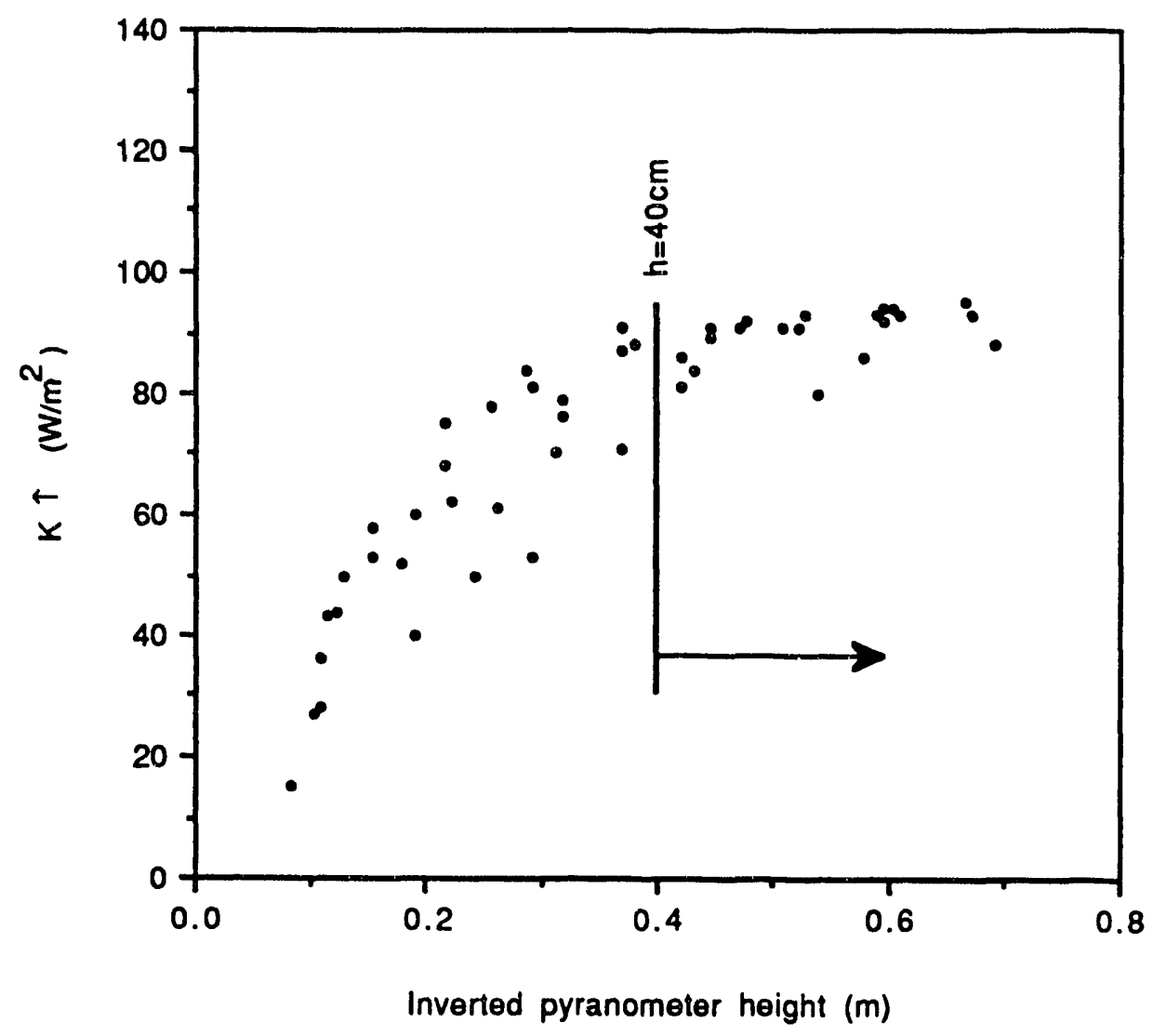

Figure 14.

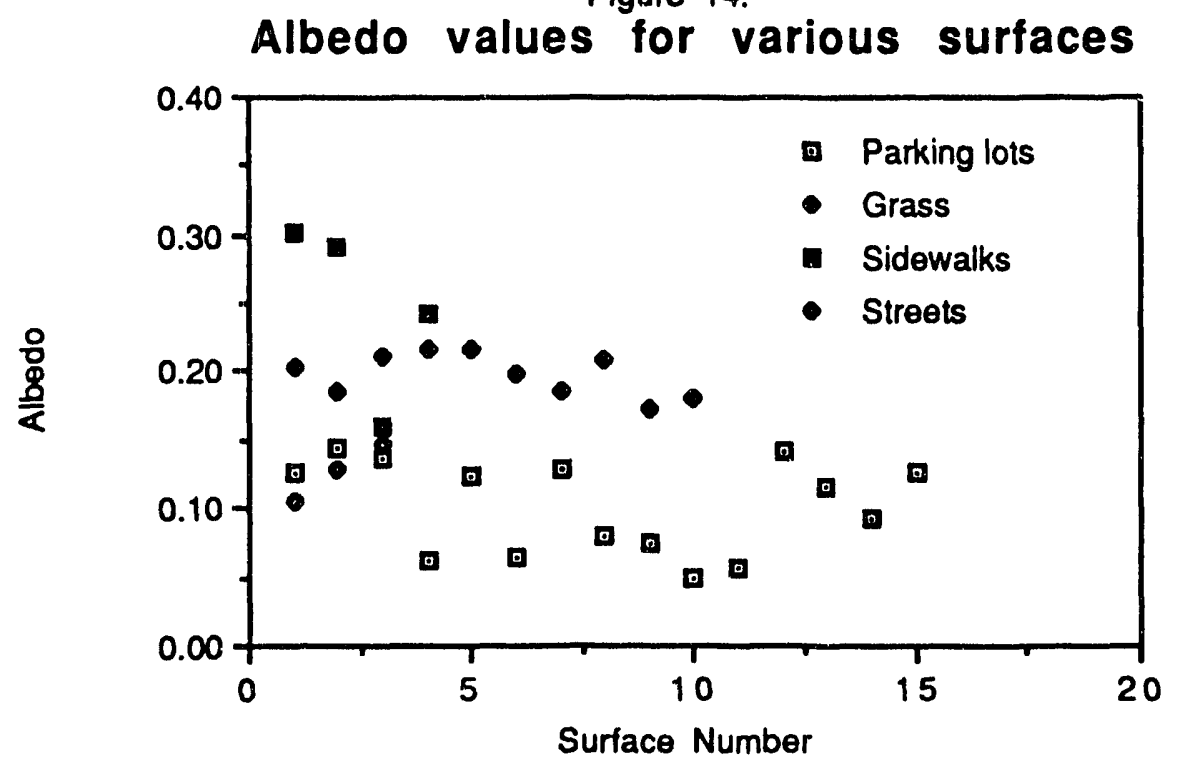


Figure 15

Albedo versus time for a flat gravel roof

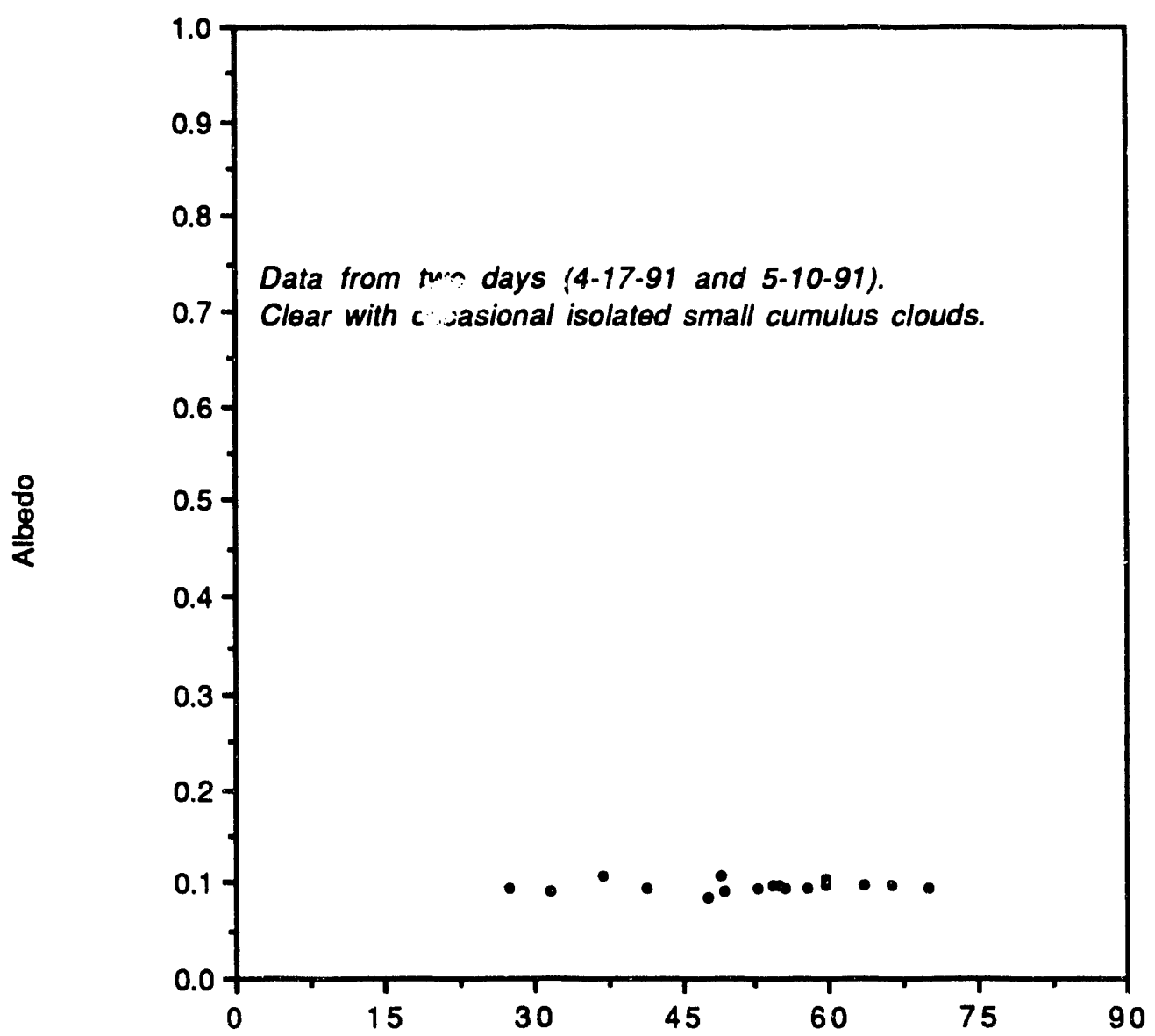

Solar altitude 
Figure 16.

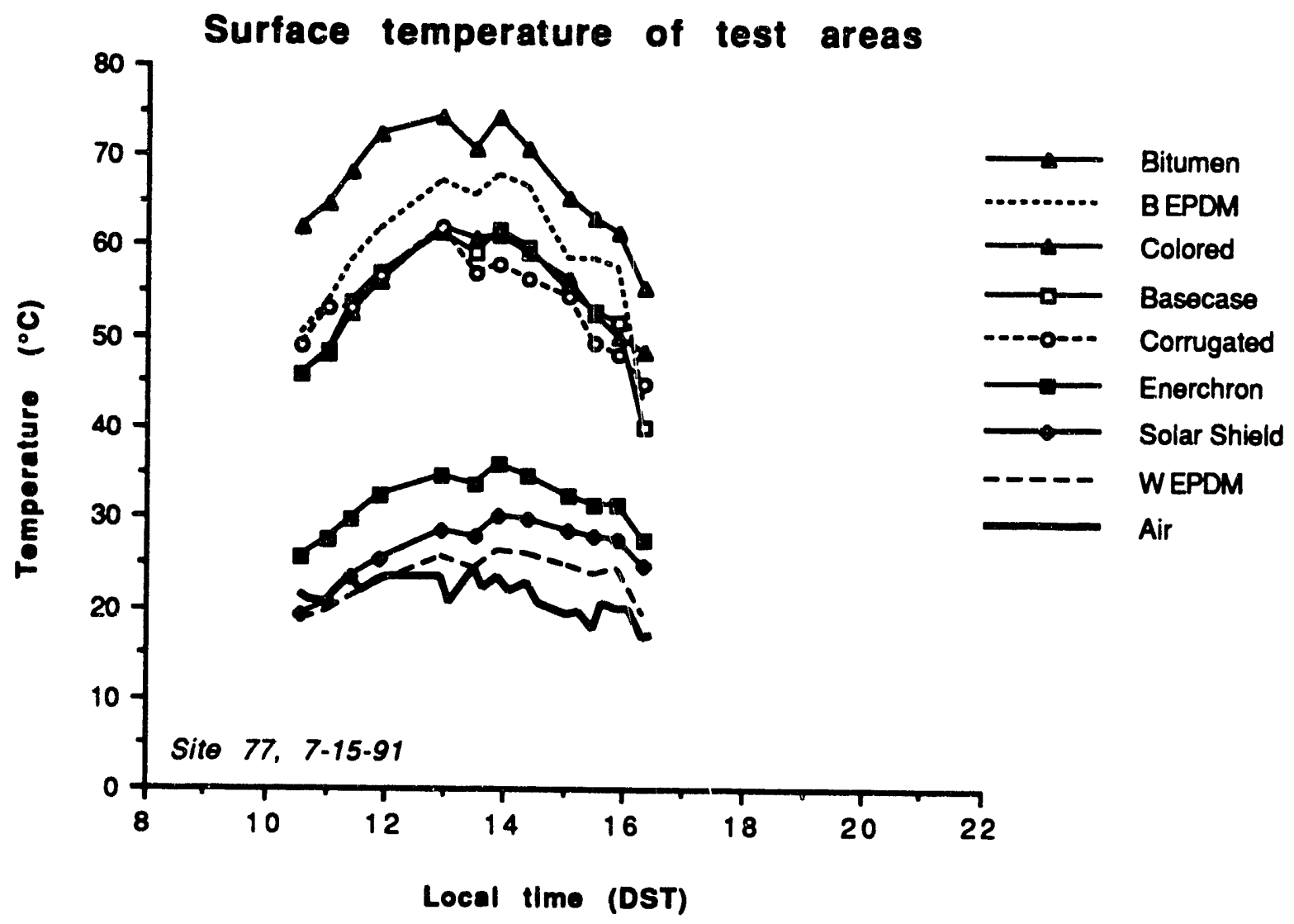

Figure 17.

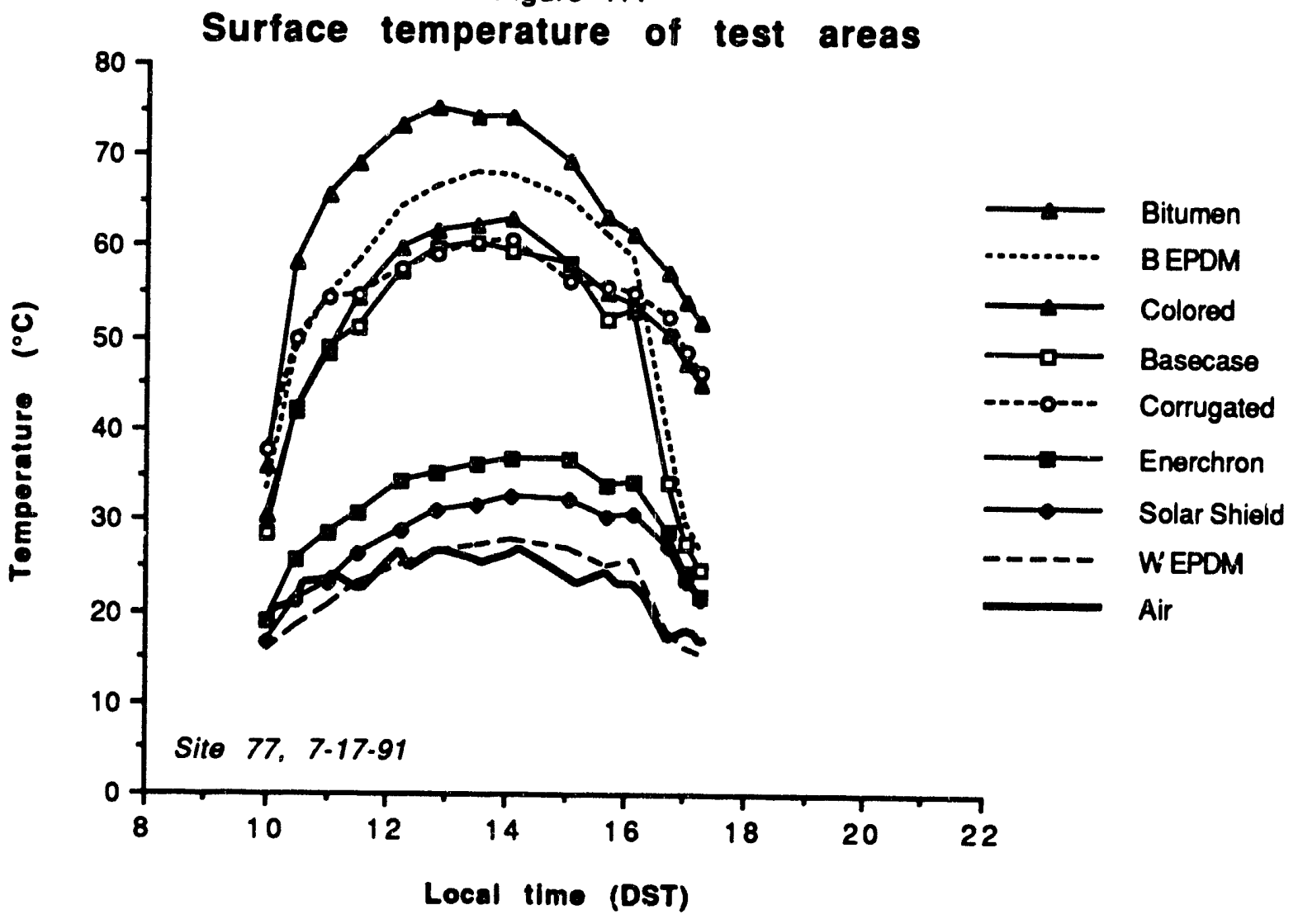


Figure 18.

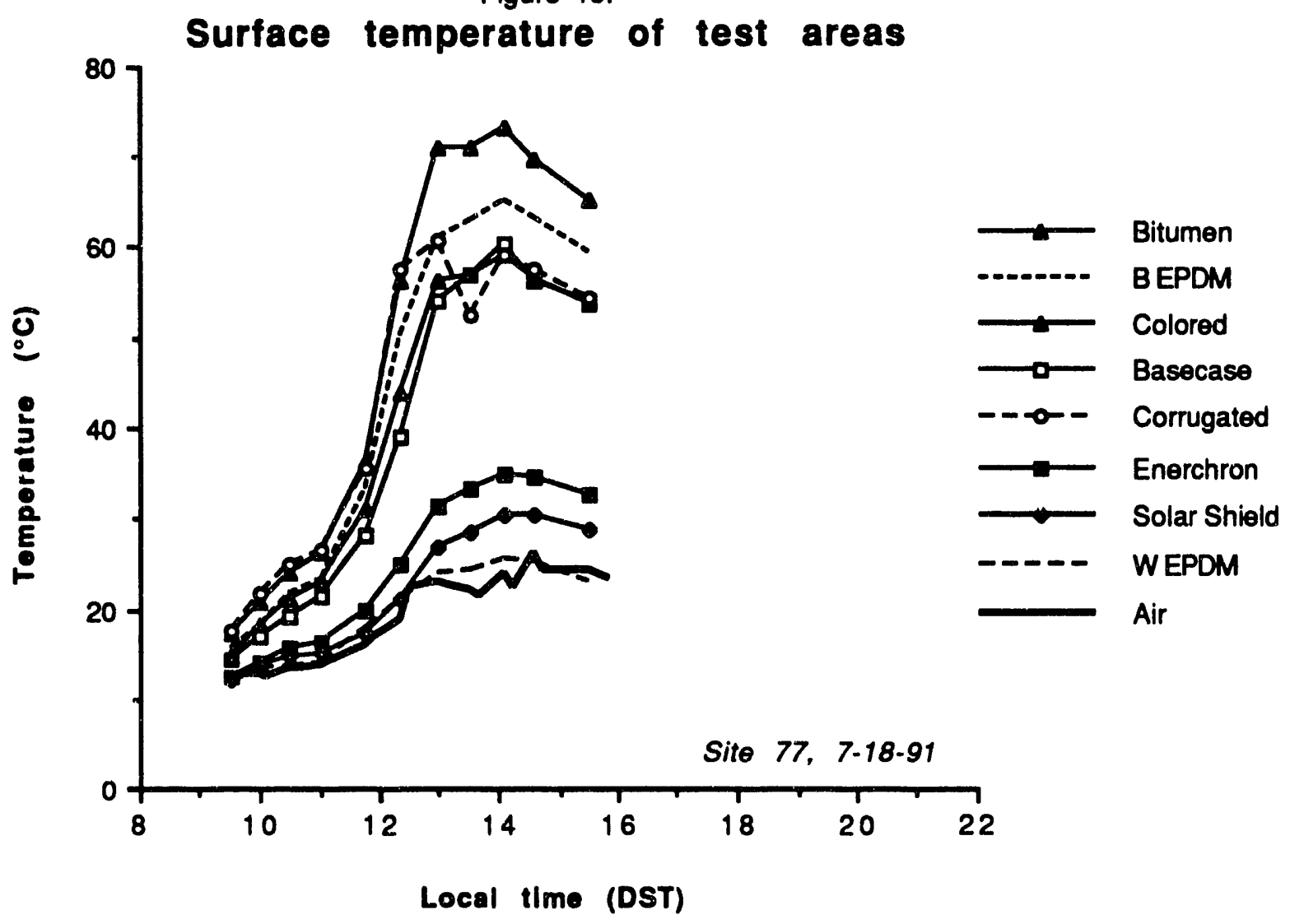

Figure 19.

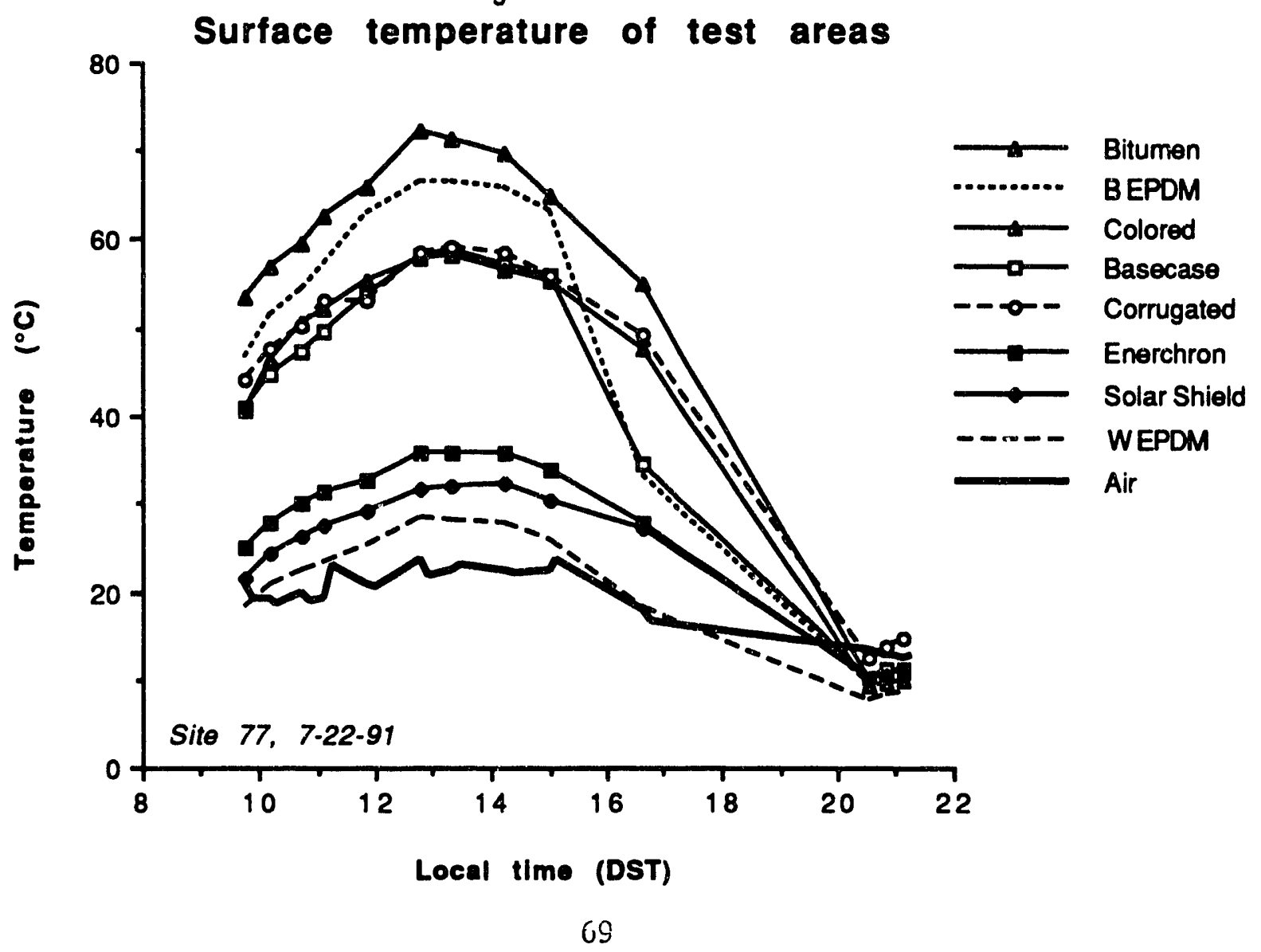


Figure 20.

\section{Surface temperature versus solar radiation for two EPDMs}

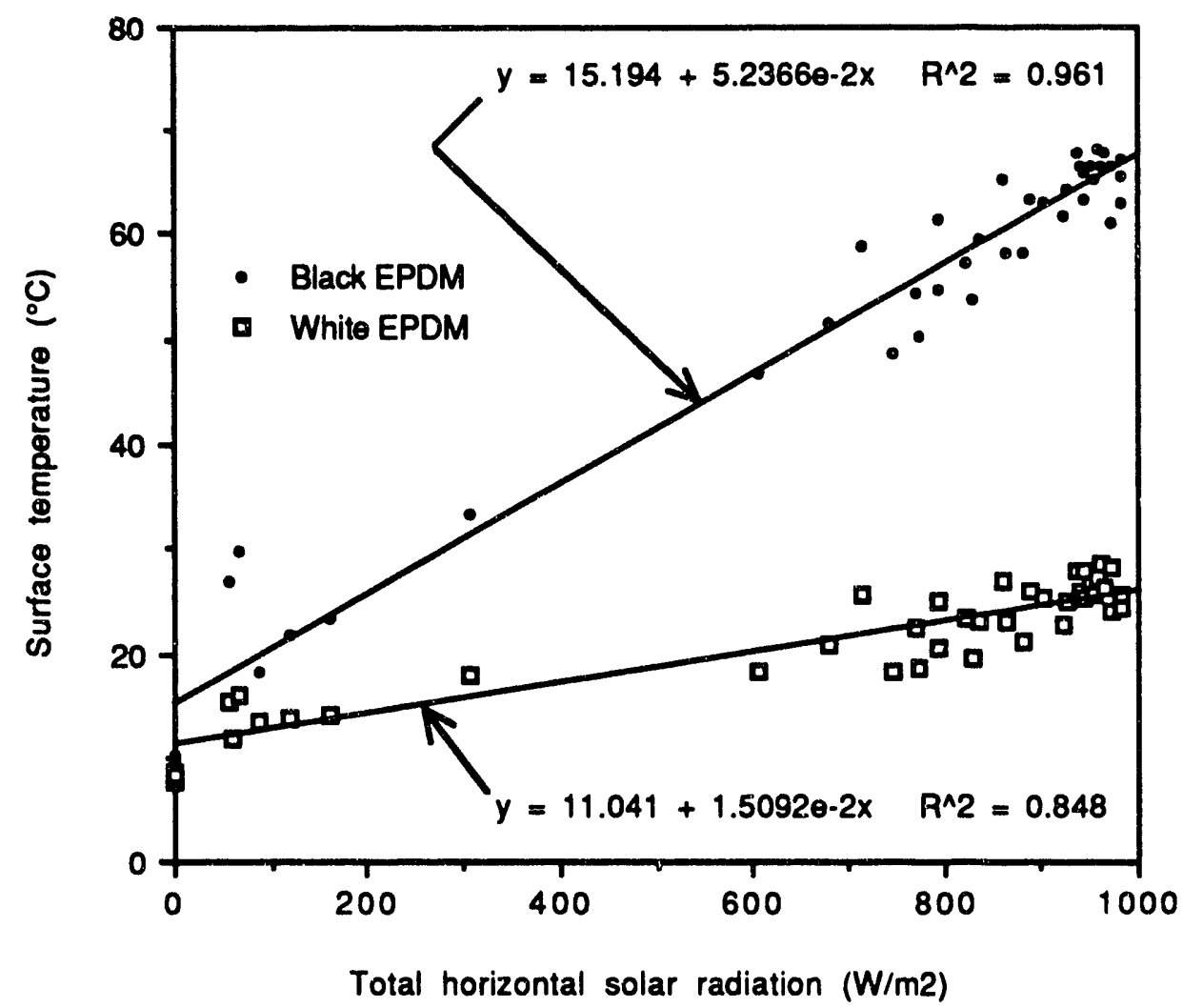

Figure 21.

Surface temperature versus solar radiation (basecase vs coated gravel)

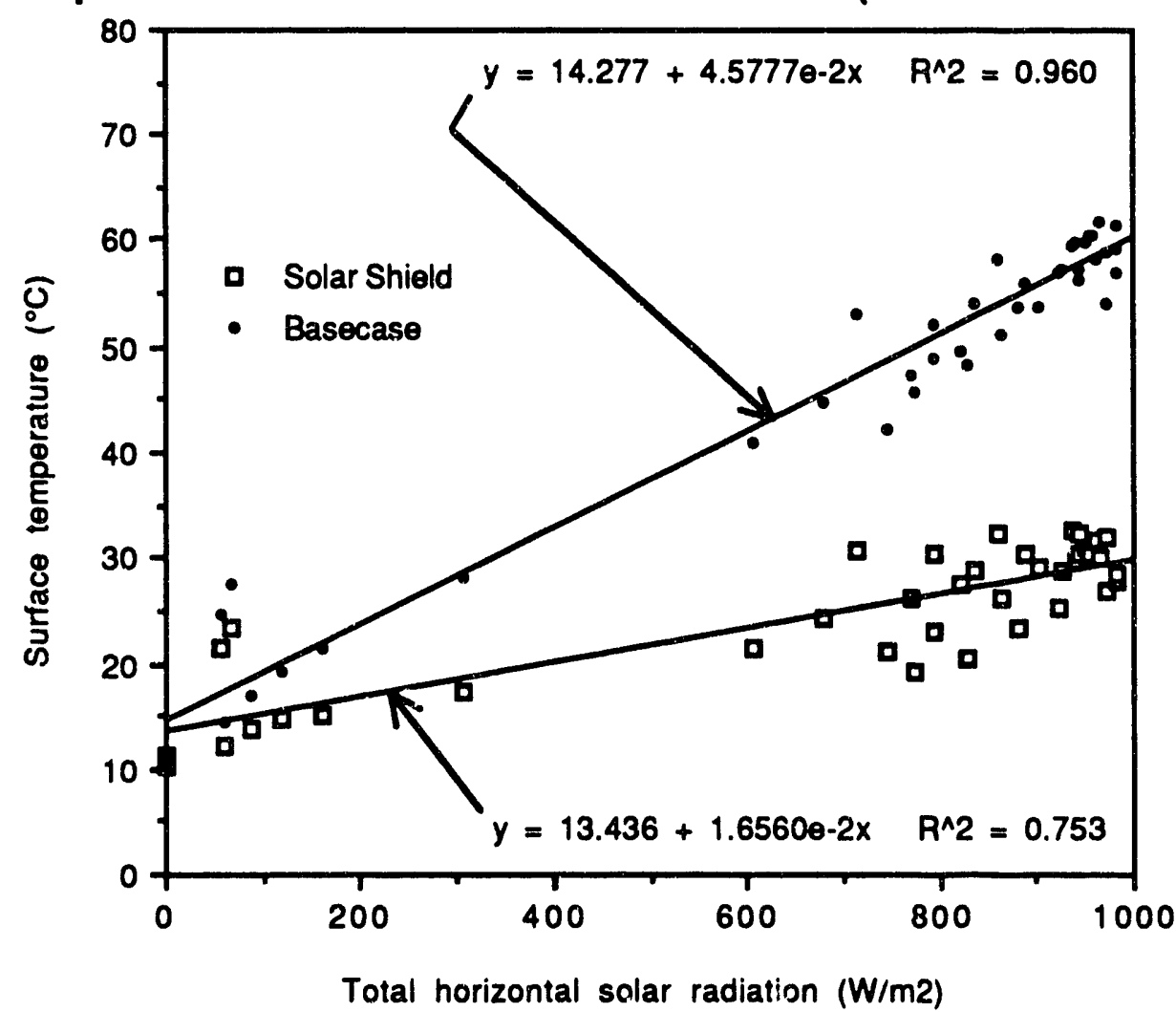


Figure 22.

Surface temperature vs solar radiation (basecase vs coated gravel)

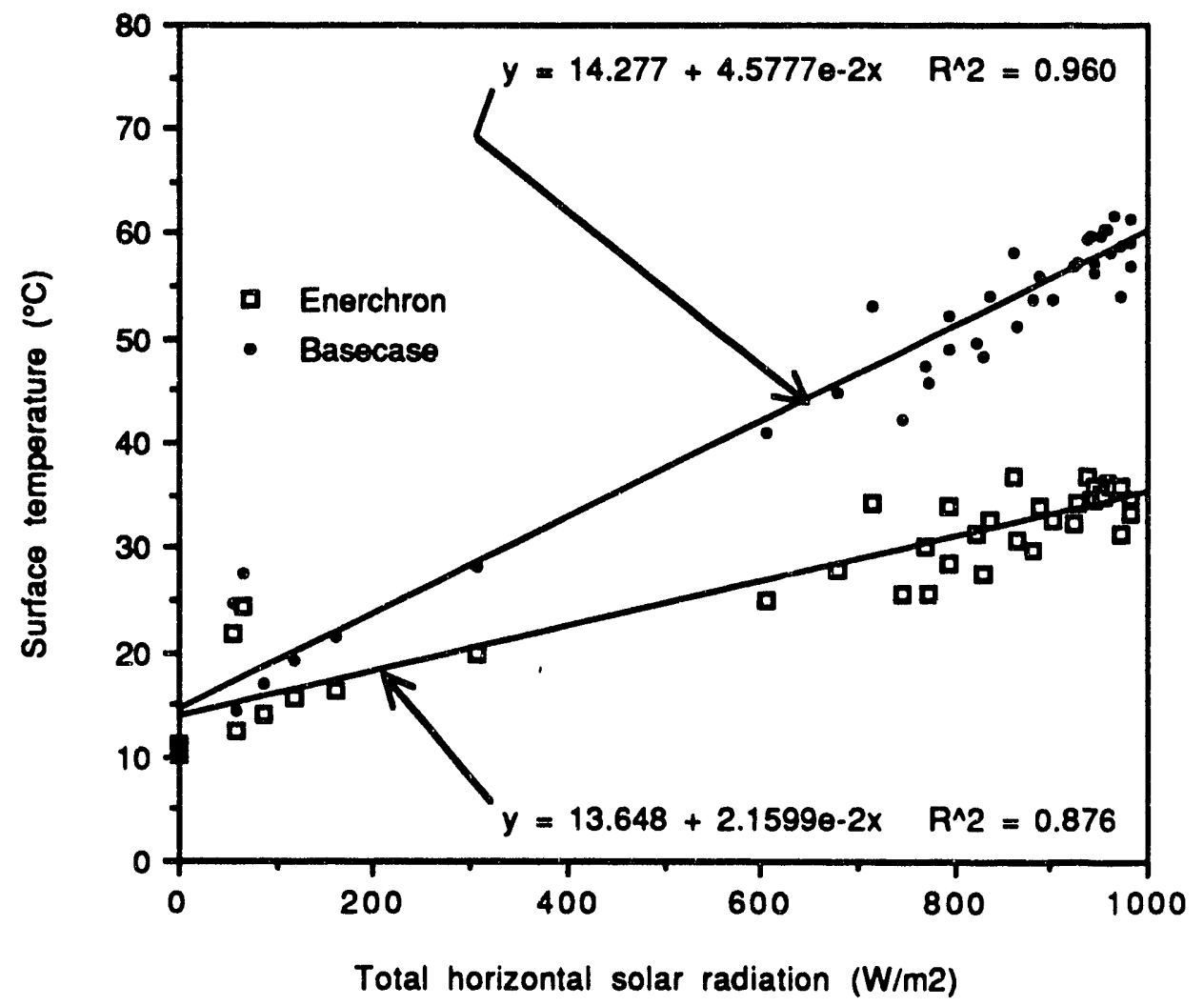

Figure 23.

Surface temperature vs solar radiation for three test areas

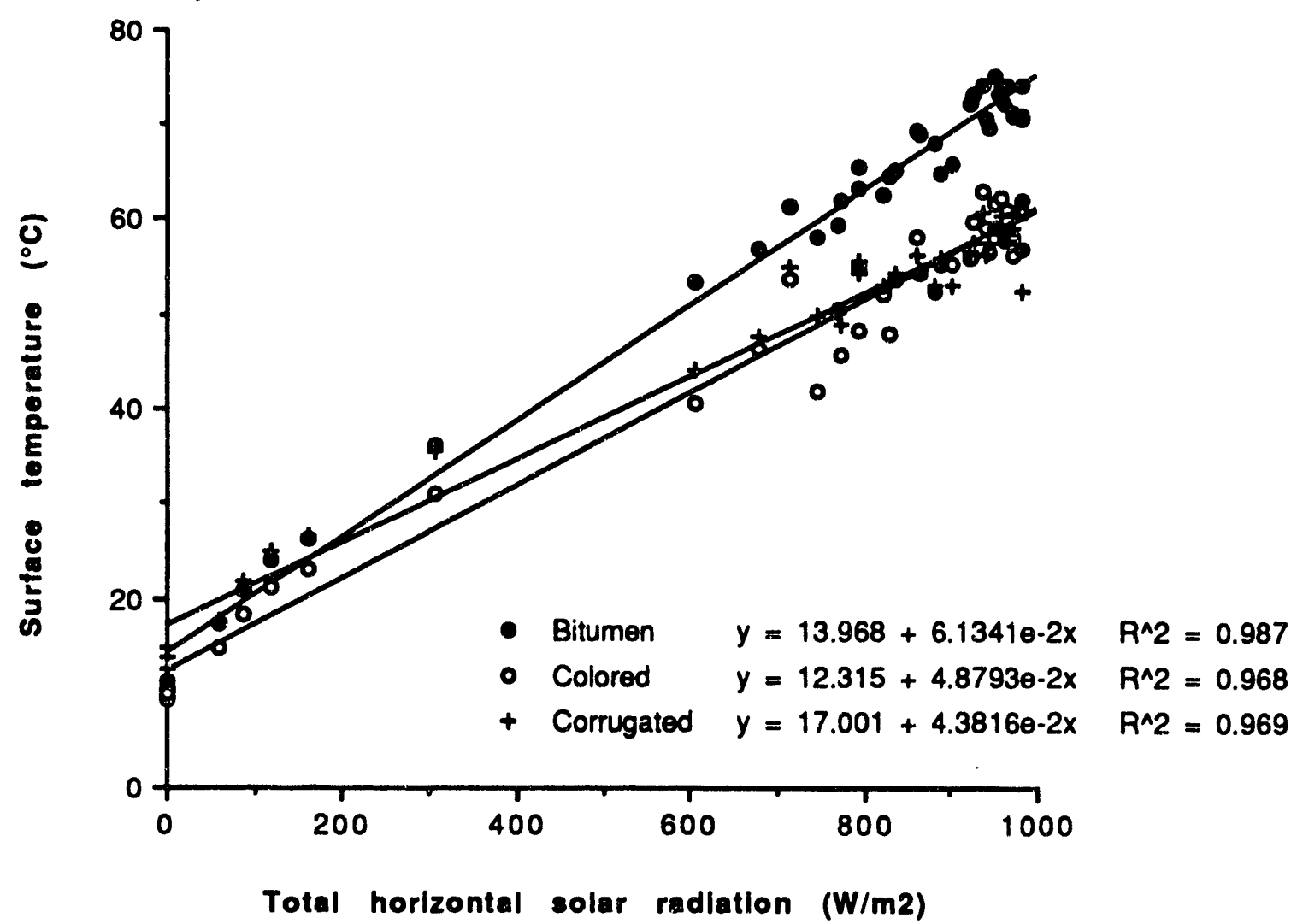


Figure 24.

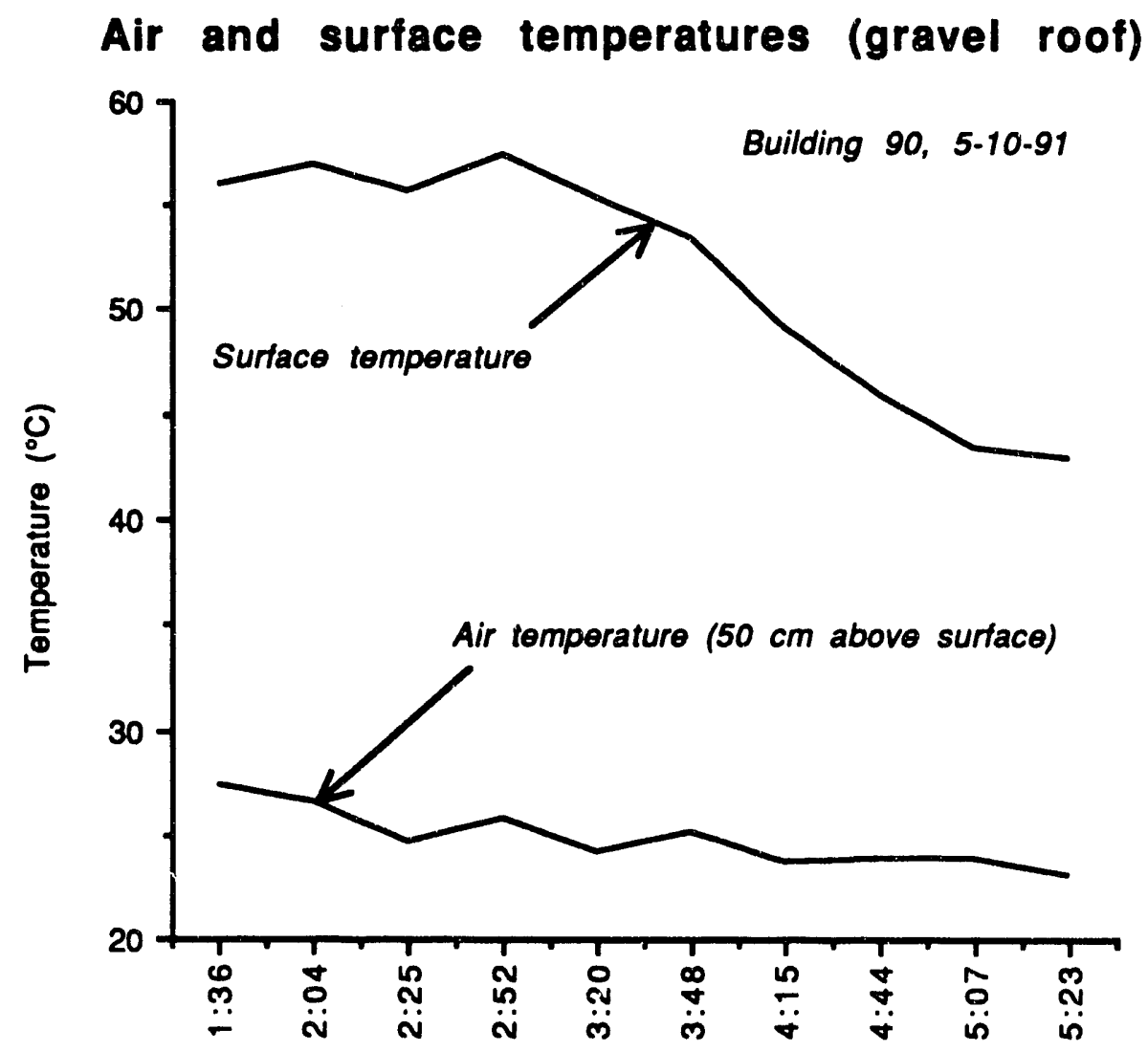

LBL local time (DST)

Figure 25.

Surface temperature vs solar radiation for a gravel roof

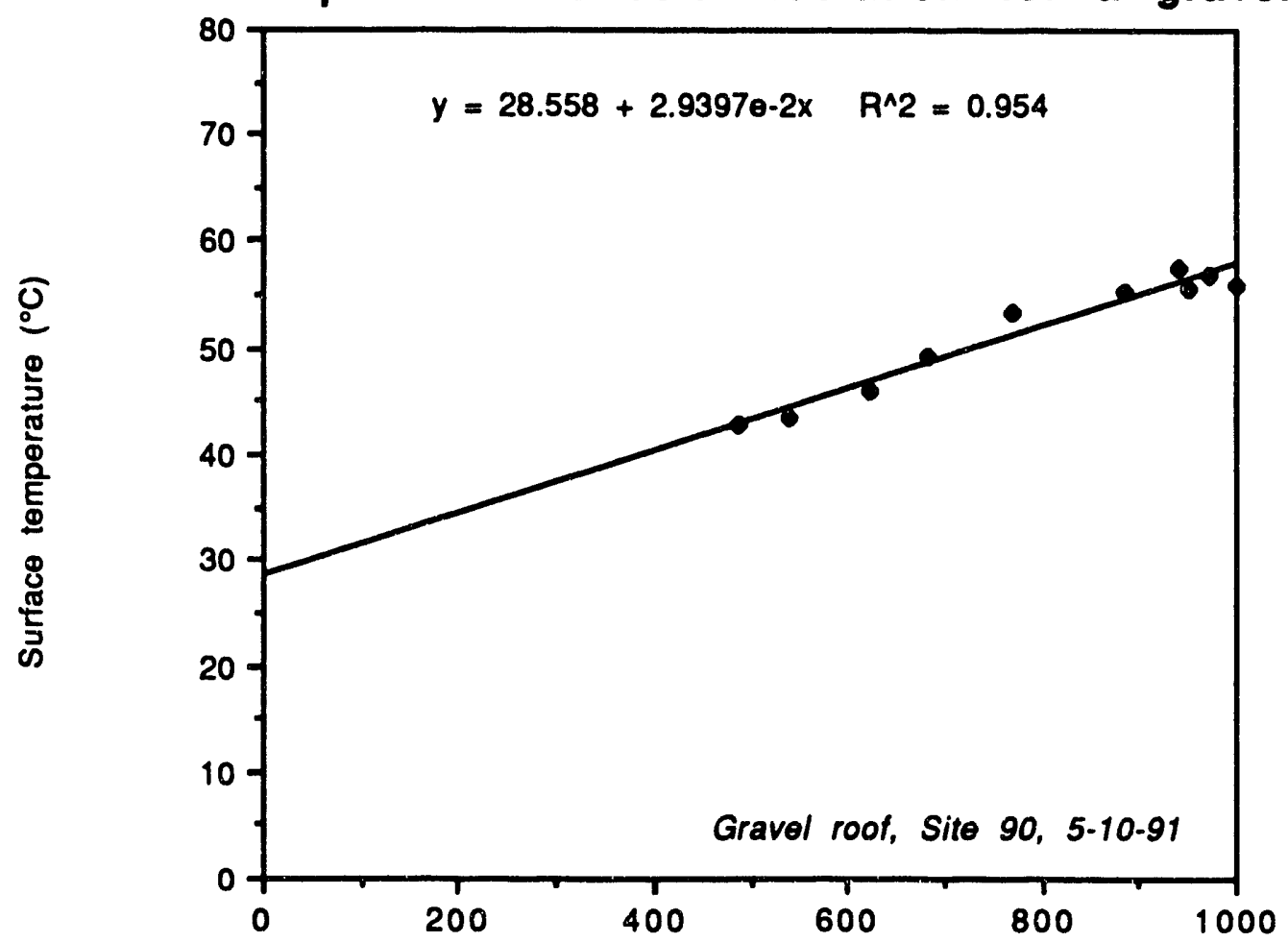

Total horizontal solar radiation (W/m2) 

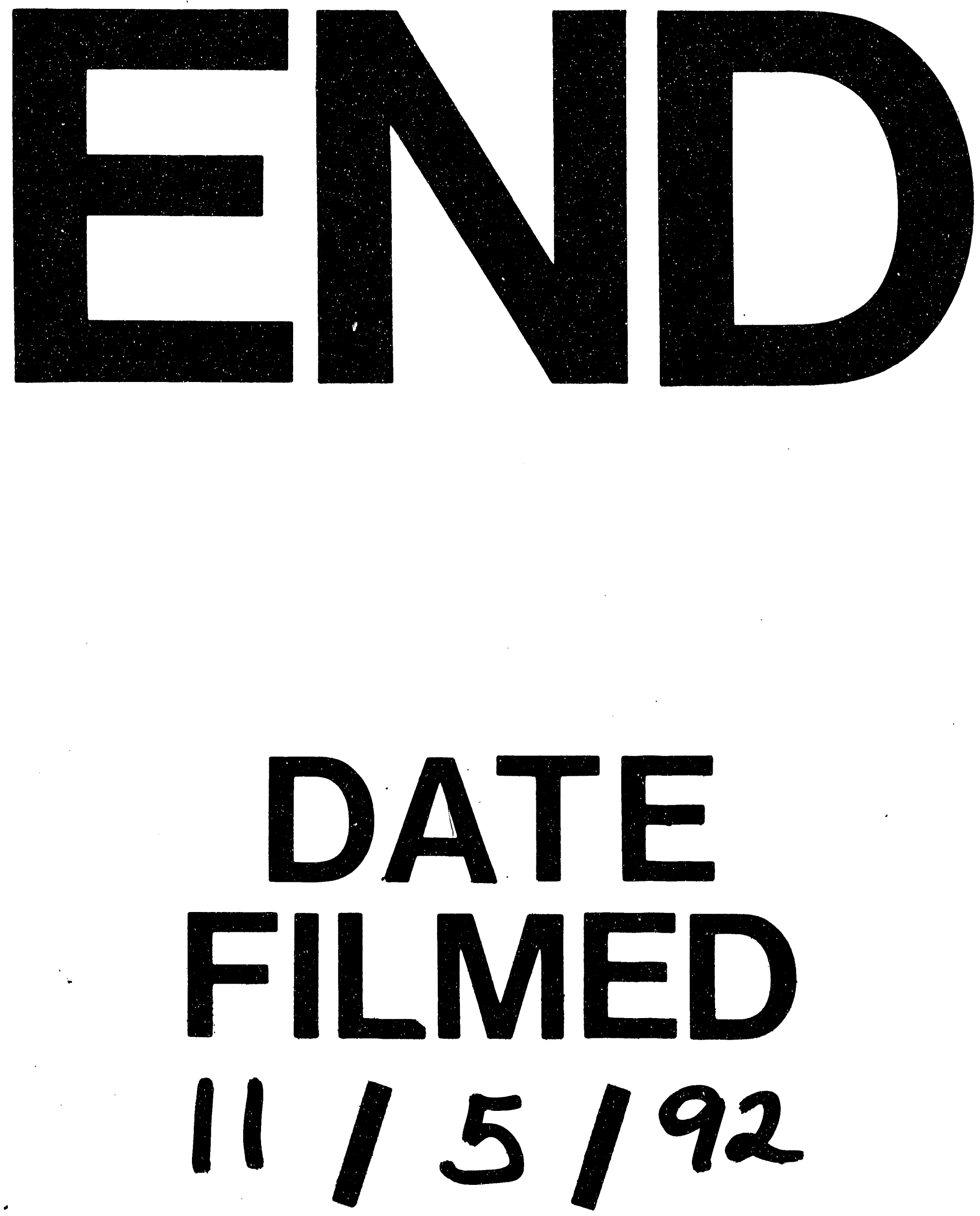

1 
